\title{
Evaluation Criteria for Aged Asphalt Concrete Surfaces; Phase II
}

Haley P. Bell, Reed B. Freeman, and E. Ray Brown

May 2008

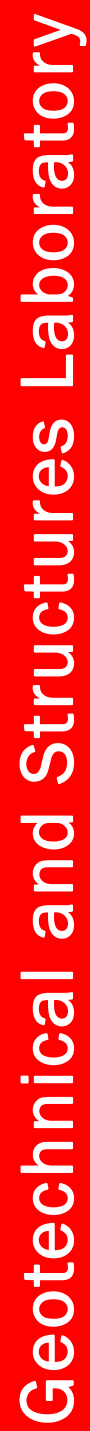

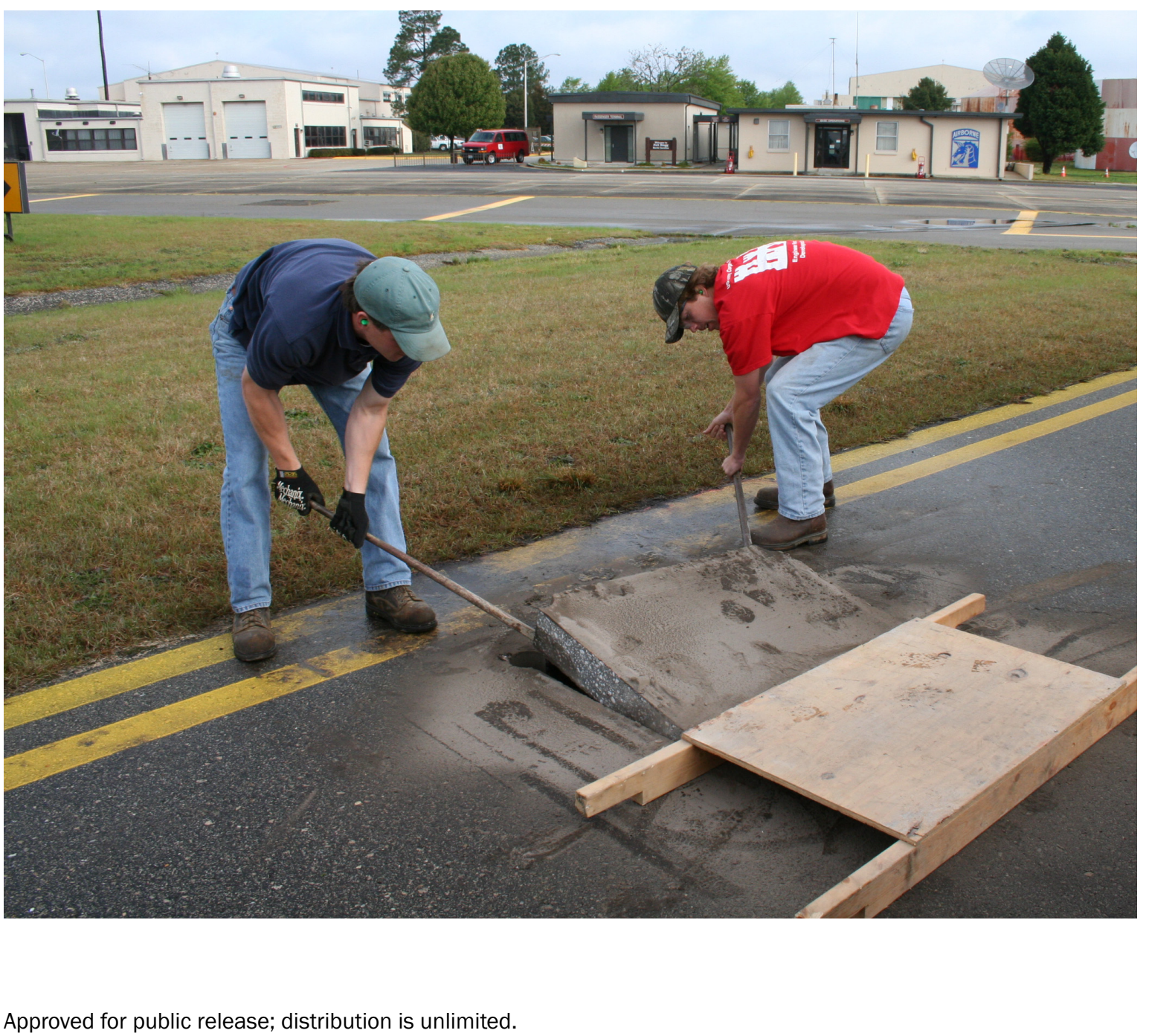




\section{Evaluation Criteria for Aged Asphalt Concrete Surfaces; Phase II}

Haley P. Bell, Reed B. Freeman, and E. Ray Brown

Geotechnical and Structures Laboratory

U.S. Army Engineer Research and Development Center

3909 Halls Ferry Road

Vicksburg, MS 39180-6199

Final report

Approved for public release; distribution is unlimited.

Prepared for Headquarters, Air Combat Command

129 Andrews Street, Suite 102

Langley AFB, VA 23666 


\begin{abstract}
An evaluation of aged asphalt concrete (AC) was performed during the period March-August 2007 at Polk Army Airfield (Fort Polk, LA), Redstone Army Airfield (Huntsville, AL), Simmons Army Airfield (Fort Bragg, NC), and Forney Army Airfield (Fort Leonard Wood, MO) to develop a method for predicting the performance of aged AC surfaces in situ. This research project was an extension of an investigation that was conducted in fiscal year 2006. Similar test procedures were followed for both projects. A portable seismic pavement analyzer was used on the in situ $\mathrm{AC}$ pavements to determine the pavement modulus. The aged $\mathrm{AC}$ samples obtained from the military airfields were brought to the U.S. Army Engineer Research and Development Center for laboratory testing. Dynamic shear rheometer tests were conducted on the asphalt binder samples, indirect tensile strength tests were run on core samples, and beam fatigue tests were performed on beam samples. The results from this study were used to develop adjustments to the current Department of Defense fatigue criterion to improve fatigue life predictions for aged AC surfaces. Also, the results of this investigation were used to develop fatigue criteria to be used when evaluating AC pavements in the field.
\end{abstract}

\footnotetext{
DISCLAIMER: The contents of this report are not to be used for advertising, publication, or promotional purposes. Citation of trade names does not constitute an official endorsement or approval of the use of such commercial products. All product names and trademarks cited are the property of their respective owners. The findings of this report are not to be construed as an official Department of the Army position unless so designated by other authorized documents.
}

DESTROY THIS REPORT WHEN NO LONGER NEEDED. DO NOT RETURN TO ORIGINATOR. 


\section{Contents}

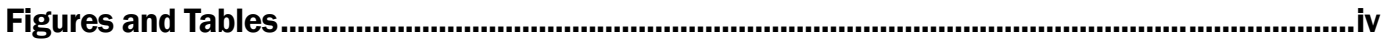

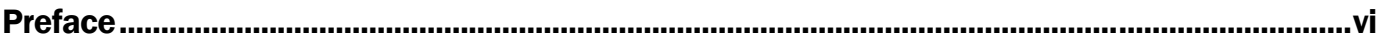

Unit Conversion Factors...........................................................................................................................vii

Summary ............................................................................................................................................viii

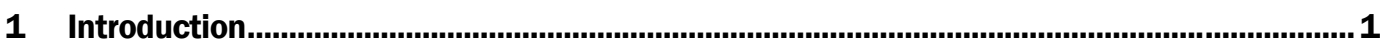

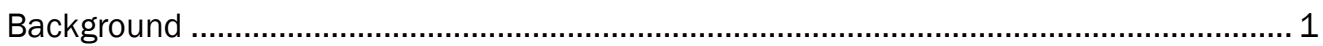

Objective and scope ......................................................................................... 1

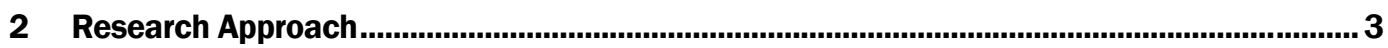

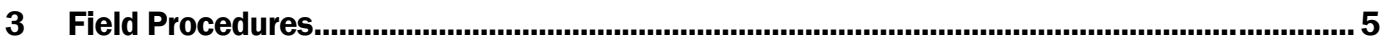

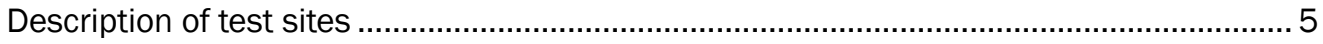

Portable seismic pavement analyzer tests ................................................................... 10

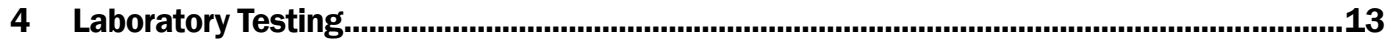

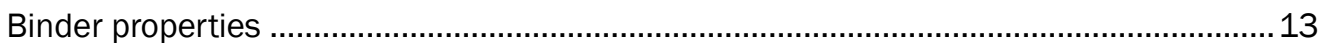

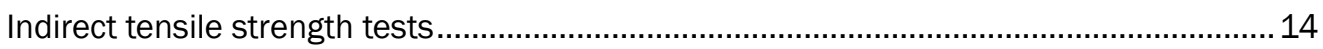

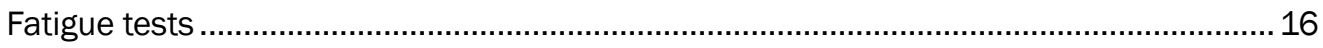

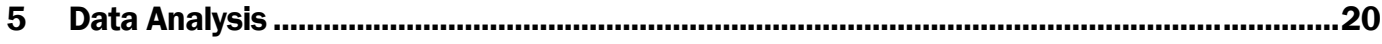

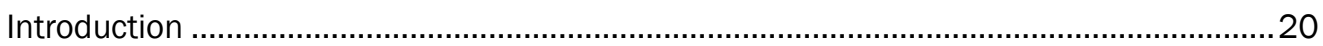

Current Department of Defense fatigue criterion.........................................................20

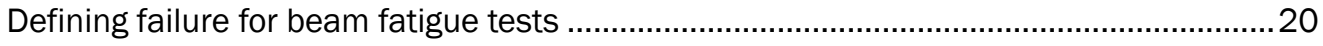

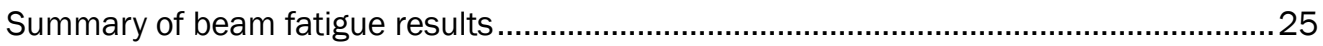

Confirmation for a new fatigue criterion for aged asphalt concrete....................................28

Development of a fatigue criterion for aged asphalt concrete ..........................................32

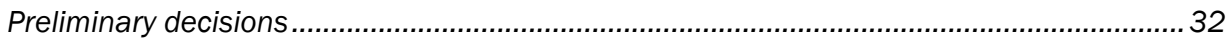

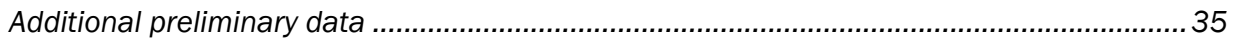

Independent variables considered for the new fatigue criterion ...........................................38

Testing independent variables for predictive significance .............................................40

Defining the new criteria in equation form ............................................................4

Extending the aged asphalt fatigue criteria to temperatures other than $77^{\circ} \mathrm{F} \ldots \ldots \ldots \ldots \ldots . . . . . . . .51$

6 Conclusions and Recommendations ...................................................................................56

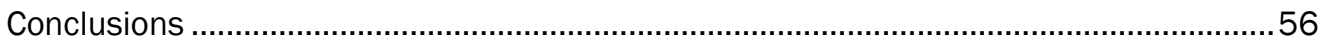

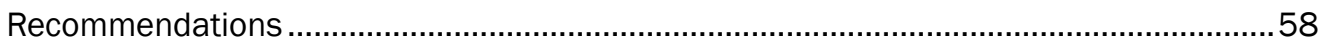

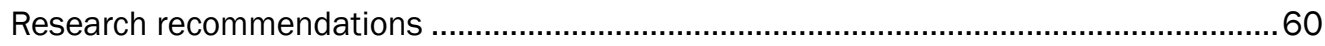

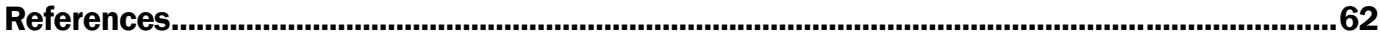

Report Documentation Page 


\section{Figures and Tables}

\section{Figures}

Figure 1. Flow chart detailing the research plan......................................................................... 3

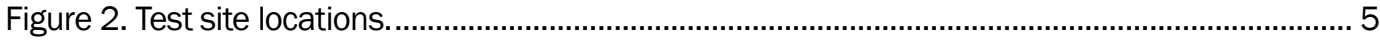

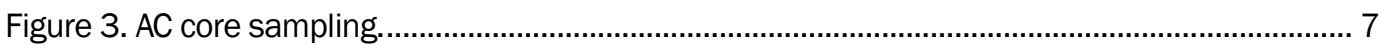

Figure 4. Obtaining the in situ pavement modulus using the PSPA................................................ 7

Figure 5. Sawing the aged AC sample....................................................................................... 8

Figure 6. Removing the aged AC sample............................................................................. 8

Figure 7. Patching the hole of the removed aged AC sample. .......................................................... 9

Figure 8. Patched AC sample............................................................................................ 9

Figure 9. Portable seismic pavement analyzer (PSPA) ..................................................................... 10

Figure 10. Before an ITS test on the Instron machine................................................................ 15

Figure 11. After an ITS test........................................................................................................... 15

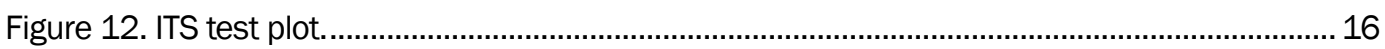

Figure 13. Beam fatigue computer, temperature chamber, and apparatus.................................. 17

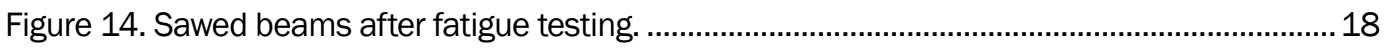

Figure 15. Fatigue data for bituminous concrete materials........................................................... 21

Figure 16. Establishing percent stiffness at failure for the laboratory-produced standard

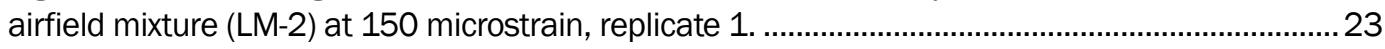

Figure 17. Establishing percent stiffness at failure for the laboratory-produced standard airfield mixture (LM-2) at 350 microstrain, replicate 3. ............................................................... 24

Figure 18. Establishing percent stiffness at failure for the laboratory-produced standard airfield mixture (LM-2) at 550 microstrain, replicate 6 . .............................................................. 24

Figure 19. Predicted versus measured $\log _{10}$ (cycles) to fatigue failure for lab-mixed samples.

Figure 20. Predicted versus measured $\log _{10}$ (cycles) to fatigue failure for aged field

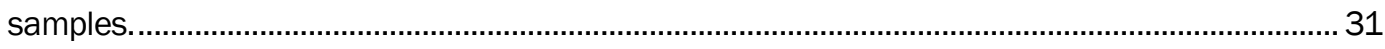

Figure 21. Summary of extreme Log Ratio values for aged field samples...................................... 31

Figure 22. Influence of AC modulus on fatigue performance of beams tested at 150 microstrain as measured by the PSPA

Figure 23. Influence of AC modulus on fatigue performance of beams tested at 350 microstrain as measured by the PSPA.

Figure 24. Influence of AC modulus on fatigue performance of beams tested at

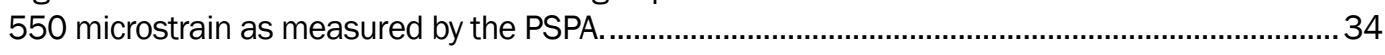

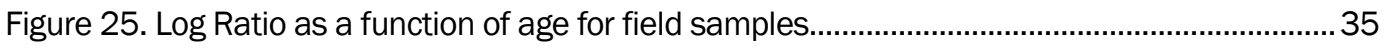

Figure 26. Two methods for measuring stiffness....................................................................... 36

Figure 27. Influence of initial beam stiffness on fatigue performance of beams tested at 150 microstrain.

Figure 28. Influence of initial beam stiffness on fatigue performance of beams tested at 350 microstrain. 
Figure 29. Influence of initial beam stiffness on fatigue performance of beams tested at 550 microstrain.

Figure 30. Influence of ITS peak stress on fatigue performance of beams tested at 150 , 350, and 550 microstrain.

Figure 31. Correlation between ITS peak stress and AC design modulus.

Figure 32. Predictions versus measured $\log _{10}\left(\varepsilon_{r}\right)$ for the linear predictive equation based on strain and $\mathrm{AC}$ design modulus.

Figure 33. Predictions versus measured $\log _{10}\left(\varepsilon_{r}\right)$ for the nonlinear predictive equation based on strain and $\mathrm{AC}$ design modulus.

Figure 34. Extreme Log Ratios for the linear predictive equation based on strain and $\mathrm{AC}$ design modulus.

Figure 35. Extreme Log Ratios for the nonlinear predictive equation based on strain and AC design modulus.

Figure 36. Linear predictive equation for fatigue of aged AC based on strain and AC design modulus.

Figure 37. Nonlinear predictive equation for fatigue of aged AC based on strain and AC design modulus.

Figure 38. Predicted versus measured $\log _{10}\left(\varepsilon_{r}\right)$ for the nonlinear predictive equation based on strain and ITS peak stress.

Figure 39. Extreme Log Ratios for the nonlinear predictive equation based on strain and ITS peak stress.

Figure 40. Nonlinear predictive equation for fatigue of aged AC based on strain and ITS peak stress.

\section{Tables}

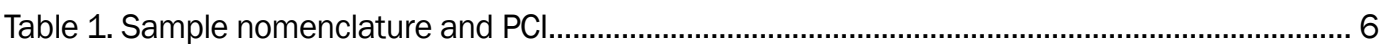

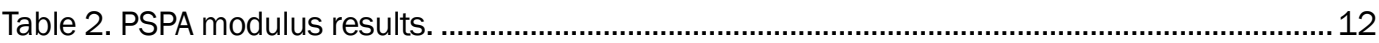

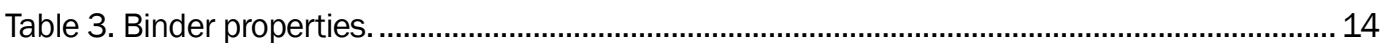

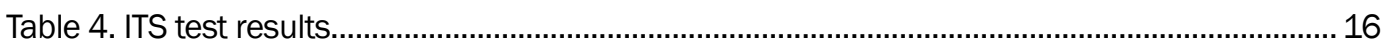

Table 5. Initial stiffness from beam fatigue tests.......................................................................... 18

Table 6. Average initial stiffness from beam fatigue tests. ............................................................... 19

Table 7. Average cycles at initial beam stiffness. .............................................................................. 22

Table 8. Summary of fatigue results for laboratory-produced standard airfield mixtures

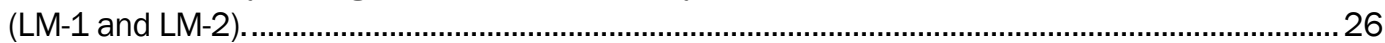

Table 9. Comparisons of predicted and measured cycles to failure. .............................................. 27

Table 10. Log Ratio data used in a two-factor analysis without replication...................................... 29

Table 11. Analysis of variance for the two-factor analysis without replication. ................................. 29

Table 12. Independent variables to be tested for predicting $\log _{10}$ (cycles) to fatigue failure............39

Table 13. Multiple regression for strain and field data.................................................................... 41

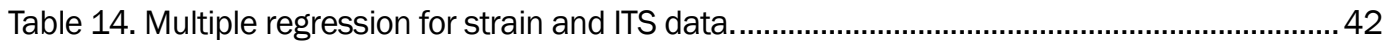

Table 15. Multiple regression for strain and DSR binder data.........................................................42

Table 16. Multiple regression for strain, PSPA modulus, and ITS stress. .......................................43 


\section{Preface}

The project described in this report was sponsored by Headquarters, U.S. Air Combat Command, Langley Air Force Base, VA.

Personnel of the U.S. Army Engineer Research and Development Center, Geotechnical and Structures Laboratory (GSL), Vicksburg, MS, prepared this publication. The research was a continuation of a Phase I project from fiscal year 2006. The findings and recommendations presented in this report are based upon evaluations of aged asphalt concrete pavements from Polk Army Airfield in Fort Polk, LA, Redstone Army Airfield in Huntsville, AL, Simmons Army Airfield in Fort Bragg, NC, and Forney Army Airfield in Fort Leonard Wood, MO, in addition to the data collected during the Phase I investigation. The required field testing for Phase II was conducted during March and April 2007, and the laboratory testing was conducted March to August 2007. The evaluation team consisted of Blake Andrews, Haley Bell, and Jason Knox, Airfields and Pavements Branch (APB), GSL. Bell, Dr. Reed B. Freeman, and Dr. E. Ray Brown, $\mathrm{APB}$, prepared this publication under the supervision of Dr. Gary Anderton, Chief, APB; Dr. Larry N. Lynch, Chief, Engineering Systems and Materials Division; Dr. William P. Grogan, Deputy Director, GSL; and Dr. David W. Pittman, Director, GSL.

COL Richard B. Jenkins was Commander and Executive Director of ERDC. Dr. James R. Houston was the Director.

Recommended changes for improving this publication in content and/or format should be submitted on DA Form 2028 (Recommended Changes to Publications and Blank Forms) and forwarded to Headquarters, U.S. Army Corps of Engineers, ATTN: CECW-EW, 441 G Street NW, Washington, DC 20314. 


\section{Unit Conversion Factors}

\begin{tabular}{|l|l|l|}
\hline Multiply & By & To Obtain \\
\hline degrees Fahrenheit & $(\mathrm{F}-32) / 1.8$ & degrees Celsius \\
\hline feet & 0.3048 & meters \\
\hline inches & 25.4 & millimeters \\
\hline pounds (force) per square inch & 6.894757 & kilopascals \\
\hline pounds (mass) & 0.4535924 & kilograms \\
\hline kips (force) per square inch & 6.894757 & megapascals \\
\hline
\end{tabular}




\section{Summary}

Personnel of the U.S. Army Engineer Research and Development Center (ERDC), Vicksburg, MS, conducted an evaluation of aged asphalt concrete (AC) surfaces during March to August 2007 to determine a method for predicting remaining pavement fatigue life. This research project was an extension of an investigation that was conducted in fiscal year 2006 (Bell and Freeman 2007). Phase II field testing took place at Polk Army Airfield in Fort Polk, LA; Redstone Army Airfield in Huntsville, AL; Simmons Army Airfield in Fort Bragg, NC; and Forney Army Airfield in Fort Leonard Wood, MO. The in situ surface modulus of the AC samples was determined using a portable seismic pavement analyzer (PSPA). Aged AC samples were removed from the airfields and brought to the ERDC asphalt laboratory where indirect tensile strength (ITS) tests (ASTM D 6931-07) and beam fatigue tests were conducted. Selected binder properties were determined from the samples. A high-quality AC airfield mixture was prepared in the ERDC asphalt laboratory for use as a control in the evaluation. Data were analyzed using a series of linear multiple regressions.

The following conclusions resulted from the evaluation of the aged AC pavements:

1. The current Department of Defense (DoD) criterion for AC fatigue life, which was developed using laboratory-produced beam samples, predicts fatigue life as a function of $\mathrm{AC}$ modulus and tensile strain (or tensile stress). The current DoD criterion has difficulty predicting fatigue failure for aged AC samples obtained from the field. Results from this study indicate that the error in this prediction can be highly unconservative. Predicted repetitions to failure were, in some cases, more than 2 log cycles (factor of 100) higher than measured repetitions to failure.

2. One significant cause of error in predicting the fatigue life of aged, field AC samples using the original DoD criterion was attributed in this report to a discrepancy between mixture properties of samples artificially aged in the laboratory and those actually aged over a significant period of time in the field. In the original DoD criterion, different modulus values were obtained by changing the beam fatigue testing temperature. Therefore, changes in mixture properties were the result of changing the stiffness of the mixture. In contrast, different $\mathrm{AC}$ modulus values measured in the field provided 
information related to the stiffening of the $\mathrm{AC}$, but this difference in modulus also occurs as the result of durability issues such as repeated loads and water damage. Also, the stiffness measured in the field was determined with the PSPA; in the laboratory, the stiffness was determined from stiffness measurements made during the beam fatigue tests.

3. The original DoD fatigue criterion showed a decrease in fatigue life as the stiffness increased, since this was based on constant strain testing. The inverse relationship between cycles to failure and strain compares favorably to that of other researchers. However, when the new model was developed during this study, it showed a direct relationship between cycles to failure and mixture stiffness. There are likely two reasons for this general difference between the two models. First, the differences may be caused by significant scatter in a relatively small database for the study in which the PSPA was used. Second, it is possible that the PSPA-measured stiffness may provide information about the integrity of the aged mixture. In the field, the asphalt mixture is exposed to repeated loads and some durability issues that may actually have adverse effects on the stiffness and the cycles to failure at the same time. In other words, the modulus may be reduced and the cycles to failure may be reduced at the same time. So, it is possible, in this case, that a reduction in stiffness in the field also results in a reduction of fatigue life.

4. A method for correcting the current DoD fatigue criterion to better predict fatigue performance of aged, field $\mathrm{AC}$ was developed and can be applied to various strain levels and $\mathrm{AC}$ moduli. This model has a similar form to the current fatigue model but does provide a much improved answer for in-place aged $\mathrm{AC}$ pavements.

5. Multivariate regression analyses were performed to find the independent variables that contributed significantly to predicting fatigue performance of aged, field AC. Similar to the original DoD fatigue criterion, strain level was the most informative independent variable for predicting the fatigue performance of aged, field $\mathrm{AC}$. The second most informative independent variable was AC design modulus, as measured by the PSPA.

6. Peak stress from the ITS test was the only other material parameter that, when used with strain level, offered a significant contribution to predicting fatigue performance of aged, field AC. When ITS peak stress was combined with both strain and AC design modulus, however, the ITS peak stress dropped out of the stepwise multivariate regression. The reason that ITS peak stress dropped out can be attributed to its positive correlation with AC design modulus. In other words, the ITS results and the AC design moduli served similar purposes in explaining variability between the 
fatigue performance of different AC samples. These independent variables did not complement each other.

7. Based on paragraph 6, ITS peak stress, as measured from core samples, can be used as a substitute for field measurements of modulus to indicating the quality (or integrity) of aged, field $\mathrm{AC}$ and to predict remaining fatigue life.

8. Material parameters that did not contribute significantly to predicting the fatigue performance of aged, field AC included AC age (this is related to the mixture stiffness), pavement condition index, several AC-mixture properties (many are related to the stiffness), and several AC binder properties (related to the stiffness).

9. All laboratory testing in this study was conducted at room temperature, so the fatigue criteria for aged, field $\mathrm{AC}$ developed herein are intended for predicting fatigue performance at $77^{\circ} \mathrm{F}$. A method is proposed, however, by which the failure prediction for aged, field $\mathrm{AC}$ is compared to a similar prediction by the original DoD fatigue criterion (using the same strain and modulus values). The ratio of these two predictions, each in terms of $\log _{10}$ (cycles), forms a correction factor that can then be applied to further predictions of fatigue performance for the aged, field $\mathrm{AC}$ as they are accomplished with the current DoD fatigue criterion. With this system, the aged, field fatigue criteria can influence predictions for fatigue performance at a wide range of temperatures and strain levels. The aged, field fatigue criteria can therefore be used in pavement evaluations in which the pavement life is divided into performance periods, each with a different mean pavement temperature.

10. There was very little correlation between the stiffness of the asphalt mixture by the PSPA test and by the beam stiffness test in the laboratory. Obtaining different results between two methods for measuring stiffness indicates part of the problem when assigning stiffness values to $\mathrm{AC}$ mixtures. As stated earlier, the PSPA likely is a measure of stiffness as well as other characteristics of the mixture that may be related to fatigue performance.

The following recommendations are based upon the results of the field and laboratory testing of aged, field $\mathrm{AC}$ pavements.

1. Pavement evaluations should include one of the following two measures of AC quality (or integrity). 
a. AC design modulus ( $15 \mathrm{~Hz}$ and $77^{\circ} \mathrm{F}$ ), as obtained by the PSPA.

b. ITS for a 4-in.-diam core, specifically the peak stress from this test.

2. If the PSPA is included in a pavement evaluation to indicate AC integrity in terms of elastic modulus, use the following equation to predict the fatigue life of aged, field $\mathrm{AC}$ at $77^{\circ} \mathrm{F}$. The estimated tensile strain at the bottom of the AC layer should be found by layered elastic analysis using the AC modulus, E.

$$
\log _{10}\left(\varepsilon_{\mathrm{ra}}\right)=7.94-\left[\frac{\mathrm{LN}\left(\mathrm{S}_{\mathrm{A}} \times 10^{6}\right)}{2.61}\right]^{2}+\frac{\mathrm{E}}{438,000 \mathrm{psi}}
$$

where:

$$
\begin{aligned}
\varepsilon_{\mathrm{ra}} & =\text { allowable strain repetitions for aged, field AC } \\
\mathrm{S}_{\mathrm{A}} & =\text { tensile strain of } \mathrm{AC}, \text { in./in. } \\
\mathrm{E} & =\mathrm{AC} \text { design modulus, psi. }
\end{aligned}
$$

3. If an ITS test is used in a pavement evaluation to indicate AC integrity in terms of peak stress, use the following equation to predict the fatigue life of aged, field $\mathrm{AC}$ at $77^{\circ} \mathrm{F}$. An estimate for $\mathrm{AC}$ modulus is needed to calculate the AC tensile strain by layered elastic analysis. Methods of estimating AC modulus are presented in the Unified Facilities Criteria "Airfield Pavement Evaluation" manual (UFC 3-260-03).

$$
\log _{10}\left(\varepsilon_{\mathrm{ra}}\right)=8.36-\left[\frac{\mathrm{LN}\left(\mathrm{S}_{\mathrm{A}} \times 10^{6}\right)}{2.62}\right]^{2}+\frac{\text { ITS Peak Stress, psi }}{264 \mathrm{psi}}
$$

4. To predict repetitions to failure for aged, field $\mathrm{AC}$ at any temperature other than $77^{\circ} \mathrm{F}$, an "aged, field $\mathrm{AC}$ fatigue correction factor" (AFC) must be calculated and applied as follows. Each $\log _{10}\left(\varepsilon_{\mathrm{r}}\right)$ is calculated with the same assumption for strain.

$$
\mathrm{AFC}=\frac{\log _{10}\left(\varepsilon_{\mathrm{ra}}\right) \text { at } 77^{\circ} \mathrm{F} \text { using aged, field asphalt criteria }}{\log _{10}\left(\varepsilon_{\mathrm{r}}\right) \text { at } 77^{\circ} \mathrm{F} \text { using the original DoD criterion }}
$$


5. Once the AFC is known, it is applied to the original DoD criterion for calculated repetitions to failure at any temperature. For this equation, $\log _{10}\left(\varepsilon_{\mathrm{r}}\right)$ is determined at the desired pavement temperature using the original DoD fatigue criterion equation (Equation 2 in the main text).

$$
\begin{gathered}
\log _{10}\left(\varepsilon_{\mathrm{rc}}\right)=\log _{10}\left(\varepsilon_{\mathrm{r}}\right) \times \mathrm{AFC} \\
\varepsilon_{\mathrm{rc}}=\left(\varepsilon_{\mathrm{r}}\right)^{\mathrm{AFC}}
\end{gathered}
$$

Chapter 1 of this report presents the objective and scope of the project, Chapter 2 provides the research plan, and Chapter 3 discusses the field procedures including a description of the test sites. Chapter 4 summarizes the laboratory testing procedures and presents the results of the laboratory tests. Chapter 5 summarizes the data analysis and findings from the evaluation, and Chapter 6 provides the conclusions and recommendations of the information gained from evaluation of the aged AC surface. 


\section{Introduction}

\section{Background}

The U.S. Air Force Civil Engineer Support Agency (AFCESA) pavement evaluation teams are under constant pressure to provide accurate field assessments of pavement load-carrying capacity. Pavement evaluation results provide critical information needed by major command engineers for mission planning and optimization of rehabilitation strategies. The AFCESA has an immediate need for testing and analytical procedures for assessing the integrity of asphalt concrete (AC) surface layers and predicting the performance of aged $\mathrm{AC}$ when subjected to heavy wheel loads and high tire pressures.

Many times, in military operations, it is necessary to use existing airfields or roads that consist of aged AC surfaces. The ability of the U.S. Air Force to select suitable operating surfaces in the theater of operation is limited by the current methods being used for the visual and structural evaluation of AC pavements, which have failed to identify problems caused by the use of such pavements. Future military missions may be severely impacted without the ability to predict the performance of aged $\mathrm{AC}$ pavements accurately.

This research was a continuation of an FYo6 evaluation of aged AC surfaces project (Bell and Freeman 2007). The results from the FYo6 project supported the need to develop a fatigue criterion for aged AC that is independent of the current Department of Defense (DoD) fatigue criterion.

\section{Objective and scope}

The purpose of this research was to address issues with evaluating and predicting the performance of deteriorated AC surfaces. To accomplish this, several aged AC samples were located and evaluated. The evaluation consisted of determining the in situ AC modulus using the portable seismic pavement analyzer (PSPA), determining the strength of the samples using indirect tensile strength (ITS) testing, measuring selected binder properties of the aged samples, and determining the fatigue life of the $\mathrm{AC}$ using beam fatigue tests. The primary objective of this investigation was to 
determine a methodology for evaluating aged AC surfaces on existing pavements. This report provides data for the following:

1. Visually inspecting aged $\mathrm{AC}$ surfaces on various airfields as presented in data from pavement condition index (PCI).

2. Completing field testing that can be used to identify and quantify parameters for evaluating the fatigue performance of aged AC surfaces.

3. Completing laboratory testing of samples removed from the aged $\mathrm{AC}$ surfaces.

4. Analyzing the data to provide guidance for evaluating any pavement system having an aged AC surface.

This report provides information about the research approach, field and laboratory testing procedures, data analysis, and recommendations for evaluating and predicting the performance of pavement having aged $\mathrm{AC}$ surfaces. The data analysis chapter (Chapter 5 ) includes the results of the Phase I and Phase II investigations. 


\section{Research Approach}

The following paragraph presents the approach for evaluating the aged AC pavements during the Phase II investigation. The same general approach was followed for the Phase I study. Figure 1 presents a flow chart of the Phase II evaluation process. Chapters 3 and 4 provide further details regarding the field and laboratory testing of the AC samples.

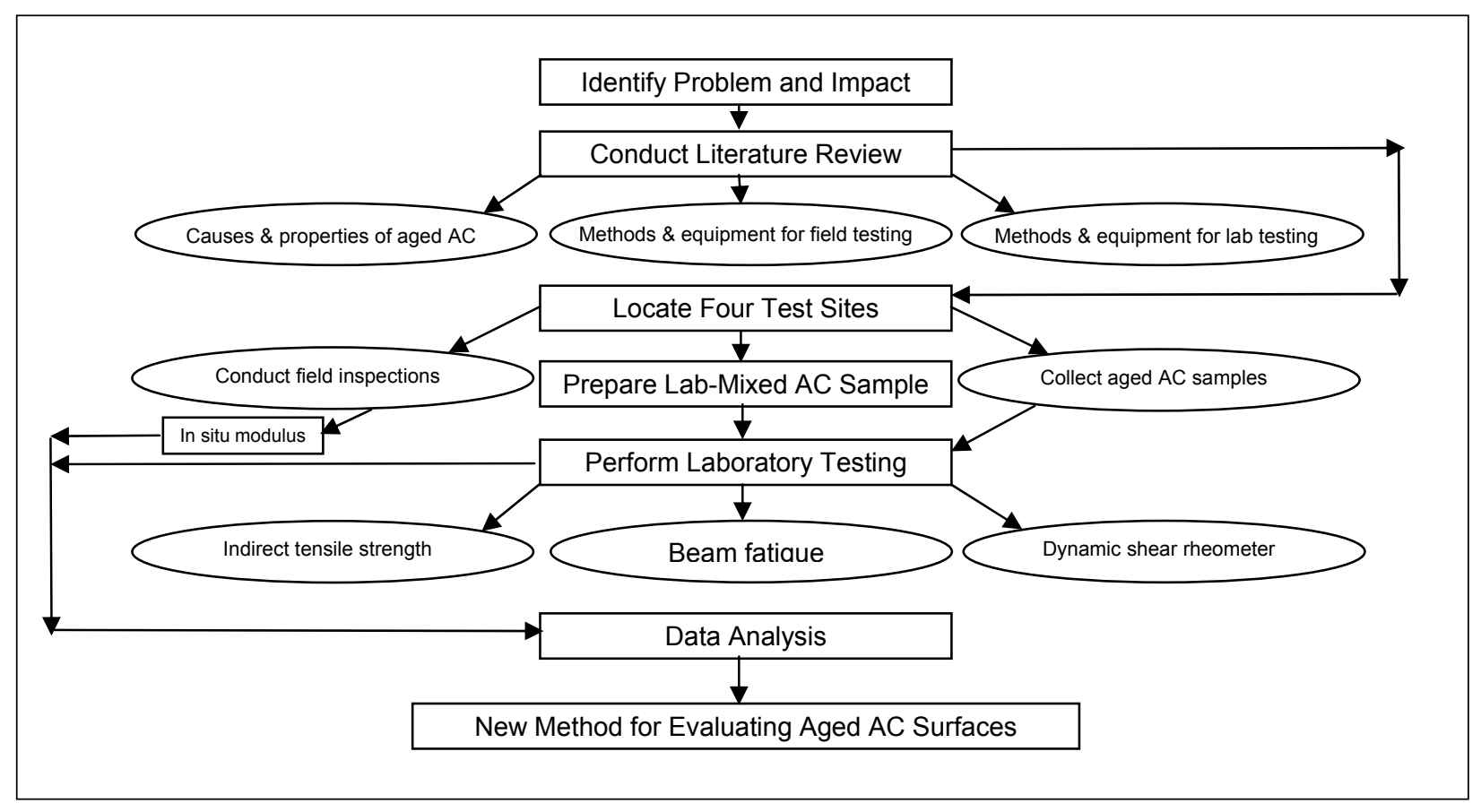

Figure 1. Flow chart detailing the research plan.

The research effort began by identifying the problem that is occurring with the aged military airfield pavements in the Middle East and the impact that these pavements are having on aircraft and military operations. Next, a literature review was conducted to help identify the causes and properties of aged AC, methods and equipment needed for the field and laboratory testing, and analytical methods for evaluating the performance of the aged AC. Once the literature review was completed, four test sites were located. Three 2- by 3-ft aged AC samples were desired from each test site. The samples were required to be at least 3 in. thick and not more than 6 in. thick. At two of the test sites, only two aged AC samples met the thickness requirements. The 3 -in. minimum thickness requirement was set because of the laboratory testing dimension requirements, and the 6-in. maximum 
requirement was set because the concrete saw blade was not large enough to saw any deeper than 6 in.

While at each test site, field inspections were conducted for each sample for which PSPA testing was completed, to measure the pavement's modulus in situ. Then, the aged samples were removed and returned to the asphalt laboratory at the Engineer Research and Development Center (ERDC) for testing. The laboratory testing included indirect tensile strength, beam fatigue, and dynamic shear rheometer (DSR). Furthermore, an airfield quality AC mixture (AC-30) was prepared in the ERDC's asphalt laboratory. This unaged sample was approximately $2 \mathrm{ft}$ by $2 \mathrm{ft}$ and about 3 in. thick. The PSPA was tested on the compacted sample after it was removed from the frame. Once all laboratory testing was complete on the aged and unaged samples, the data from the field and laboratory testing were used for the data analysis. The data analysis portion of the investigation included running a series of linear multiple regressions to aid in developing a method for predicting aged $\mathrm{AC}$ pavement performance. This evaluation was completed with the development of a new method for evaluating aged $\mathrm{AC}$ pavements. 


\section{Field Procedures}

\section{Description of test sites}

The evaluation of aged AC began in March 2007 at Polk Army Airfield in Fort Polk, LA, and Redstone Army Airfield in Huntsville, AL. Field testing continued in April 2007 at Simmons Army Airfield in Fort Bragg, NC, and Forney Army Airfield in Fort Leonard Wood, MO. Further investigations, including the laboratory testing, began in March 2007 and concluded in August 2007. Figure 2 shows the geographical locations of the test sites. Ten aged AC samples were obtained from these four locations (Table 1).

A high-quality standard airfield mixture AC sample (AC-30) was prepared in the ERDC asphalt laboratory. This mixture was produced to conform to both UFC 3-25-03 (Standard Practice Manual for Flexible Pavements) and UFGS-02749 (Hot-Mix Asphalt (HMA) for Airfields). The sample (listed as LM-2) was prepared in a portable pugmill mixer and compacted in a steel frame. The purpose of the laboratory-prepared sample was to use it as a control for the aged AC samples.

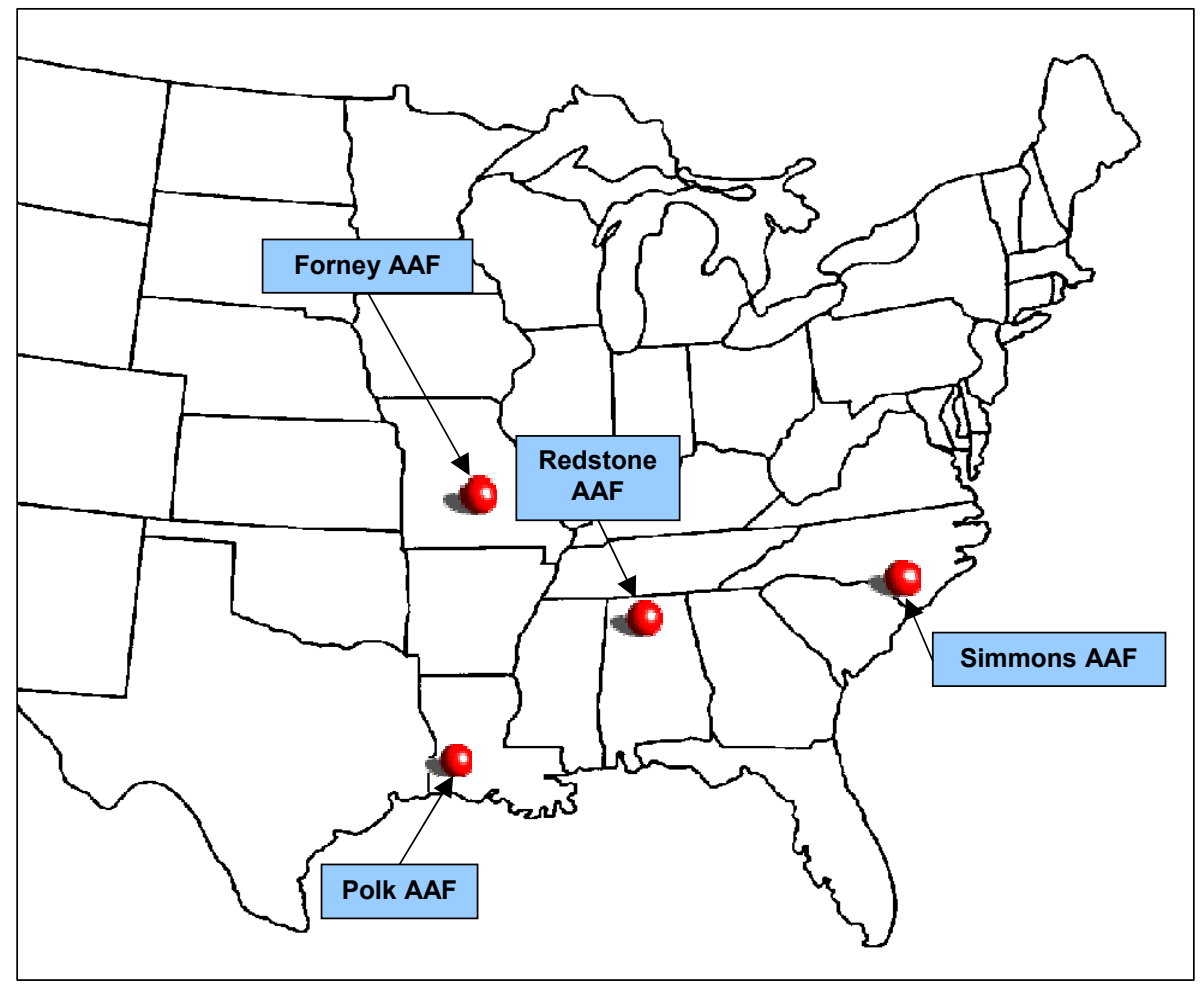

Figure 2. Test site locations. 
Table 1. Sample nomenclature and PCl.

\begin{tabular}{|l|l|c|l|l|}
\hline Sample & Airfield & Age, $y$ r & PCl & PCl Rating \\
\hline LM-2 & ----------- & 0 & No data & No data \\
\hline P-1 & Polk Army Airfield & 22 & 8 & Failed \\
\hline P-2 & Polk Army Airfield & 7 & 82 & Very Good \\
\hline R-1 & Redstone Army Airfield & 21 & 43 & Fair \\
\hline R-2 & Redstone Army Airfield & 41 & 47 & Fair \\
\hline S-1 & Simmons Army Airfield & 14 & 57 & Good \\
\hline S-2 & Simmons Army Airfield & 14 & 53 & Fair \\
\hline S-3 & Simmons Army Airfield & 14 & 48 & Fair \\
\hline F-1 & Forney Army Airfield & 27 & 43 & Fair \\
\hline F-2 & Forney Army Airfield & 27 & 59 & Good \\
\hline F-3 & Forney Army Airfield & 7 & 66 & Good \\
\hline
\end{tabular}

Two or three samples were obtained from each site. The samples were approximately $2 \mathrm{ft}$ by $3 \mathrm{ft}$ and at least $3 \mathrm{in}$. thick. Each sample produced nine beams for beam fatigue testing and three 4-in.-diam cores for ITS testing.

Table 1 gives a summary of the samples obtained from the field testing. Included in the table is the PCI and rating determined from recent airfield pavement condition surveys. A pavement condition survey is a visual inspection of the airfield pavements to determine the present surface condition. The condition survey consists of inspecting the pavement surface for various types of distress, determining the severity of each distress, and measuring the quantity of each distress. The estimated quantities and severity of each distress type are used to compute the PCI for each feature. The PCI is a numerical indicator based on a scale from o to 100 and is determined by measuring pavement surface distress that reflects the surface condition of the pavement. Pavement condition ratings are assigned to different levels of PCI values. The distress types, severity levels, methods of survey, and PCI calculations are described in ASTM D 5340-04.

Figures 3-8 illustrate the basic procedure for field testing, removal of the aged AC samples, and pavement repair. Each sample was tested with the PSPA to obtain the in situ AC modulus before being removed from the airfield. The LM-2 sample was tested with the PSPA in the ERDC asphalt laboratory prior to the removal of the beams and cores. Cores were extracted on-site, and the beams were sawn in the laboratory. Once the in situ modulus was obtained with the PSPA and the cores were extracted, the sample was sawed and removed, and the hole was patched. 


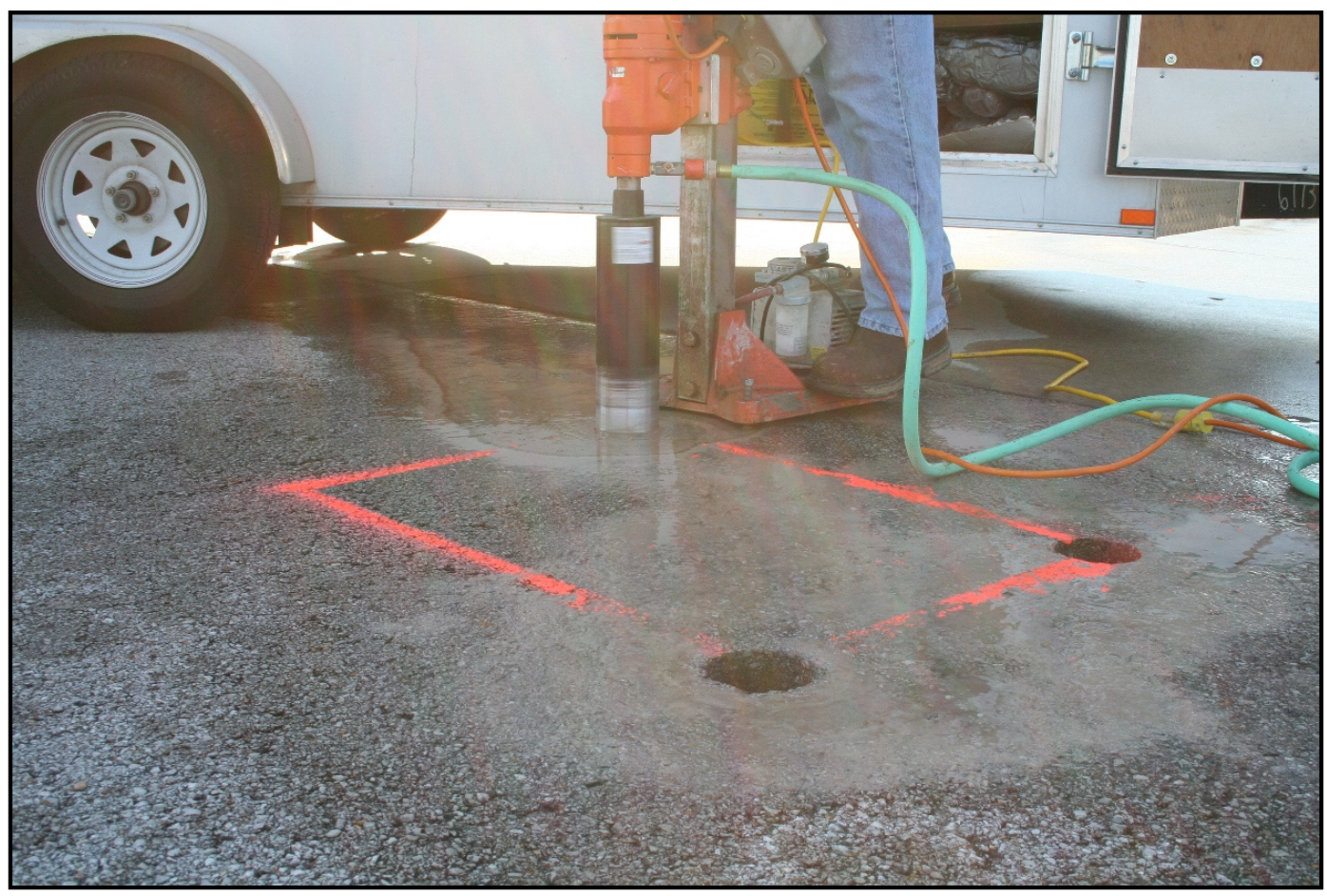

Figure 3. AC core sampling.

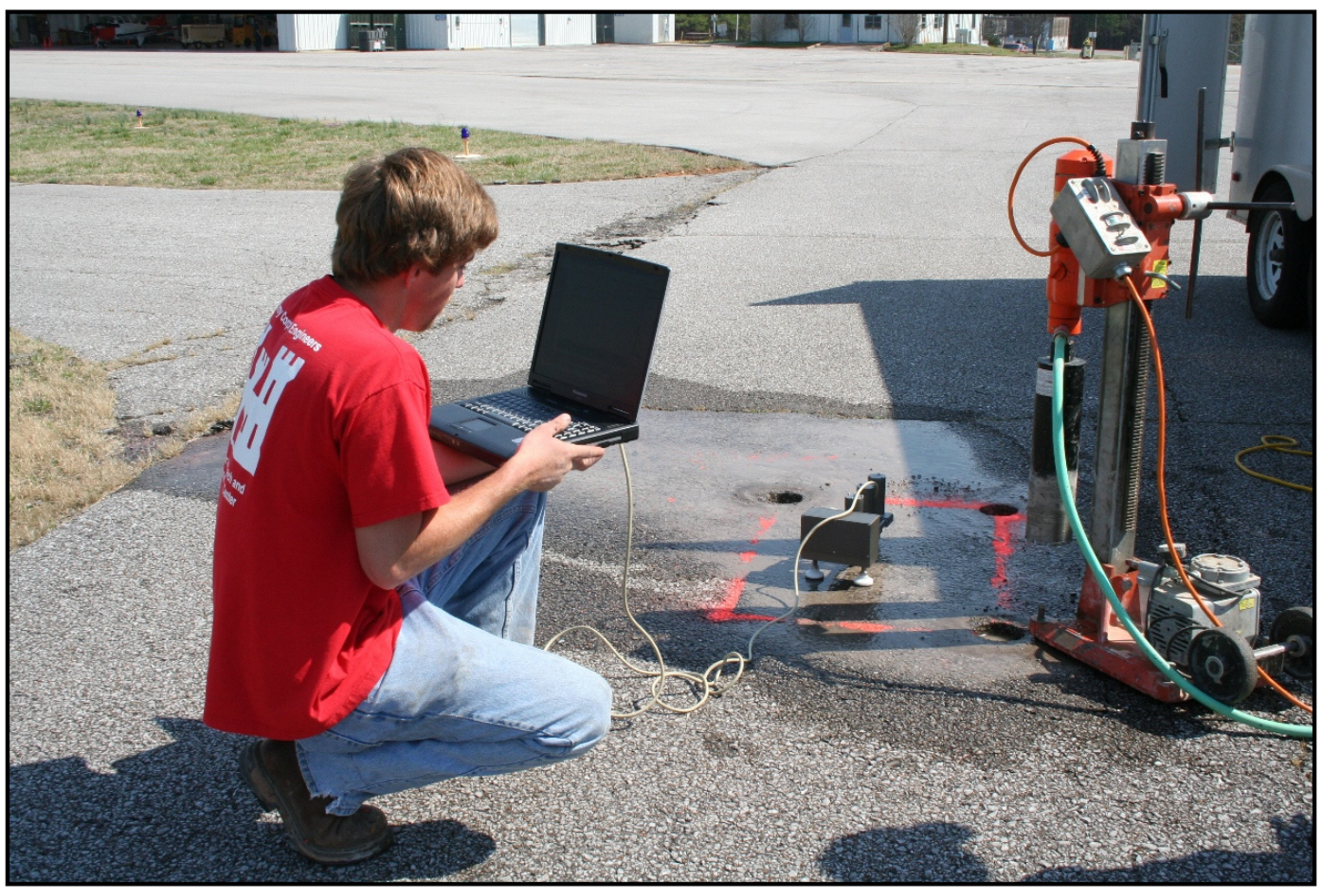

Figure 4. Obtaining the in situ pavement modulus using the PSPA. 


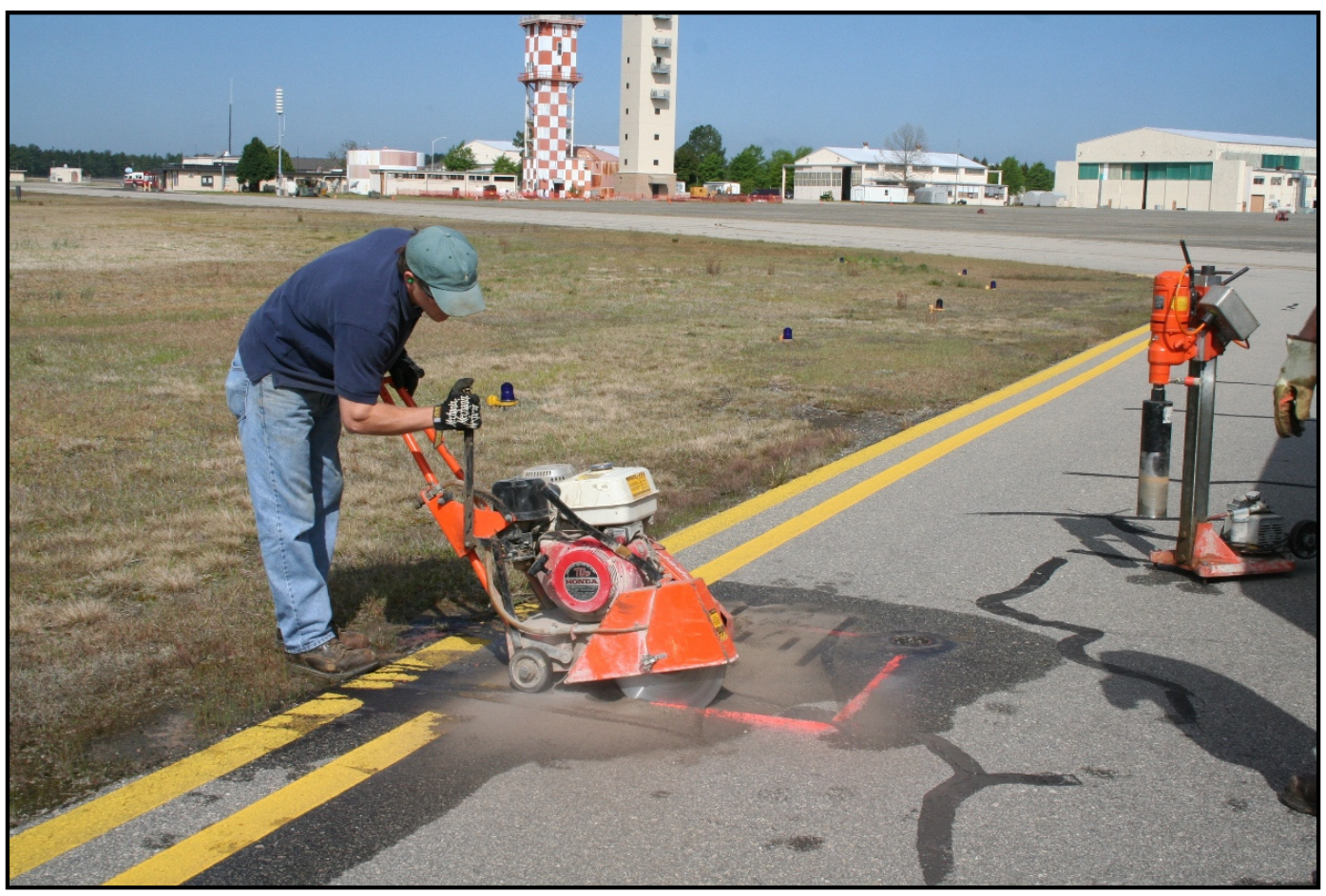

Figure 5. Sawing the aged AC sample.

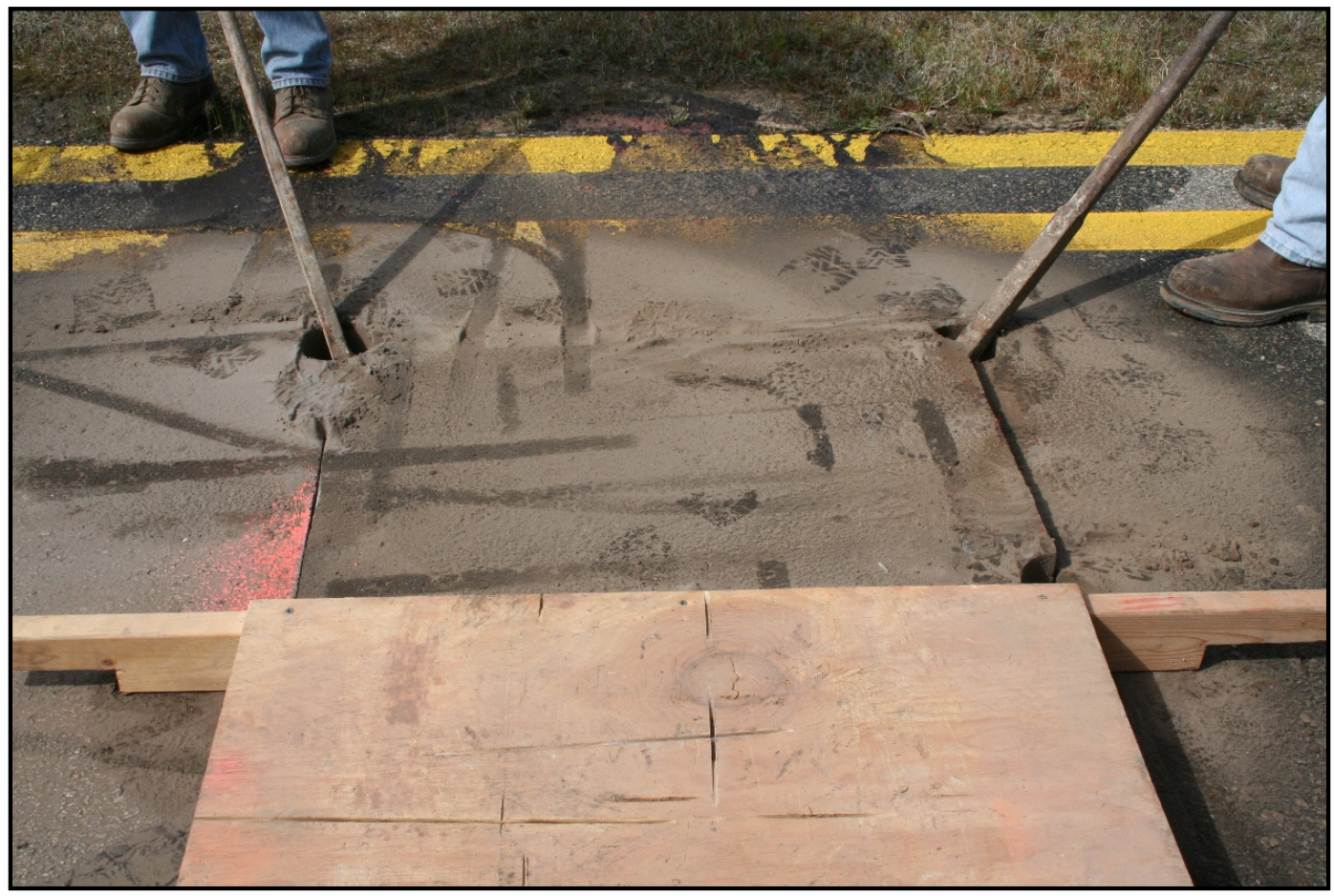

Figure 6. Removing the aged AC sample. 


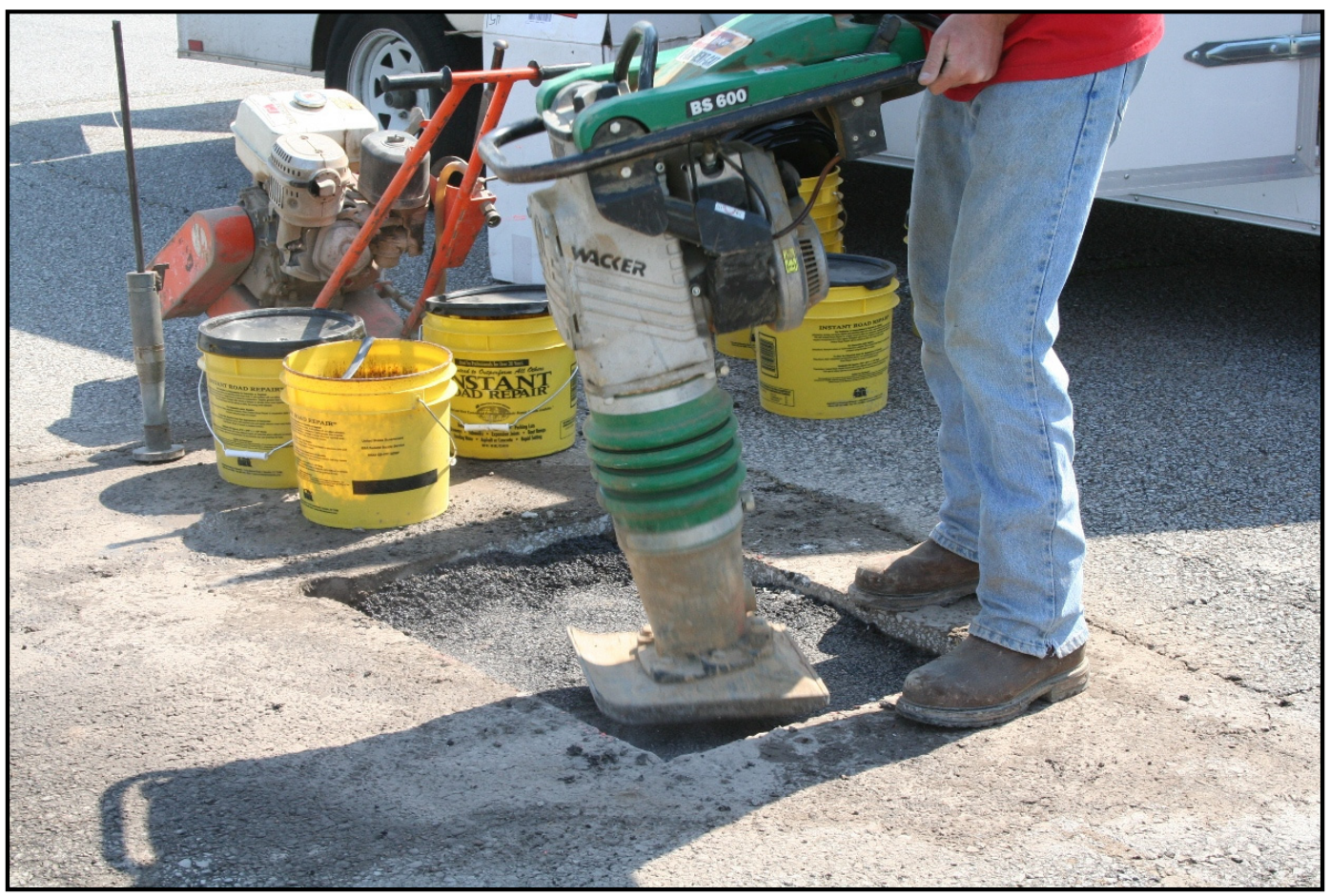

Figure 7. Patching the hole of the removed aged AC sample.

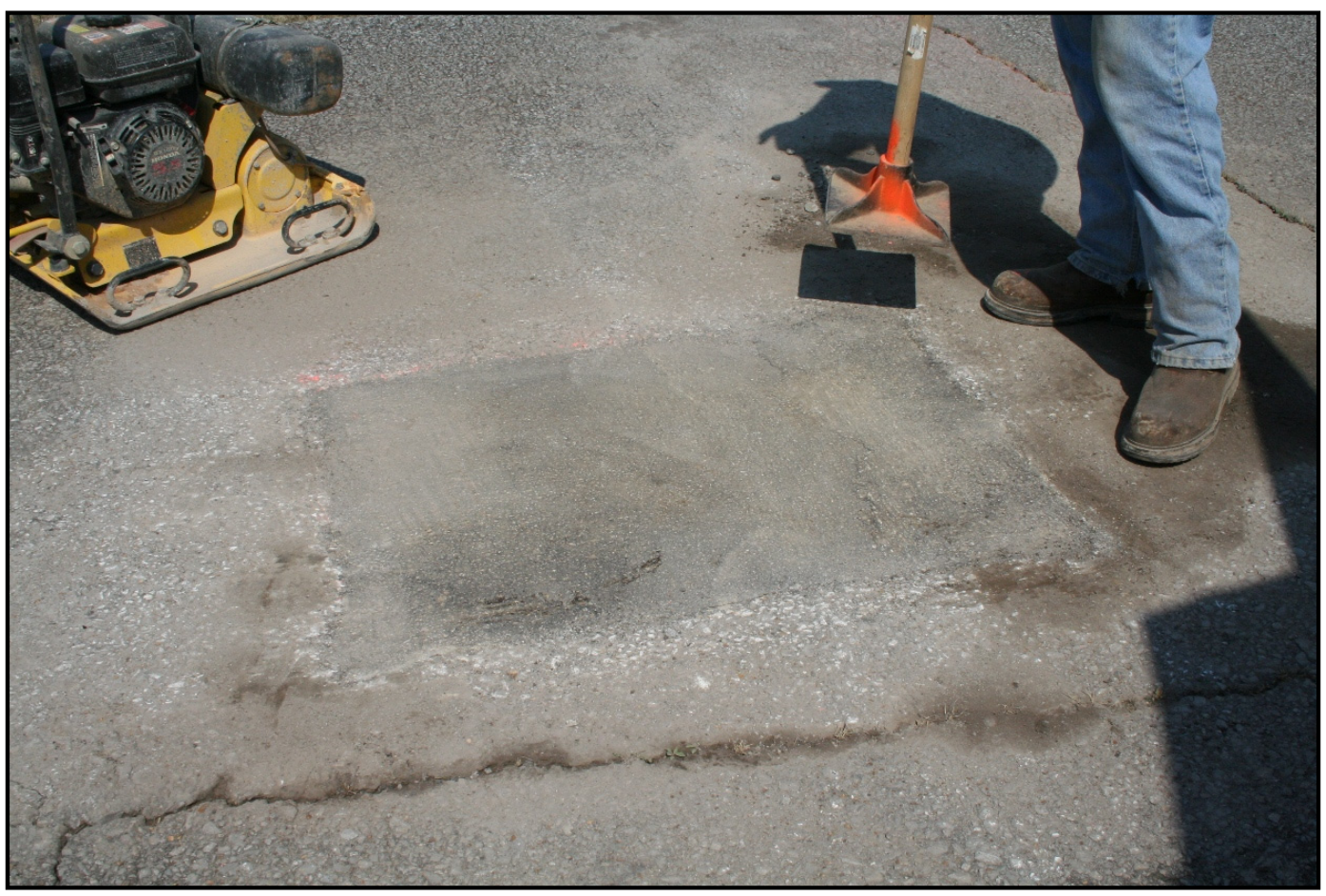

Figure 8. Patched AC sample. 


\section{Portable seismic pavement analyzer tests}

The PSPA (Figure 9) is a nondestructive testing device that rapidly measures Young's modulus via ultrasonic surface waves, completing tests within a few seconds. The PSPA is used to estimate the in situ seismic modulus of concrete pavements and determine relevant strength parameters for use in pavement evaluations such as those conducted by the DoD in accordance with the UFC 3-260-03 (Headquarters, Departments of the Army, the Navy, and the Air Force 2001a).

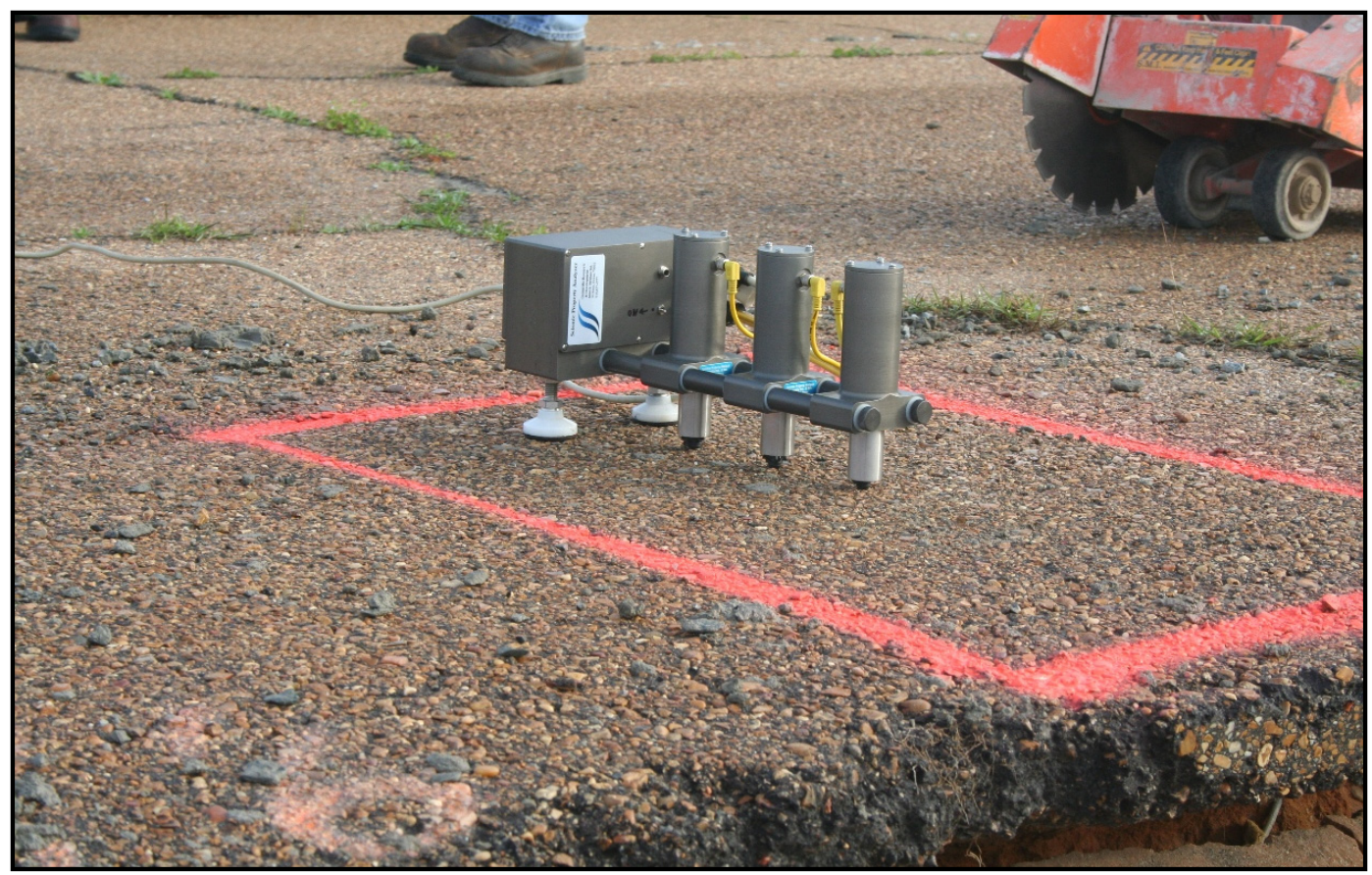

Figure 9. Portable seismic pavement analyzer.

The PSPA device is operated from a laptop computer, which is connected to an electronics box by a cable that transmits power to the receivers and the source. The source impacts the pavement surface, generating surface waves that are detected by the receivers. The measured signals are returned to the data acquisition board in the computer. The velocity at which the surface waves propagate is determined, and the modulus is computed.

For this study, the PSPA was used to measure the modulus of the aged AC samples before they were removed from the airfields. An average modulus for each sample was determined by conducting three to five PSPA tests at the same location. The modulus of AC pavements depends upon temperature; therefore, a design modulus was used to standardize the PSPA 
results to predict pavement performance. The PSPA reports the seismic modulus at the temperature of the pavement in the field at the time of testing. The AC design modulus is used to adjust the modulus measured by the PSPA to a temperature of $77^{\circ} \mathrm{F}$ and a design frequency of $15 \mathrm{~Hz}$ using Equation 1 (Nazarian et al. 2005).

$$
E_{77^{\circ} F}=\frac{E_{P S P A}}{\left(\left\{-0.0109 *\left[(T-32) * \frac{5}{9}\right]+1.2627\right\} *(3.2)\right)}
$$

where:

$$
\begin{aligned}
E_{77^{\circ} \mathrm{F}} & =\text { AC design modulus, ksi } \\
E_{P S P A} & =\text { modulus measured from the PSPA, ksi } \\
T & =\text { AC pavement temperature, }{ }^{\circ} \mathrm{F} .
\end{aligned}
$$

The AC design modulus is incorporated with the test results during the data analysis phase. The adjusted AC modulus value (AC design modulus) to use for recording or analyzing is $E_{77^{\circ} \mathrm{F}}$. Table 2 shows the in situ modulus values (both measured with the PSPA and adjusted using Equation 1) of the AC samples. These data were obtained before the samples were removed from the airfield. Table 2 shows that the laboratory-prepared sample (LM-2) has the lowest stiffness. Samples R-1, R-2, F-1, and F-2 are some of the oldest samples, and they have some of the highest measured modulus values. Typically, the higher the $\mathrm{AC}$ pavement temperature, the lower the surface modulus will be. Table 2 does not show a definite trend between pavement temperature and measured PSPA modulus of all the samples. This is because the samples were from different locations, and the moduli are heavily influenced by the air voids of the pavement, mix design, etc. 
Table 2. PSPA modulus results.

\begin{tabular}{|l|l|l|l|}
\hline Sample & Temperature, $^{\circ} \mathbf{F}$ & PSPA Modulus, ksi & AC Design Modulus, ksi \\
\hline LM-2 & 72 & 1160 & 355 \\
\hline P-1 & 72 & 1625 & 498 \\
\hline P-2 & 79 & 1948 & 622 \\
\hline R-1 & 62 & 2388 & 690 \\
\hline R-2 & 86 & 1765 & 589 \\
\hline S-1 & 59 & 2388 & 679 \\
\hline S-2 & 74 & 1840 & 570 \\
\hline S-3 & 91 & 1780 & 614 \\
\hline F-1 & 59 & 2683 & 763 \\
\hline F-2 & 69 & 1526 & 459 \\
\hline F-3 & 89 & 1260 & 429 \\
\hline
\end{tabular}




\section{Laboratory Testing}

\section{Binder properties}

Several mixture and binder properties of the samples were obtained for the Phase I investigation, and most proved to be insignificant for predicting pavement performance. The results of the Phase I investigation indicated that $\mathrm{AC}$ mixture parameters (density, $\mathrm{AC}$ content, and gradation) contributed minimally toward adjusting the current $\mathrm{DoD} A C$ fatigue criterion to improve predictions of fatigue life for aged AC pavements. No mixture properties were obtained for the Phase II evaluation. The viscoelastic binder stiffness property, $G^{*} /(\sin \delta)$, proved to be the only significant binder property for aged AC fatigue life predictions for the Phase I investigation. Viscosity, penetration, and the viscoelastic binder stiffness property $G^{*}(\sin \delta)$ obtained in Phase I proved to be unhelpful in predicting pavement performance.

DSR tests (ASTM D 7175-05e1) were performed on the extracted Phase II binders to characterize the viscous and elastic behavior of the binders at high and intermediate service temperatures. The results generally indicate a pavement's resistance to permanent deformation and fatigue cracking. DSR results are commonly summarized as $G^{*} /(\sin \delta)$ and $G^{*}(\sin \delta)$, where $G^{*}$ is the complex shear modulus relating to the total resistance of the binder to shear deformation and $\delta$ is the phase angle relating to the binder's viscous $(\delta=90)$ and elastic $(\delta=0)$ nature. The term $G^{*} /(\sin \delta)$ basically characterizes the binder's resistance to rutting. As the value of $G^{*} /(\sin \delta)$ increases, the tendency of a mix to rut decreases. The term $G^{*}(\sin \delta)$ provides the binder's resistance to fatigue cracking. As the value of $G^{*}(\sin \delta)$ increases, the more work will be dissipated per traffic loading cycle (Roberts et al. 1996). Although the results of the Phase I investigation showed that $G^{*}(\sin \delta)$ was not significant for adjusting the current criterion to predict aged AC performance, the parameter was included in the Phase II analysis because the result was easily obtained.

Binders from aged $\mathrm{AC}$ and the standard laboratory mixture were evaluated with the DSR test at a temperature of $153^{\circ} \mathrm{F}\left(67^{\circ} \mathrm{C}\right)$. This temperature was chosen because the samples are equivalent to PG 67-XX. The binder properties tested are listed in Table 3. The DSR results show that LM-2 had the 
lowest stiffness, and sample R-2 had the highest stiffness. This is most likely because LM-2 was unaged, and R-2 was the oldest aged AC sample, at 41 years old.

\section{Indirect tensile strength tests}

ITS tests (ASTM D 6931-07) are used to determine the tensile strength of a cored sample. For this evaluation, the tests were performed on an Instron ${ }^{\circledR}$ machine in the ERDC asphalt laboratory. The Instron machine applied a uniaxial load at a controlled deformation rate of 2 in. per minute. The ITS tests (Figures 10 and 11) were conducted at room temperature on 4-in.diam cores that were approximately 2 in. in height. Three cores were tested per AC sample. Figure 12 presents an example plot of an ITS test result.

Table 3. Binder properties.

\begin{tabular}{|l|l|l|}
\hline Sample & $\begin{array}{l}G^{\star} /(\sin \delta) \\
\text { psi }\end{array}$ & $\begin{array}{l}G^{\star}(\sin \delta) \\
\text { psi }\end{array}$ \\
\hline LM-2 & 0.1885 & 0.1885 \\
\hline P-1 & 4.5832 & 5.8305 \\
\hline P-2 & 0.8122 & 0.8267 \\
\hline R-1 & 1.5664 & 1.6389 \\
\hline R-2 & 9.7175 & 14.5908 \\
\hline S-1 & 3.4664 & 3.9595 \\
\hline S-2 & 1.7550 & 1.9870 \\
\hline S-3 & 2.4801 & 2.7992 \\
\hline F-1 & 0.7832 & 0.8412 \\
\hline F-2 & 2.1030 & 2.3496 \\
\hline F-3 & 5.3809 & 6.9763 \\
\hline
\end{tabular}

Table 4 gives the results of the ITS tests, which are read from the load versus deformation plot of each sample. The results present the average of the three replicates. Peak strength is used to calculate the tensile strength of the sample, and energy is measured as the area under the load versus deformation plot up to peak load. Although the results of the Phase I investigation indicated that the peak stress value of the ITS test was the only ITS material parameter that offered a significant contribution to adjusting the current DoD fatigue criterion, the ITS energy to peak stress and ITS deformation at peak stress were recorded because the data were easy to obtain. The results in Table 4 show that LM-2 had the lowest peak stress because the unaged sample consisted of the softest asphalt binder. 


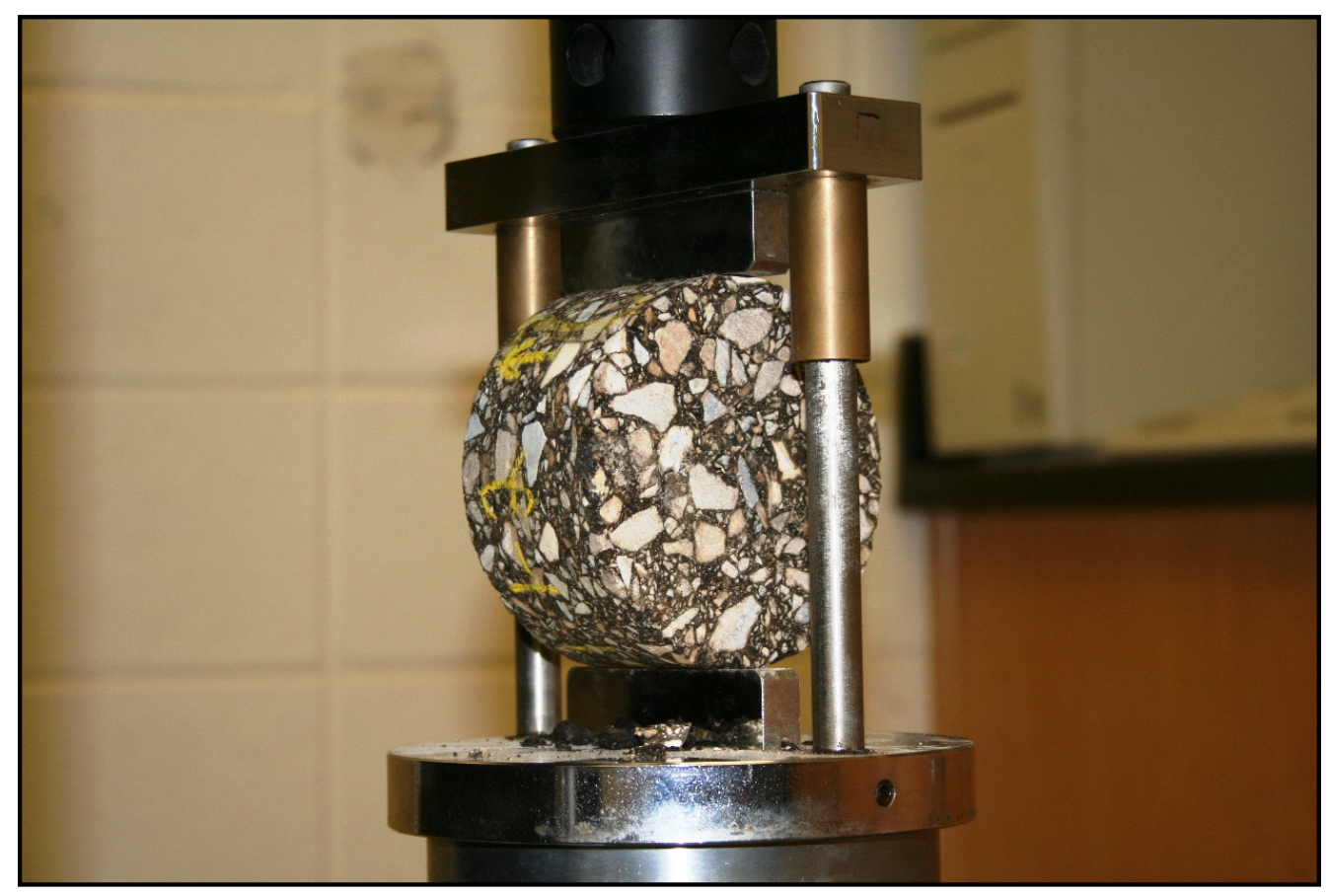

Figure 10. Before an ITS test on the Instron machine.

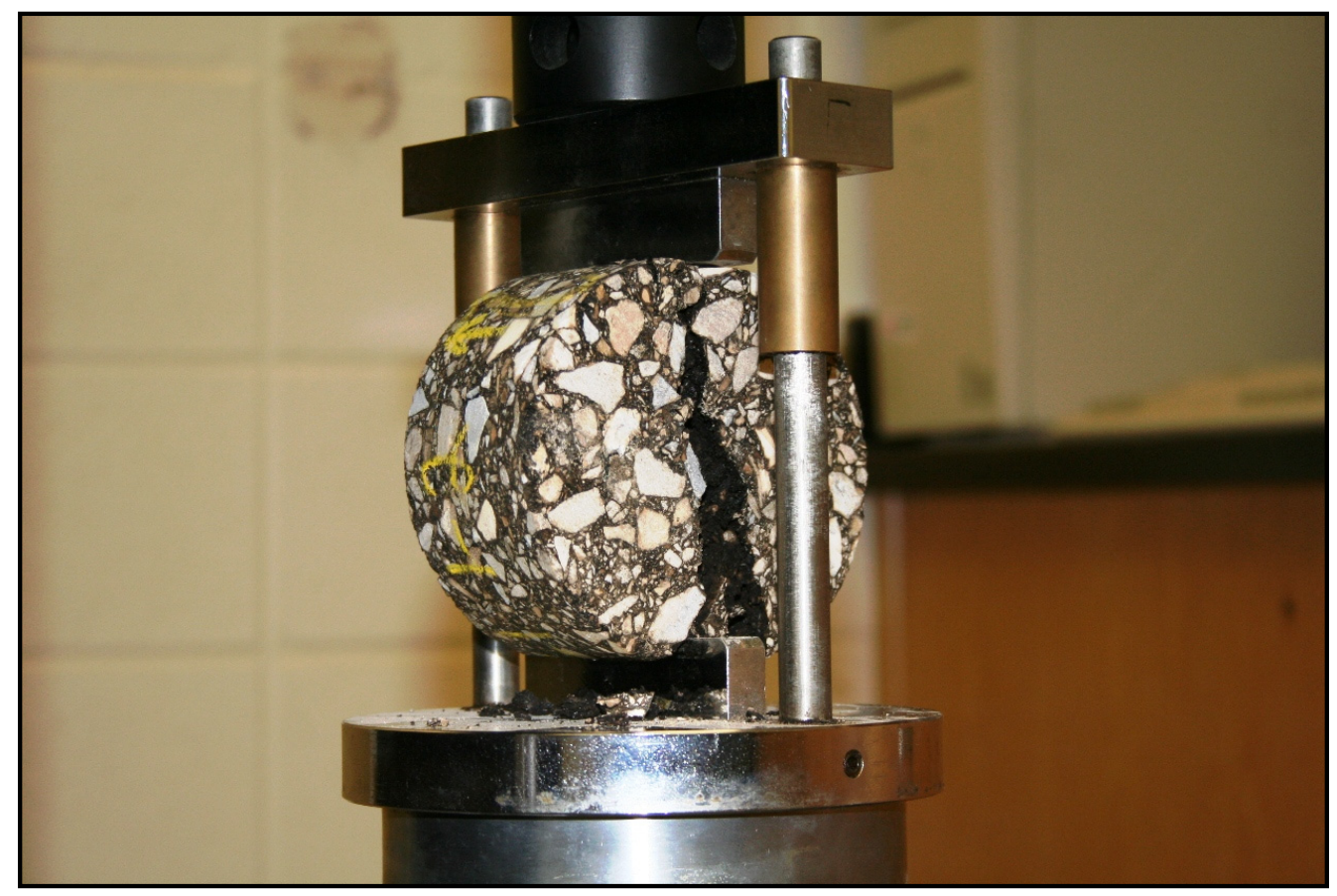

Figure 11. After an ITS test. 


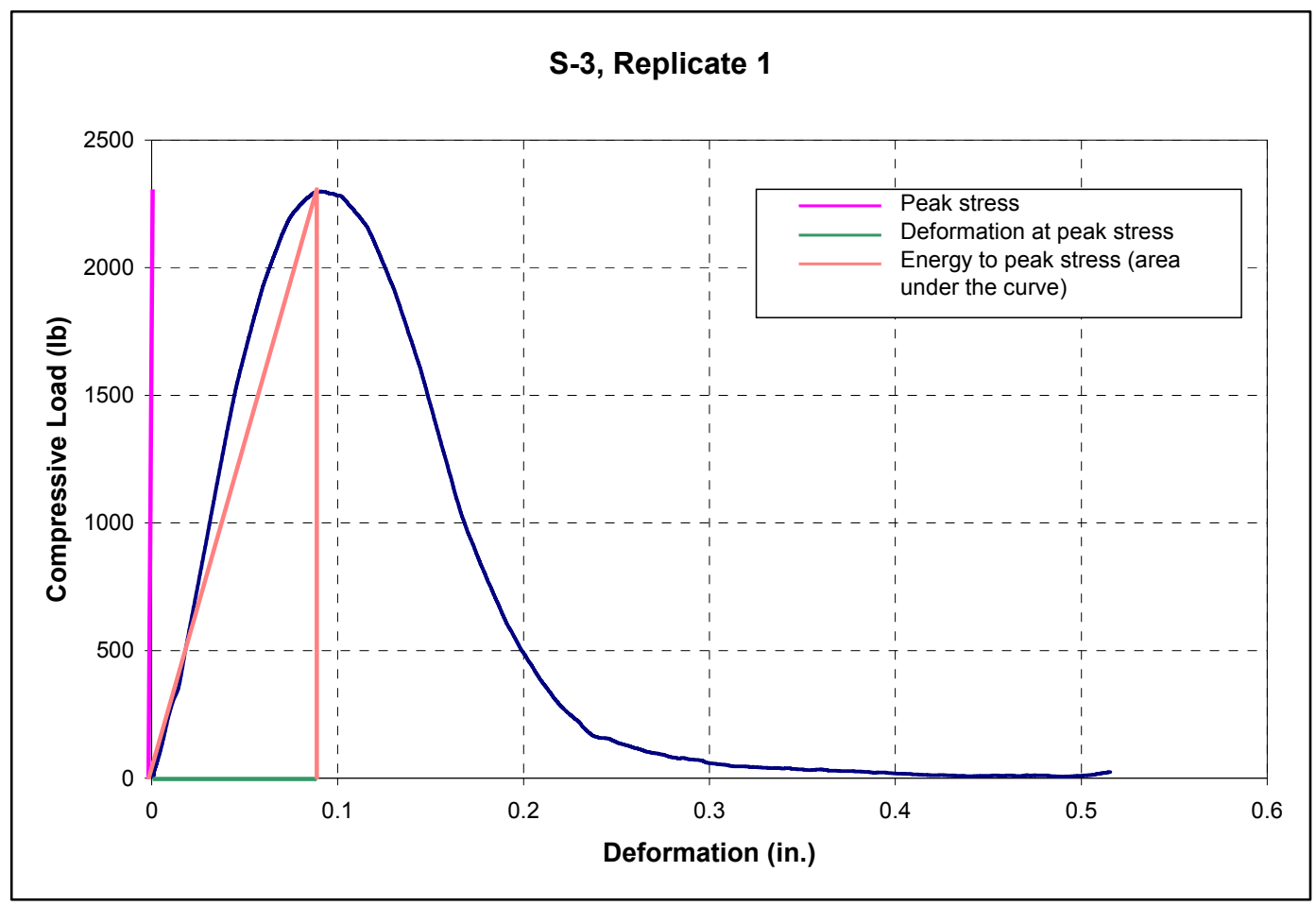

Figure 12. ITS test plot.

Table 4. ITS test results.

\begin{tabular}{|l|l|l|l|}
\hline Sample & Peak Stress, psi & $\begin{array}{l}\text { Deformation at Peak Stress } \\
\text { in. }\end{array}$ & $\begin{array}{l}\text { Energy to Peak Stress } \\
\text { in.-lb }\end{array}$ \\
\hline LM-2 & 118 & 0.167 & 129 \\
\hline P-1 & 237 & 0.059 & 90 \\
\hline P-2 & 358 & 0.085 & 202 \\
\hline R-1 & 262 & 0.082 & 135 \\
\hline R-2 & 188 & 0.065 & 76 \\
\hline S-1 & 256 & 0.076 & 123 \\
\hline S-2 & 263 & 0.097 & 163 \\
\hline S-3 & 258 & 0.113 & 183 \\
\hline F-1 & 232 & 0.067 & 100 \\
\hline F-2 & 164 & 0.086 & 91 \\
\hline F-3 & 191 & 0.081 & 94 \\
\hline
\end{tabular}

\section{Fatigue tests}

Fatigue life of the aged and unaged samples was determined with beam fatigue testing. The apparatus used in this study included an environmental chamber, and testing followed the Strategic Highway Research Program test procedure (designated M 009). The beams were subjected to 
repeated flexural bending. Figure 13 shows the beam fatigue apparatus and data collection setup.

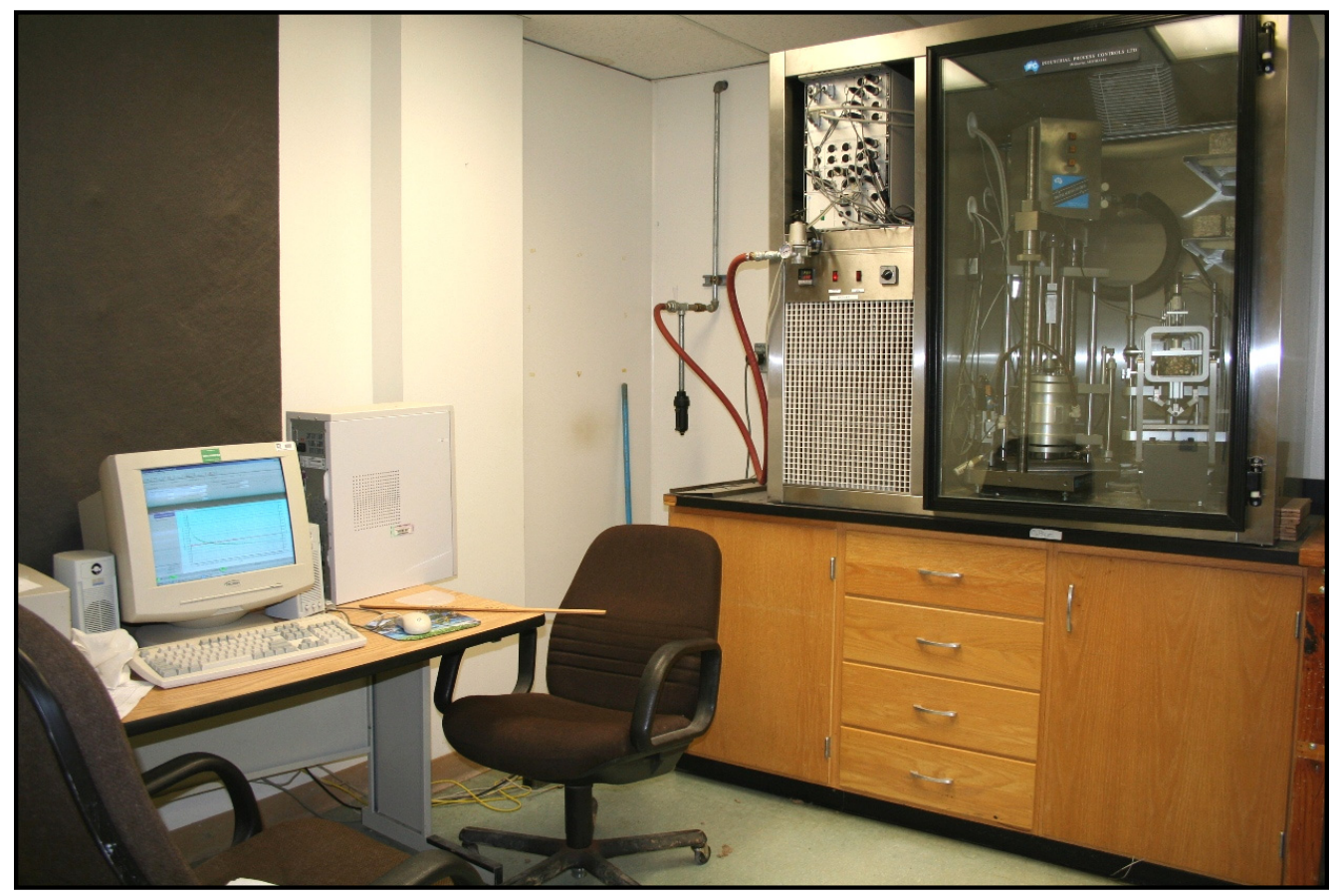

Figure 13. Beam fatigue computer, temperature chamber, and apparatus.

For this evaluation, replicates of two or three beams of each sample were tested at a constant strain of 150,350 , and 550 microstrain. These strain levels were identified in the Phase I report (Tables 19 and 20 of Bell and Freeman 2007) as common strain levels received for various pavement structures under $\mathrm{C}-17, \mathrm{C}-130$, and $\mathrm{F}-15$ aircraft loads. The environmental chamber was set to a testing temperature of $68^{\circ} \mathrm{F}$. This temperature is $9^{\circ} \mathrm{F}$ below the common definition of "room temperature" $\left(77^{\circ} \mathrm{F}\right.$ or $\left.25^{\circ} \mathrm{C}\right)$; however, the difference was considered inconsequential in the analysis. The fatigue performance of the beams was referenced as that at $77^{\circ} \mathrm{F}$ to coincide with the temperature for the measured AC design modulus, as obtained from PSPA testing.

Testing of the AC beams (Figure 14), 2.5 in. wide, 2.0 in. tall, and 15 in. long, was terminated at 850,000 load cycles $(24 \mathrm{hr}$ ) or when the stiffness level reached 72,519 psi (500 MPa). Failure typically occurred within this time frame, as will be discussed in Chapter 5 . Table 5 presents the initial stiffness of each beam tested. The plan was to test each sample at each strain level three times. However, in some cases, the beams broke before they could be tested in the beam fatigue machine. Initial stiffness was 


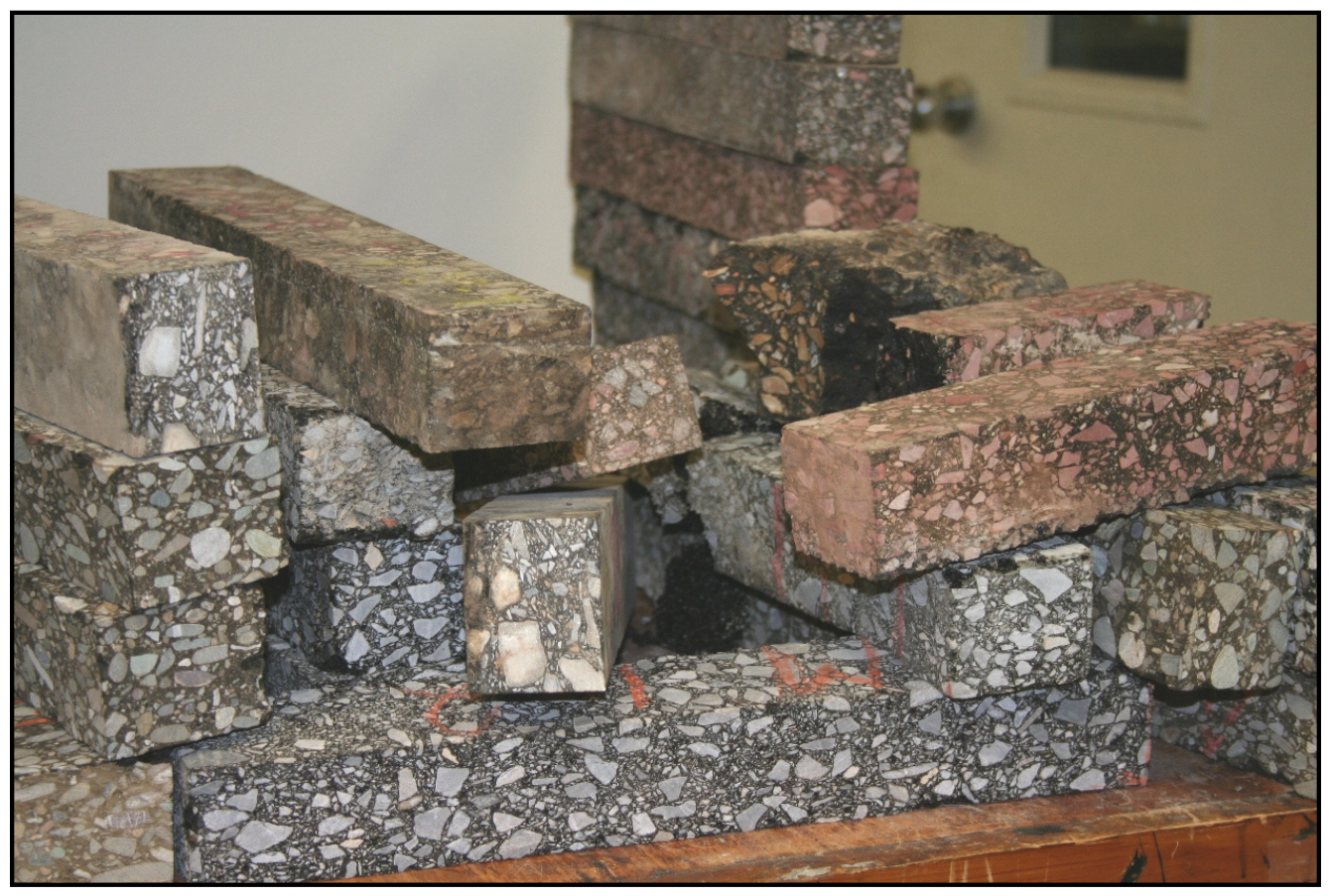

Figure 14. Sawed beams after fatigue testing.

Table 5. Initial stiffness from beam fatigue tests.

\begin{tabular}{|c|c|c|c|c|c|c|c|c|c|}
\hline \multirow[b]{3}{*}{ Sample } & \multicolumn{9}{|c|}{ Initial Stiffness, ksi } \\
\hline & \multicolumn{3}{|c|}{$150 \mu \varepsilon$} & \multicolumn{3}{|c|}{$350 \mu \varepsilon$} & \multicolumn{3}{|c|}{$550 \mu \varepsilon$} \\
\hline & Rep. 1 & Rep. 2 & Rep. 3 & Rep. 1 & Rep. 2 & Rep. 3 & Rep. 1 & Rep. 2 & Rep. 3 \\
\hline LM-2 & 600 & 273 & $---a$ & 522 & 455 & 480 & 531 & 401 & $----a$ \\
\hline P-1 & 1150 & 1240 & 1380 & 1020 & 1120 & 1030 & 971 & 944 & 966 \\
\hline P-2 & 1670 & 1660 & 1670 & 1550 & 1520 & 1480 & 1520 & 1590 & 1330 \\
\hline $\mathrm{R}-1$ & 1030 & 998 & 1030 & 1040 & 970 & 961 & 843 & 838 & 905 \\
\hline $\mathrm{R}-2$ & 152 & 147 & $---a$ & 111 & 118 & $---a$ & 117 & 111 & --- a \\
\hline S-1 & 380 & 473 & 595 & 257 & 192 & 280 & 174 & 403 & 359 \\
\hline S-2 & 958 & 1010 & 1050 & 956 & 996 & $---b$ & 784 & 739 & $---b$ \\
\hline S-3 & 555 & 660 & --- a & 625 & 533 & 645 & $28^{c}$ & 646 & --- a \\
\hline $\mathrm{F}-1$ & 809 & 965 & 1290 & 1200 & 1140 & 976 & 608 & 851 & 619 \\
\hline $\mathrm{F}-2$ & 615 & $---d$ & ---a & 524 & 566 & 517 & 706 & 377 & 588 \\
\hline F-3 & 418 & 389 & 698 & 964 & $169 d$ & $---b$ & 127 & 416 & --- a \\
\hline $\begin{array}{l}\text { a Beam br } \\
\text { ' Large cra } \\
\text { c Invalid da } \\
\text { d Beam wa }\end{array}$ & $\begin{array}{l}\text { before fatig } \\
\text { n beam be } \\
\text { not include } \\
\text { mmed too }\end{array}$ & $\begin{array}{l}\text { testing. } \\
\text { e fatigue te } \\
\text { in data ana } \\
\text { ort to test. }\end{array}$ & $\begin{array}{l}\text { ing; not ab } \\
\text { sis. }\end{array}$ & o test. & & & & & \\
\hline
\end{tabular}


defined as the earliest stiffness value at which a reasonably accurate measurement of stiffness could be made on the fatigue plot (stiffness versus repetitions to failure). Table 5 shows that initial stiffness was lower at 550 microstrain when compared to 150 and 350 microstrain, as expected. Values listed in Table 6 represent the averages of two or three replicates for each sample. The results of the beam fatigue tests will be presented in detail in Chapter 5 .

Table 6. Average initial stiffness from beam fatigue tests.

\begin{tabular}{|l|c|c|c|}
\hline \multirow{2}{*}{ Sample } & \multicolumn{3}{|c|}{ Initial Stiffness, ksi } \\
\cline { 2 - 4 } & $150 \mu \varepsilon$ & $350 \mu \varepsilon$ & $550 \mu \varepsilon$ \\
\hline LM-2 & 437 & 487 & 466 \\
\hline P-1 & 1257 & 1057 & 960 \\
\hline P-2 & 1667 & 1517 & 1480 \\
\hline R-1 & 1019 & 990 & 862 \\
\hline R-2 & 150 & 115 & 114 \\
\hline S-1 & 483 & 243 & 312 \\
\hline S-2 & 1006 & 976 & 762 \\
\hline S-3 & 608 & 601 & 646 \\
\hline F-1 & 1021 & 1105 & 693 \\
\hline F-2 & 615 & 536 & 557 \\
\hline F-3 & 502 & 964 & 272 \\
\hline
\end{tabular}




\section{Data Analysis}

\section{Introduction}

This chapter describes analyses of the results presented in the previous chapters and elaborates on the beam fatigue results. It includes the data from both the Phase I and Phase II evaluations. Specifically, the fatigue data will be used to develop a new design criterion for evaluating pavements with aged AC surfaces. Some of the text in this chapter is repeated from the Phase I report (Bell and Freeman 2007) for completeness in presentation.

\section{Current Department of Defense fatigue criterion}

The current DoD criterion for fatigue of $\mathrm{AC}$ pavements is allowable strain repetitions, $\varepsilon_{\mathrm{r}}$ (Headquarters, Departments of the Army, the Navy, and the Air Force 2001b):

$$
\varepsilon_{\mathrm{r}}=10^{\mathrm{X}}
$$

where:

$$
\begin{aligned}
\mathrm{X} & =2.68-5.0^{*} \log \mathrm{S}_{\mathrm{A}}-2.665^{*} \log \mathrm{E} \\
\mathrm{S}_{\mathrm{A}} & =\text { tensile strain of } \mathrm{AC}, \mathrm{in} . / \mathrm{in} . \\
\mathrm{E} & =\text { elastic modulus of } \mathrm{AC}, \text { psi. }
\end{aligned}
$$

Equation 2 was derived from a graphical plot of allowable load repetitions, in terms of both strain and stress (Figure 15), which was proposed by Barker and Brabston (1975) for use by the U.S. Army Corps of Engineers. The plot was originally presented in the United States by Heukelom and Klomp (1963), who referenced Nijboer (1959) as the original developer.

\section{Defining failure for beam fatigue tests}

Constant strain tests are considered to provide reasonable representation for relatively thin ( $\leq 2$ in.) AC surface layers on pavements. Unfortunately, the failure of beams tested in this manner is not easy to define. As a beam is damaged in these tests, modulus decreases, and the same imposed 


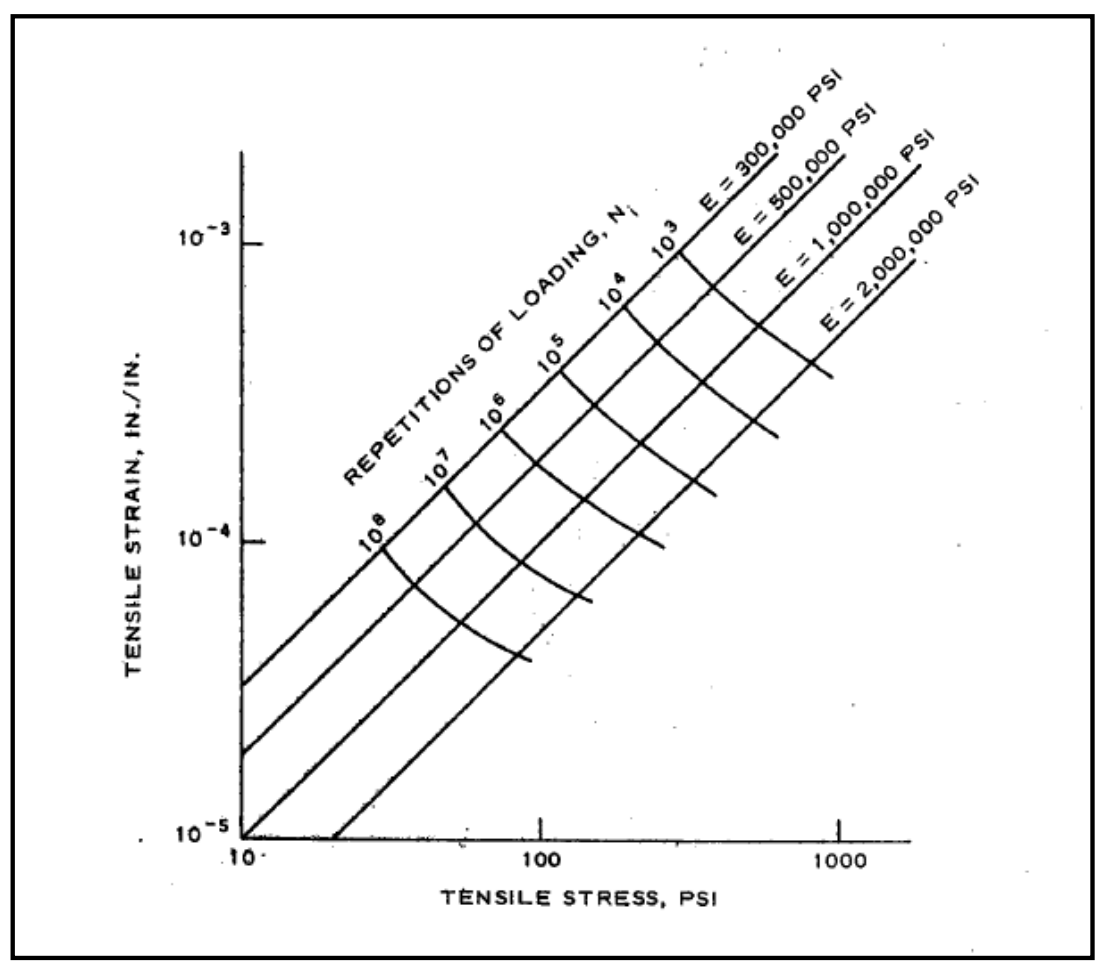

Figure 15. Fatigue data for bituminous concrete materials (Nijboer 1959).

deflections produce progressively smaller stresses. With strain levels that are reasonable for pavements, the beams will not break. As a consequence, arbitrary definitions for beam failure have been established, such as the number of repetitions at the time that beam stiffness is reduced to $50 \%$ of its initial value (Yoder and Witczak 1975). Beam stiffness reductions from $40 \%$ to $80 \%$ have been explored for defining beam failure (Kingham and Kallas 1972).

To calculate a loss in stiffness, an "initial stiffness" must be defined. Initial stiffness could not be based on a predefined number of preconditioning repetitions because some of the aged samples showed relatively large changes in stiffness over the first couple of hundred repetitions. Therefore, in this study, initial stiffness was defined as the earliest stiffness value at which there were sufficient data to obtain an accurate initial measurement of stiffness on the semilog fatigue plot. Cycles at initial stiffness ranged from 55 to 153 for lab-mixed samples, and from 15 to 240 for aged AC samples (including both Phase I and Phase II beams) (Table 7). Again, Phase I beams were only tested at 550 microstrain, and Phase II beams were tested at 150, 350, and 550 microstrain. Samples L-2, B-1, and B-2 were tested at 150, 350, or 550 microstrain during Phase II because there were leftover samples from the Phase I investigation. 
Table 7. Average cycles at initial beam stiffness.

\begin{tabular}{|c|c|c|c|c|c|c|}
\hline \multirow[b]{2}{*}{ Sample } & \multicolumn{3}{|c|}{ Cycles at Initial Stiffness } & \multicolumn{3}{|c|}{ Initial Beam Stiffness, ksi } \\
\hline & $150 \mu \varepsilon$ & $350 \mu \varepsilon$ & $550 \mu \varepsilon$ & $150 \mu \varepsilon$ & $350 \mu \varepsilon$ & $550 \mu \varepsilon$ \\
\hline LM-1 & $\begin{array}{ll}--- \\
--\end{array}$ & $\begin{array}{l}--- \\
---\end{array}$ & 153 & $\begin{array}{ll}--- \\
--\end{array}$ & $\begin{array}{ll}--- \\
--\end{array}$ & 466 \\
\hline VA-3 & -ב--- & ב--- & 30 & ב--- & -ב--- & 743 \\
\hline $\mathrm{H}-1$ & ב-- & - & 73 & 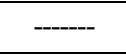 & - & 560 \\
\hline $\mathrm{H}-2$ & --- & -ב--- & 58 & - & -ב-- & 1290 \\
\hline $\mathrm{H}-3$ & -ב--- & -ב--- & 50 & - & -ב--- & 1210 \\
\hline RG-1 & - & -ב--- & 40 & - & -ב--- & 808 \\
\hline RG-2 & ב-ב- & ב-ב- & 30 & - & ב-ב-- & 1450 \\
\hline L-1 & $\begin{array}{ll}--- \\
-\cdots-\end{array}$ & $\begin{array}{ll}--- \\
-\cdots-\end{array}$ & 40 & -ב-ב- & ב--- & 343 \\
\hline $\mathrm{L}-2$ & 110 & 20 & 50 & 1130 & 993 & 813 \\
\hline C-1 & -ב--- & -ב--- & 48 & - & -ב--- & 1120 \\
\hline $\mathrm{C}-2$ & -ב-- & ב---- & 48 & -..- & ---- & 1380 \\
\hline B-1 & 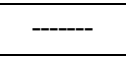 & 70 & 68 & - & 1111 & 890 \\
\hline B-2 & - & 70 & 33 & 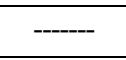 & 808 & 531 \\
\hline B-3 & -- & ב---- & 70 & 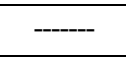 & --- & 293 \\
\hline KA-1 & - & ---- & 50 & - & ---- & 151 \\
\hline LM-2 & 120 & 87 & 55 & 437 & 487 & 466 \\
\hline P-1 & 93 & 73 & 53 & 1257 & 1057 & 960 \\
\hline P-2 & 83 & 50 & 70 & 1667 & 1517 & 1480 \\
\hline R-1 & 117 & 63 & 53 & 1019 & 990 & 862 \\
\hline $\mathrm{R}-2$ & 240 & 90 & 70 & 150 & 115 & 114 \\
\hline S-1 & 103 & 70 & 60 & 483 & 243 & 312 \\
\hline S-2 & 170 & 60 & 85 & 1006 & 976 & 762 \\
\hline S-3 & 100 & 90 & 80 & 608 & 601 & 646 \\
\hline F-1 & 163 & 60 & 67 & 1021 & 1105 & 693 \\
\hline F-2 & 190 & 83 & 23 & 615 & 536 & 557 \\
\hline F-3 & 110 & 15 & 30 & 502 & 964 & 272 \\
\hline
\end{tabular}

This study offered a unique combination of fatigue test results. While tests are typically conducted only on laboratory-produced beams, this study included a combination of both laboratory-produced beams and beams sawn from field samples. This broad range of beam sources led to a broad range of beam test results, which then led to the need for a reexamination of how beam test results are quantified.

Rather than defining the "repetitions to beam failure" as some arbitrary percentage of lost stiffness, a definition for beam failure was derived using the current DoD AC fatigue criterion and the laboratory-produced standard airfield mixtures. The PSPA modulus for the laboratory-produced 
mixtures was applied to the current DoD criterion (Equation 2), along with the knowledge that the beams were tested at 550 microstrain in Phase I and 150,350 , and $55^{\circ}$ microstrain in Phase II, to determine the predicted cycles to failure.

Given an AC design PSPA modulus of $452 \mathrm{ksi}$ for Phase I, the predicted cycles at failure was 8,080 for 550 microstrain testing according to Equation 2. Furthermore, given an AC design PSPA modulus of $355 \mathrm{ksi}$ for Phase II, the predicted cycles to failure were 10,190,000, 147,000, and 15,000 for 150, 350, and 550 microstrain, respectively, based on Equation 2. Examples of findings for replicate beams of the standard airfield mixtures of Phase II are shown in Figures 16-18, and the results are summarized in Table 7. Figure 16 shows the beam fatigue results for one of the laboratory-produced airfield mixtures at 150 microstrain. Most of the samples at 150 microstrain did not lose a substantial portion of stiffness before the test was stopped. Therefore, many of the plots had to be extrapolated to determine the number of cycles to failure. A linear extrapolation was used for each sample.

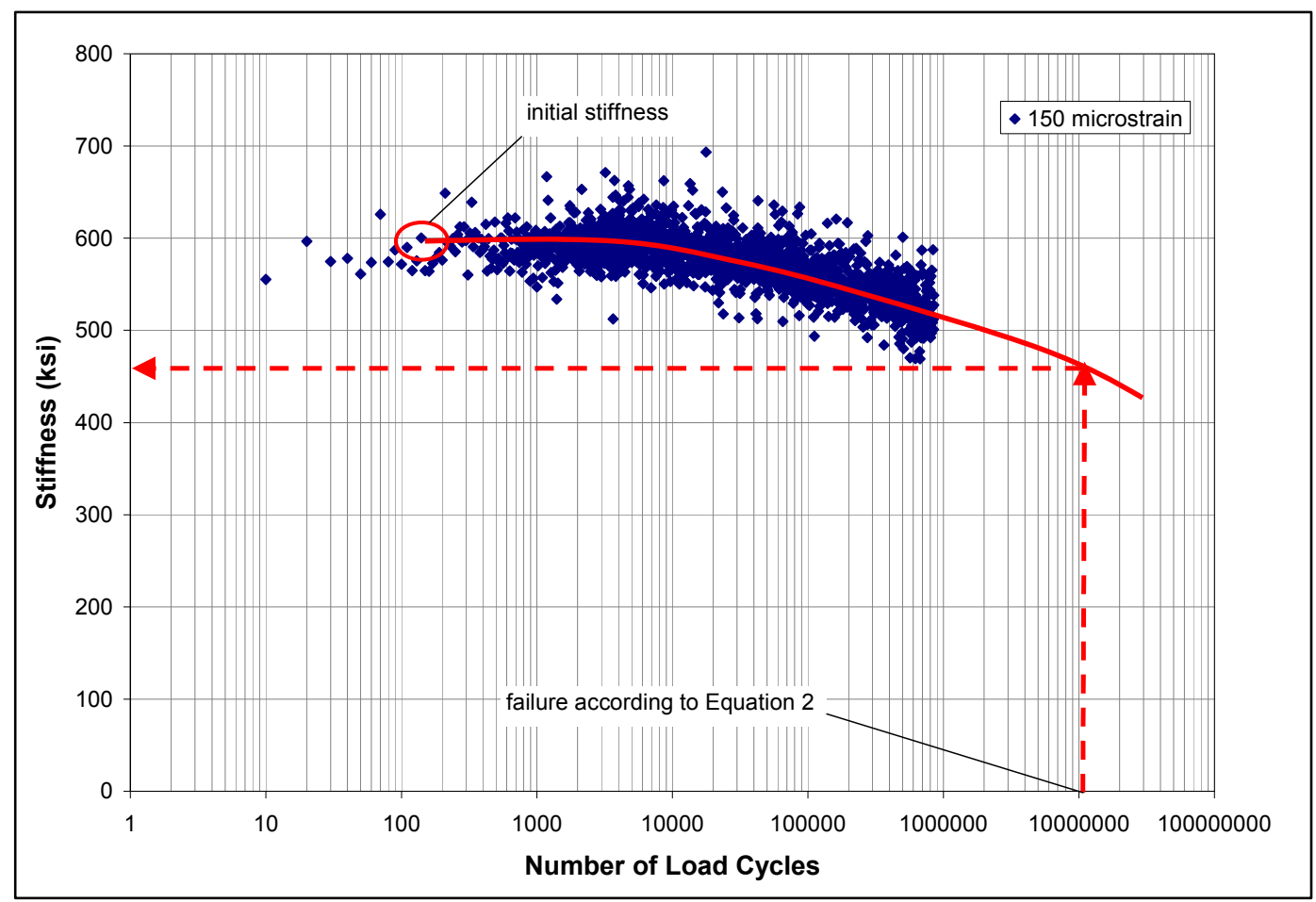

Figure 16. Establishing percent stiffness at failure for the laboratory-produced standard airfield mixture (LM-2) at 150 microstrain, replicate 1. 


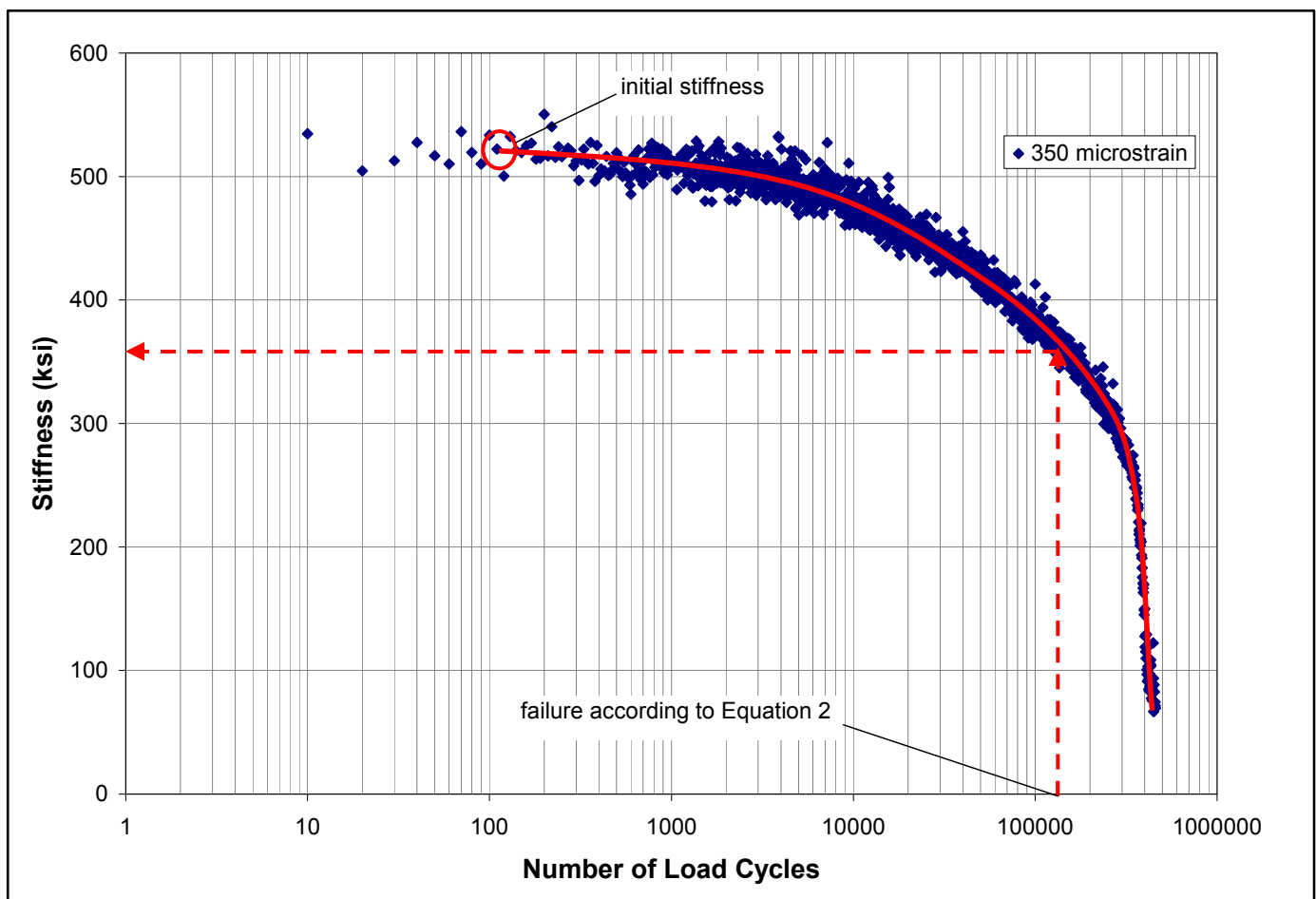

Figure 17. Establishing percent stiffness at failure for the laboratory-produced standard airfield mixture (LM-2) at 350 microstrain, replicate 3.

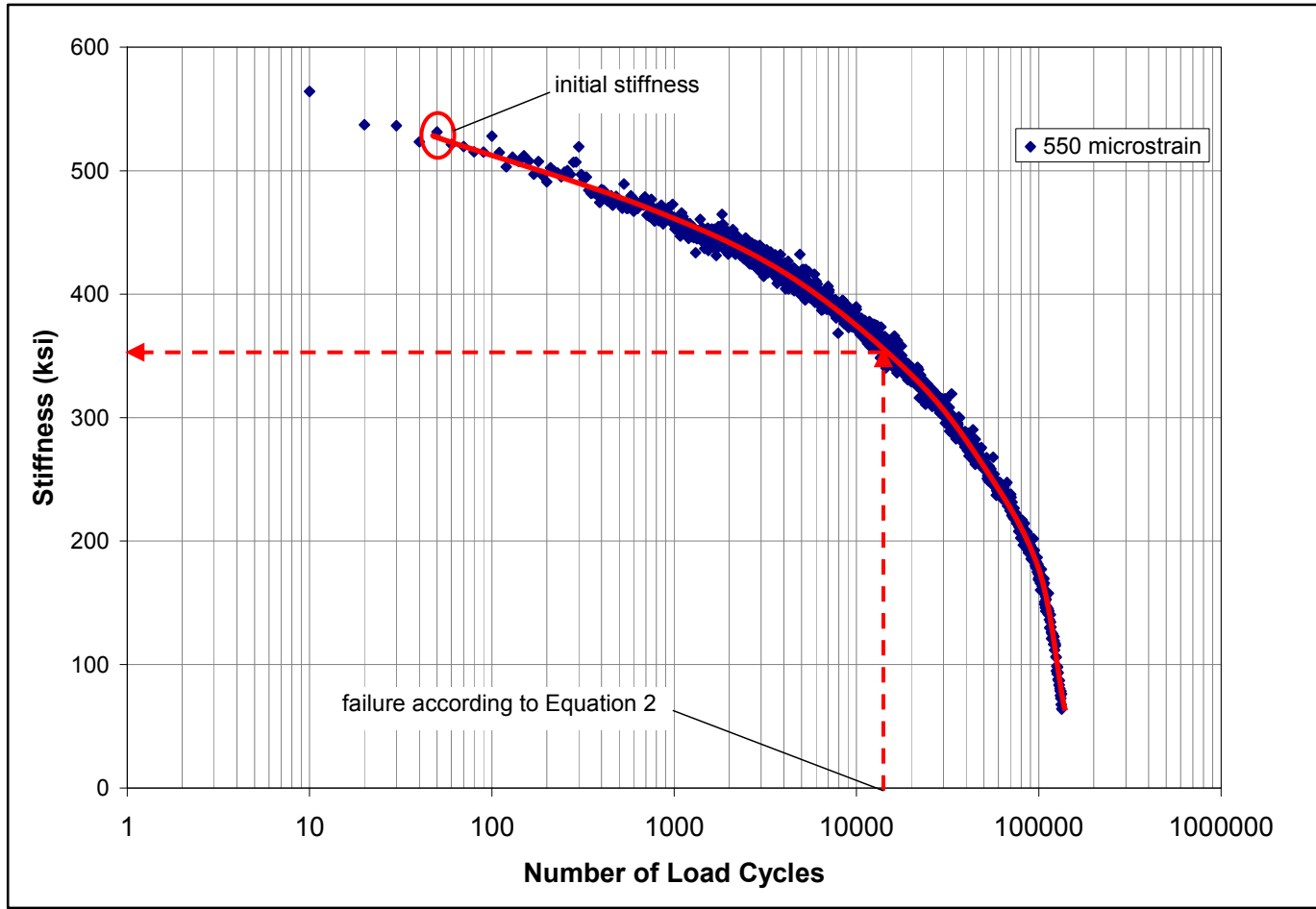

Figure 18. Establishing percent stiffness at failure for the laboratory-produced standard airfield mixture (LM-2) at 550 microstrain, replicate 6. 
The average values for percent of initial beam stiffness at failure were 85,66 , and $71 \%$ for 150,350 , and 550 microstrain, respectively (Table 8 ). The percent of initial beam stiffness appears to be relatively high for tests performed at 150 microstrain. Typically, failure is defined when the stiffness is reduced under repeated loading to $50 \%$ of the initial stiffness. However, for this study, it was decided to keep the number of cycles to failure to a reasonable number. If a reduction of $50 \%$ in modulus were set as failure, then the number of cycles would have been much too high, resulting in excessive testing times. Hence, failure was defined at $85 \%$ of initial stiffness for the 150-microstrain level and $69 \%$ of initial stiffness for the $350-$ and 550-microstrain levels.

\section{Summary of beam fatigue results}

Measured and predicted cycles to failure for the beam fatigue tests are summarized in Table 9. For measured values, the table shows average cycles to failure where the averages were calculated by averaging the $\log _{10}$ (cycle) values. The reason for using the $\log _{10}$ adjustment when averaging is that fatigue data are generally positively skewed. The $\log _{10}$ adjustment improves the symmetry of positively skewed distributions so that a single replicate with relatively high cycles to failure does not have an overriding influence on the mean value.

The predicted cycles to failure in Table 9 were all calculated with the original DoD criterion (Equation 2). To facilitate further analyses and refinement of the current DoD criterion, the level of conservatism needed to be represented as a single value. This was accomplished using the base $10 \log$ of the ratio of cycles as follows:

$$
\log \text { Ratio }=\log _{10}\left(\frac{\text { Measured cycles }}{\text { Predicted cycles }}\right)
$$

where:

Measured cycles $=$ cycles to failure in the beam fatigue test $(85 \%$ of initial stiffness for 150 microstrain and $69 \%$ of initial stiffness for 350 and 550 microstrain)

Predicted cycles $=$ cycles to failure using the current DoD fatigue criterion (Equation 2). 
Table 8. Summary of fatigue results for laboratory-produced standard airfield mixtures (LM-1 and LM-2).

\begin{tabular}{|c|c|c|c|c|c|c|c|c|c|}
\hline Sample & Replicate & Strain, $\mu \varepsilon$ & $\begin{array}{l}\text { Design PSPA } \\
\text { Modulus, ksi }\end{array}$ & $\begin{array}{l}\text { Cycles at } \\
\text { Initial } \\
\text { Stiffness }\end{array}$ & $\begin{array}{l}\text { Initial Beam } \\
\text { Stiffness } \\
\text { ksi }\end{array}$ & $\begin{array}{l}\text { Predicted } \\
\text { Cycles to } \\
\text { Fatigue } \\
\text { Failure }\end{array}$ & $\begin{array}{l}\text { Stiffness at } \\
\text { Predicted } \\
\text { Failure, ksia }\end{array}$ & $\begin{array}{l}\text { Percent of } \\
\text { Initial Beam } \\
\text { Stiffness at } \\
\text { Failure }\end{array}$ & $\begin{array}{l}\text { Average } \\
\text { Percent of } \\
\text { Initial Beam } \\
\text { Stiffness at } \\
\text { Failure }\end{array}$ \\
\hline \multirow{7}{*}{ LM-2 } & 1 & \multirow{2}{*}{150} & \multirow{7}{*}{355} & 140 & 600 & \multirow{2}{*}{$10,190,000$} & 470 & 78 & \multirow{2}{*}{85} \\
\hline & 2 & & & 100 & 273 & & 250 & 92 & \\
\hline & 3 & \multirow{3}{*}{350} & & 110 & 522 & \multirow{3}{*}{147,000} & 360 & 69 & \multirow{3}{*}{66} \\
\hline & 4 & & & 80 & 455 & & 309 & 68 & \\
\hline & 5 & & & 70 & 480 & & 298 & 62 & \\
\hline & 6 & \multirow{2}{*}{550} & & 50 & 531 & \multirow{2}{*}{15,000} & 356 & 67 & \multirow{5}{*}{71} \\
\hline & 7 & & & 60 & 401 & & 277 & 69 & \\
\hline \multirow{3}{*}{ LM-1 } & 1 & \multirow{3}{*}{550} & \multirow{3}{*}{452} & 270 & 449 & \multirow{3}{*}{8,080} & 310 & 69 & \\
\hline & 2 & & & 150 & 442 & & 339 & 77 & \\
\hline & 3 & & & 40 & 506 & & 365 & 72 & \\
\hline
\end{tabular}


Table 9. Comparisons of predicted and measured cycles to failure.

\begin{tabular}{|c|c|c|c|c|c|c|c|c|c|}
\hline \multirow[b]{2}{*}{ Sample } & \multicolumn{3}{|c|}{ Predicted Cycles to Failurea } & \multicolumn{3}{|c|}{ Measured Cycles to Failure } & \multicolumn{3}{|c|}{ Log Ratiod } \\
\hline & $150 \mu \varepsilon$ & $350 \mu \varepsilon$ & $550 \mu \varepsilon$ & $150 \mu \varepsilon^{b}$ & $350 \mu \varepsilon^{c}$ & $550 \mu \varepsilon^{c}$ & $150 \mu \varepsilon$ & $350 \mu \varepsilon$ & $550 \mu \varepsilon$ \\
\hline LM-1 & - & - & 8,080 & - & - & 11,100 & - & - & 0.14 \\
\hline VA-3 & - & - & 3,650 & - & - & 773 & - & - & -0.67 \\
\hline $\mathrm{H}-1$ & - & - & 3,880 & - & - & 4,880 & - & - & 0.10 \\
\hline $\mathrm{H}-2$ & - & - & 1,820 & - & - & 11,200 & - & - & 0.79 \\
\hline $\mathrm{H}-3$ & - & - & 2,600 & - & - & 1,310 & - & - & -0.30 \\
\hline RG-1 & - & - & 4,160 & - & - & 2,050 & - & - & -0.31 \\
\hline RG-2 & - & - & 1,450 & - & - & 5,720 & - & - & 0.60 \\
\hline L-1 & - & - & 32,500 & - & - & 1,980 & - & - & -1.22 \\
\hline $\mathrm{L}-2$ & $2,350,000$ & 33,900 & 3,540 & 33,000 & 570 & 5,040 & -1.85 & -1.77 & 0.15 \\
\hline$C-1$ & - & - & 1,050 & - & - & 8,890 & - & - & 0.93 \\
\hline$C-2$ & - & - & 1,900 & - & - & 5,300 & - & - & 0.45 \\
\hline B-1 & - & 94,700 & 9,890 & - & 91,400 & 11,300 & - & -0.02 & 0.06 \\
\hline B-2 & - & 52,500 & 5,480 & - & 72,700 & 8,010 & - & 0.14 & 0.16 \\
\hline B-3 & - & - & 6,170 & - & - & 1,960 & - & - & -0.50 \\
\hline KA-1 & - & - & 4,080 & - & - & 7,360 & - & - & 0.26 \\
\hline LM-2 & $10,200,000$ & 147,000 & 15,400 & $10,200,000$ & 127,000 & 14,000 & 0.00 & -0.06 & -0.04 \\
\hline P-1 & $4,130,000$ & 59,800 & 6,240 & 16,500 & 399 & 331 & -2.40 & -2.18 & -1.28 \\
\hline $\mathrm{P}-2$ & $2,290,000$ & 33,100 & 3,450 & 640,000 & 38,600 & 4,830 & -0.55 & 0.07 & 0.15 \\
\hline $\mathrm{R}-1$ & $1,730,000$ & 25,100 & 2,620 & $11,700,000$ & 363,000 & 11,600 & 0.83 & 1.16 & 0.65 \\
\hline $\mathrm{R}-2$ & $2,640,000$ & 38,200 & 3,990 & 283,000 & 18,300 & 3,380 & -0.97 & -0.32 & -0.07 \\
\hline S-1 & $1,810,000$ & 26,200 & 2,730 & 886,000 & 309,000 & 4,570 & -0.31 & 1.07 & 0.22 \\
\hline S-2 & $2,880,000$ & 41,700 & 4,350 & $1,960,000$ & 14,700 & 2,610 & -0.17 & -0.45 & -0.22 \\
\hline $\mathrm{S}-3$ & $2,370,000$ & 34,200 & 3,570 & $9,000,000$ & 112,000 & 2,920 & 0.58 & 0.52 & -0.09 \\
\hline $\mathrm{F}-1$ & $1,330,000$ & 19,200 & 2,000 & $2,360,000$ & 6,850 & 2,680 & 0.25 & -0.45 & 0.13 \\
\hline $\mathrm{F}-2$ & $5,140,000$ & 74,300 & 7,750 & 118,000 & 15,000 & 984 & -1.64 & -0.69 & -0.90 \\
\hline$F-3$ & $6,150,000$ & 89,000 & 9,280 & 10,400 & 1,000 & 534 & -2.77 & -1.95 & -1.24 \\
\hline $\begin{array}{l}\text { a Predicte } \\
\text { b Measur } \\
\text { c Measur } \\
\text { d As defin }\end{array}$ & $\begin{array}{l}\text { ent DoD fati } \\
35 \% \text { of the ir } \\
69 \% \text { of the ir } \\
\text { ion } 3 .\end{array}$ & on $(\mathrm{Eq}$ & $\begin{array}{l}\text { atigue } d \\
\text { atigue } d\end{array}$ & & & & & & \\
\hline
\end{tabular}


The Log Ratio values for all AC samples are included in Table 9. Given that fatigue data may range over several orders of magnitude, the use of logarithms kept the data within limits that were easy to plot and compare. Also, logarithms tend to normalize fatigue data that typically have positive skew. While using Log Ratio as defined in Equation 3, the following rules apply to calculated quantities:

1. If $\log$ Ratio $=+2$, the measured cycles to failure exceeded the predicted cycles to failure by a factor of 100. In this case, the prediction was highly conservative.

2. If $\log$ Ratio $=+1$, the measured cycles to failure exceeded the predicted cycles to failure by a factor of 10 . In this case, the prediction was conservative.

3. If $\log$ Ratio $=0$, the measured cycles to failure equaled the predicted cycles to failure.

4. If $\log$ Ratio $=-1$, the predicted cycles to failure exceeded the measured cycles to failure by a factor of 10 . In this case, the prediction was unconservative.

5. If $\log$ Ratio $=-2$, the predicted cycles to failure exceeded the measured cycles to failure by a factor of 100. In this case, the prediction was highly unconservative.

\section{Confirmation for a new fatigue criterion for aged asphalt concrete}

The Log Ratio values were used to determine whether a new criterion is needed when evaluating the potential future performance of aged AC. The necessary decision is whether the original DoD fatigue criterion predicts cycles to fatigue failure with sufficient accuracy and precision. The first step in this analysis was to determine whether the analyses should treat the three strain levels separately. To investigate this question, a two-factor analysis (without replication) was performed on the Log Ratio values for all the aged AC samples that were tested at all three strain levels. In this analysis, the Log Ratio was the dependent variable, and the two treatment factors were AC sample source and strain level (microstrain). There were 11 field samples from which beams were tested at all three strain levels (Table 10). 
Table 10. Log Ratio data used in a two-factor analysis without replication.

\begin{tabular}{|l|l|l|l|}
\hline \multirow{2}{*}{ Sample } & \multicolumn{3}{|c|}{ Microstrain } \\
\cline { 2 - 4 } & 150 & 350 & 550 \\
\hline P-1 & -2.40 & -2.18 & -1.28 \\
\hline P-2 & -0.554 & 0.0668 & 0.146 \\
\hline R-1 & 0.830 & 1.16 & 0.646 \\
\hline R-2 & -0.970 & -0.320 & -0.072 \\
\hline S-1 & -0.310 & 1.07 & 0.224 \\
\hline S-2 & -0.167 & -0.453 & -0.222 \\
\hline S-3 & 0.579 & 0.515 & -0.087 \\
\hline F-1 & 0.249 & -0.448 & 0.127 \\
\hline F-2 & -1.64 & -0.695 & -0.896 \\
\hline F-3 & -2.77 & -1.95 & -1.24 \\
\hline L-2 & -1.85 & -1.77 & 0.15 \\
\hline
\end{tabular}

The analysis of variance for the two-factor analysis is presented in Table 11. In this analysis, 0.05 was chosen as the level of significance and represents the probability of incorrectly stating that a difference exists among either AC sources or strain levels. Using a level of significance of 0.05 is common for engineering applications. Given that both calculated $\mathrm{P}$-values are less than 0.05, neither the AC sample sources nor the strain levels can be considered as being drawn from the same population. As a result, AC sample sources will be considered as individual observations. Also, analyses of Log Ratio will differentiate among the three strain levels that were used in the beam fatigue tests.

Table 11. Analysis of variance for the two-factor analysis without replication.

\begin{tabular}{|c|c|c|c|c|c|}
\hline Source of Variation & \begin{tabular}{|l|} 
Sum of \\
Squares
\end{tabular} & $\begin{array}{l}\text { Degrees of } \\
\text { Freedom }\end{array}$ & \begin{tabular}{|l|} 
Mean \\
Square
\end{tabular} & F-statistic & P-value ${ }^{a}$ \\
\hline Asphalt Sample Source & 26.37 & 10 & 2.637 & 9.724 & $<0.001$ \\
\hline Strain Level in Fatigue Test & 1.959 & 2 & 0.9796 & 3.612 & 0.0458 \\
\hline Error & 5.424 & 20 & 0.2712 & & \\
\hline Total & 33.76 & 32 & & & \\
\hline
\end{tabular}


Now, predicted and measured cycles to failure will be compared for both laboratory-mixed samples and aged AC samples. Comparisons will be based on $\log _{10}$ (cycles) and Log Ratio. Predictions versus measured failure for the laboratory-mixed samples are shown in Figure 19. The predictions are shown to be accurate for all three strain levels. Of course, the method of reducing fatigue-test data was developed using the laboratory-mixed samples, so the high correlation coefficient is not surprising.

Figure 20 is a similar plot for aged samples. In this figure, the deviation from the line of equality tends to be more on the unconservative side, and there are several cases in which the deviation exceeds two log cycles. Extreme deviations of predicted cycles to failure versus measured cycles to failure are summarized in the bar chart shown in Figure 21. Based on these findings, a new criterion is needed for predicting the fatigue life of aged AC as it is evaluated in the field.

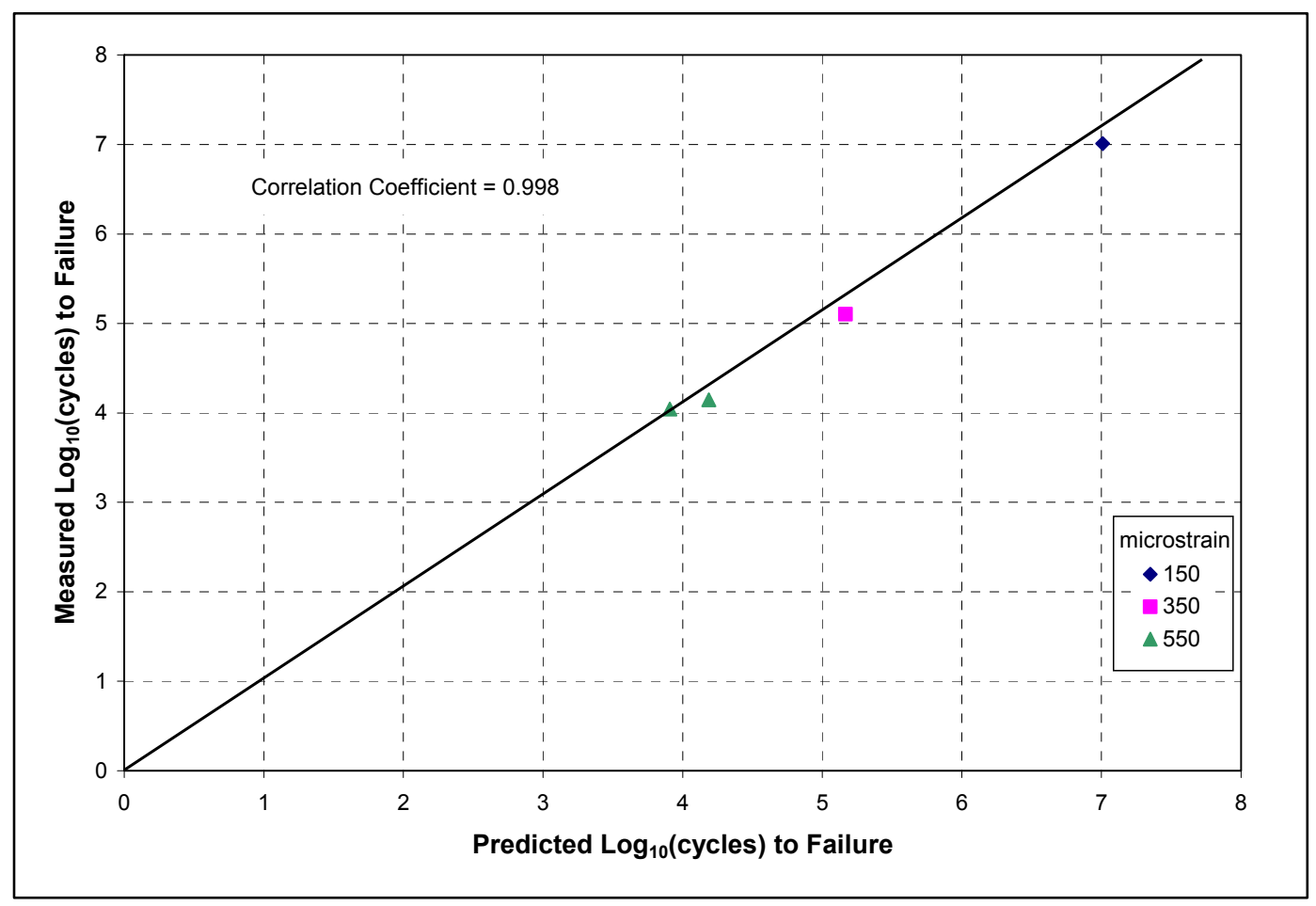

Figure 19. Predicted versus measured $\log _{10}$ (cycles) to fatigue failure for lab-mixed samples. 


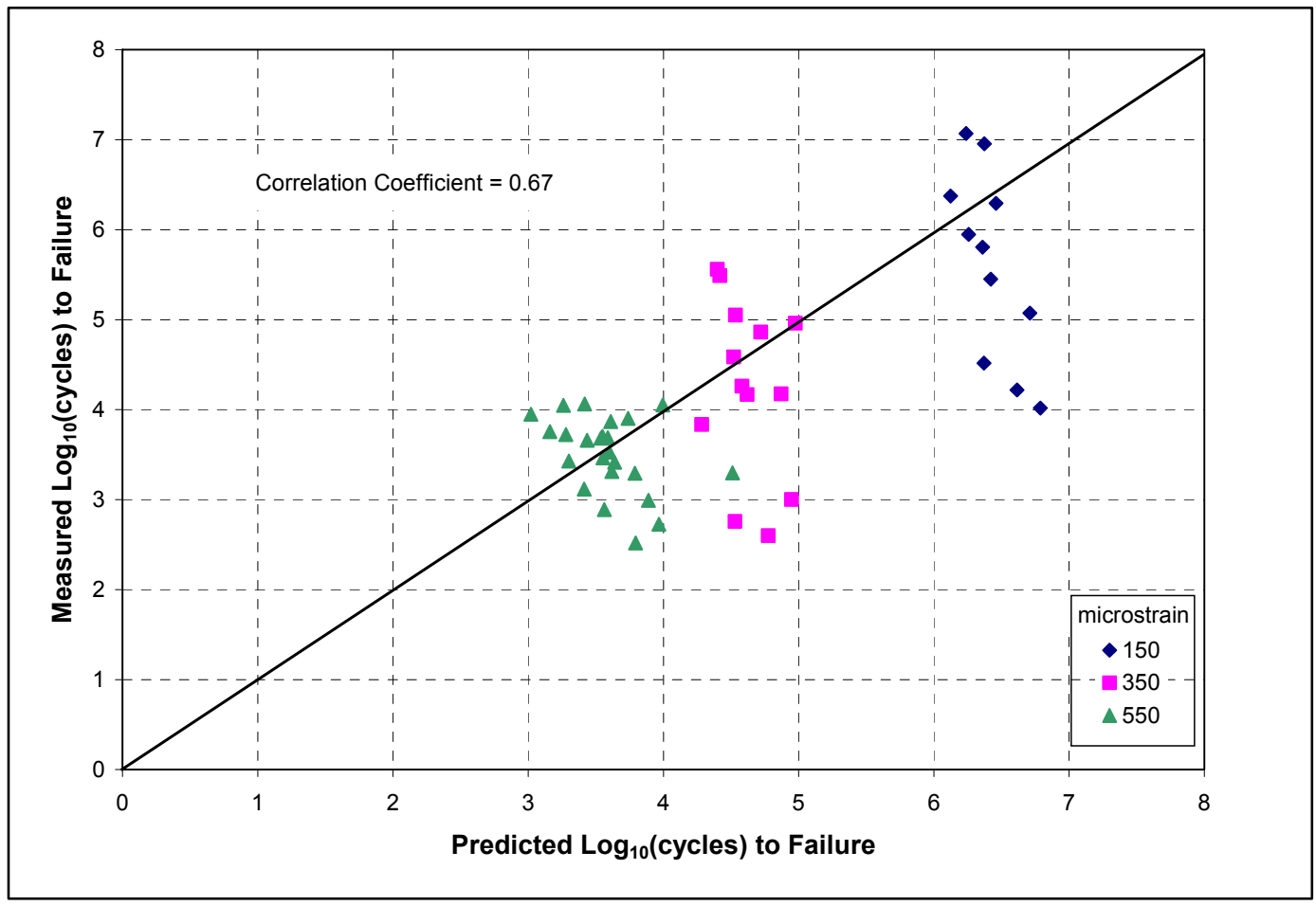

Figure 20. Predicted versus measured $\log _{10}$ (cycles) to fatigue failure for aged field samples.

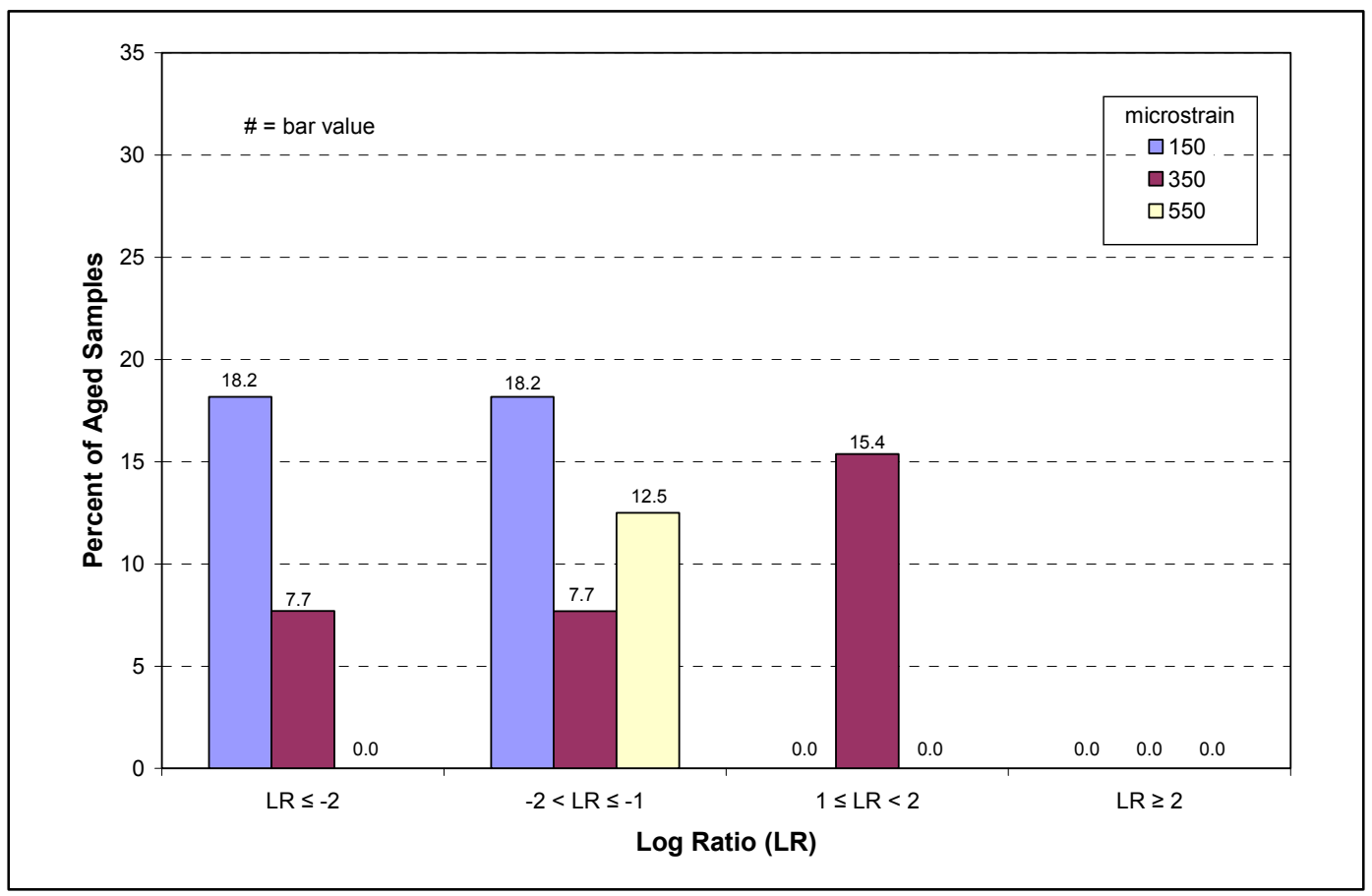

Figure 21. Summary of extreme Log Ratio values for aged field samples. 


\section{Development of a fatigue criterion for aged asphalt concrete}

\section{Preliminary decisions}

Two decisions were necessary to begin the development of a fatigue criterion for aged $\mathrm{AC}$.

1. Should the new criterion involve adjusting the current DoD criterion, or should it be an independent criterion?

2. Is there a minimum age for $\mathrm{AC}$ in the field to which the new criterion should be applied?

To answer the first question, the influence of modulus and strain level on $\log _{10}$ (cycles) to failure for aged samples was compared to the influence of the same two independent variables in the original DoD criterion (Equation 2). In the original DoD criterion, $\log _{10}$ (cycles) to failure decreased with increases in either strain level or modulus (see Equation 2 and Figure 15). For the aged samples, Figures 22-24 show $\log _{10}$ (cycles) to failure as functions of modulus for strain levels of 150,350 , and 550 microstrain, respectively. These figures show clearly that $\log _{10}$ (cycles) to failure decrease with increases in strain level, similar to the original DoD criterion. Contrary to the original DoD criterion, however, these figures show increased cycles to failure with increases in modulus; the most significant influence of modulus is at small strains.

While the original DoD criterion penalizes high-modulus AC, the beam fatigue data collected in this study show that this penalization is not applicable to aged $\mathrm{AC}$ pavements at room temperature $\left(77^{\circ} \mathrm{F}\right)$. The authors believe that during the development of the original DoD criterion, the high-modulus, laboratory-compacted AC samples showed shorter fatigue lives because the higher moduli were created primarily by lowering the testing temperature. For a given sample of $\mathrm{AC}$, lowering the testing temperature will shorten fatigue lives for two main reasons.

1. As temperatures decrease, $\mathrm{AC}$ behaves in a more brittle manner.

2. For a given sample of $\mathrm{AC}$ and a given level of strain, decreases in temperature will increase modulus values, thus causing higher stresses during fatigue testing. 


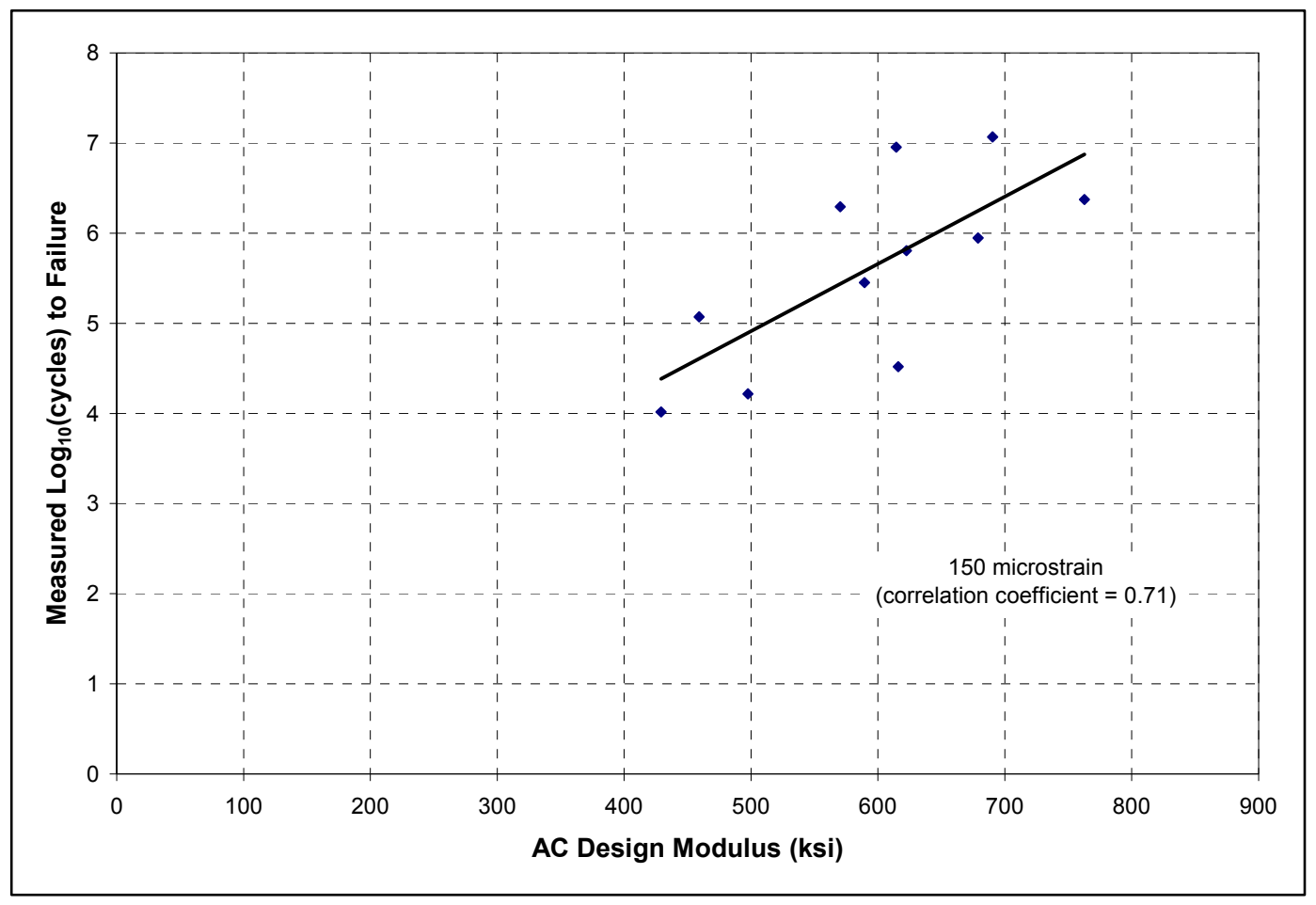

Figure 22. Influence of AC modulus on fatigue performance of beams tested at 150 microstrain as measured by the PSPA.

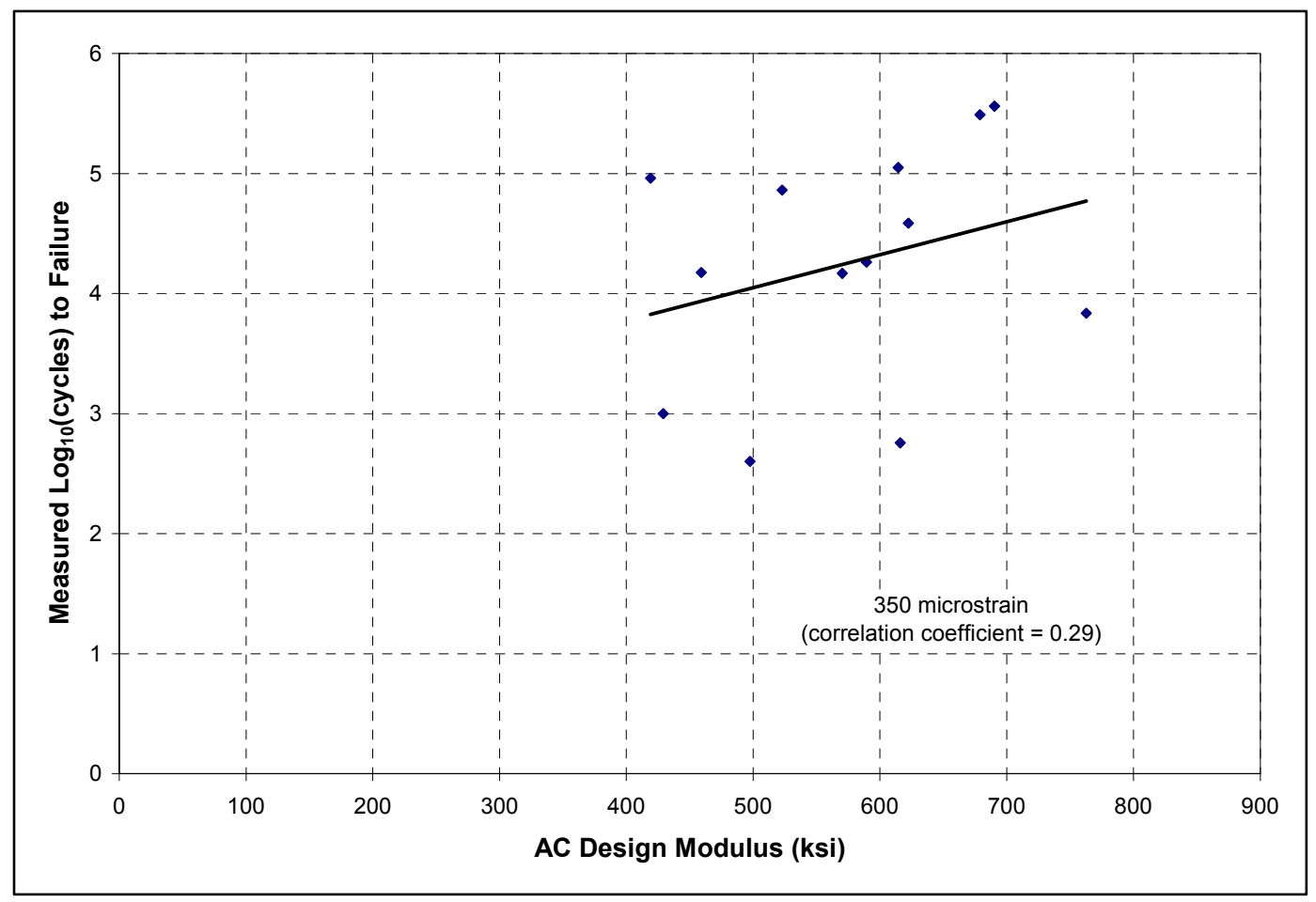

Figure 23. Influence of AC modulus on fatigue performance of beams tested at 350 microstrain as measured by the PSPA. 


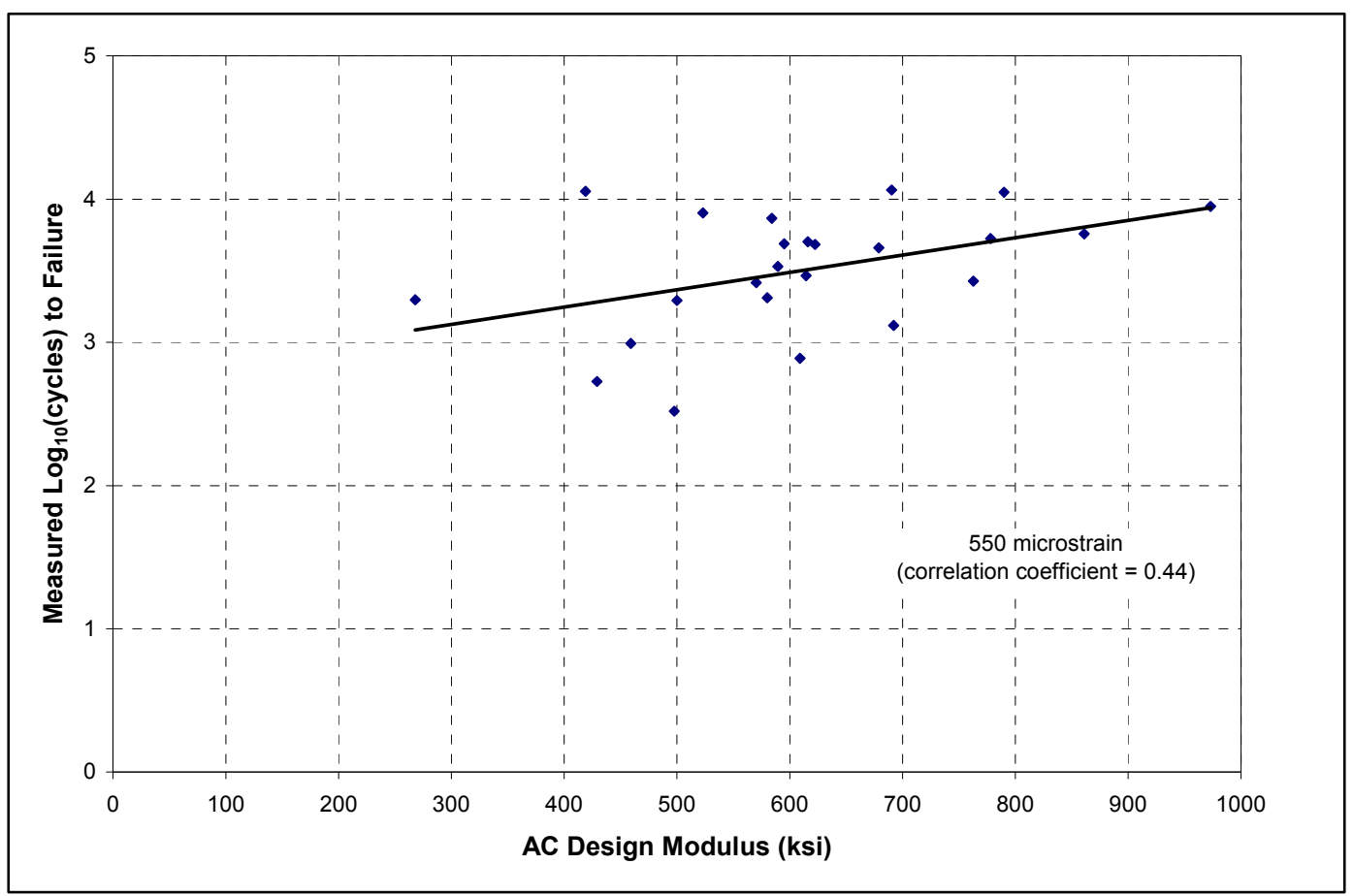

Figure 24. Influence of AC modulus on fatigue performance of beams tested at 550 microstrain as measured by the PSPA.

Now, in the case of comparing aged field AC samples, all at room temperature $\left(77^{\circ} \mathrm{F}\right)$, it appears that the modulus values measured by the PSPA provide more of an indication of material integrity as opposed to brittleness. The low-modulus samples tended to degrade quickly under fatigue cycling, and high-modulus samples tended to be better able to withstand repeated strains as shown in Figures 22-24. As a result of this disparity between the significance of modulus values, as found when comparing laboratory-mixed samples (at different temperatures) to aged field samples (all at room temperature), the decision was made to begin the development of a new fatigue criterion independently of the original DoD criterion. The new criterion would be for room temperature only $\left(77^{\circ} \mathrm{F}\right)$, and then the original criterion could be used to adjust predictions for different pavement design temperatures.

Given that a new criterion is needed, the second decision was to determine whether there is a minimum age for airfield $\mathrm{AC}$ in order for the $\mathrm{AC}$ to require the use of the new criterion in the pavement evaluation. To investigate this question, Log Ratio was plotted as a function of age (years) of field AC (Figure 25). From the figure, there does not appear to be any relationship between age and Log Ratio. Some of the worst occurrences of unconservatism occur for AC only 7 years old. Therefore, the new criterion 
will be recommended for any case in which a pavement evaluation includes estimated AC design modulus. Design moduli in this study all relied on field measurements obtained with the PSPA.

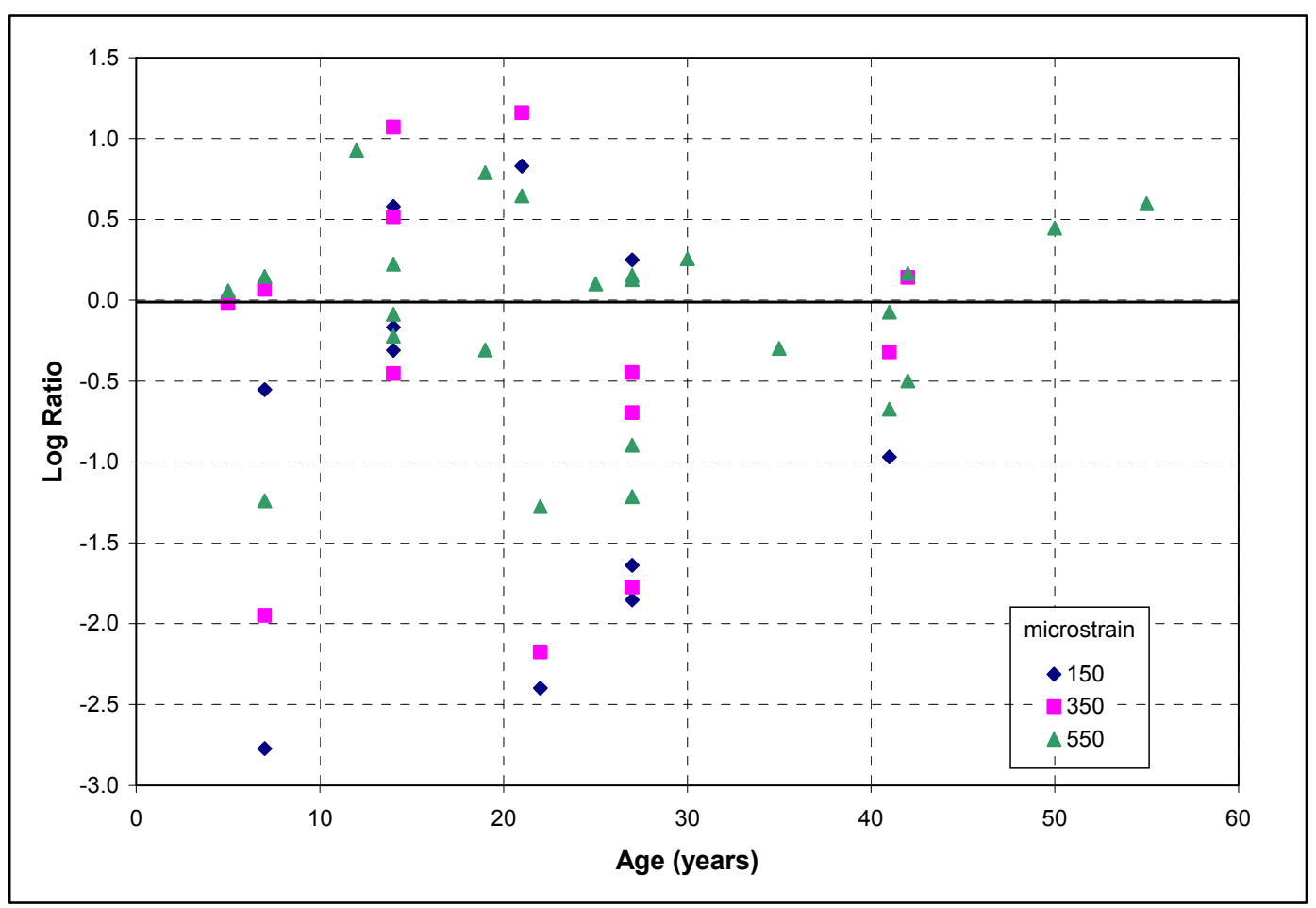

Figure 25. Log Ratio as a function of age for field samples.

\section{Additional preliminary data}

Initial stiffness determined from the beam fatigue testing and PSPA testing (AC design modulus) are two methods for measuring stiffness. Figure 26 shows that there is very little correlation between PSPA-measured modulus and initial beam stiffness. This shows the difficulty in measuring stiffness of aged AC. Figure 26 indicates that the PSPA is possibly measuring something more than just stiffness (as stated in the previous section). Figures 27-29 show that there is very little correlation between initial beam stiffness and measured $\log _{10}$ (cycles) to failure at 150,350 , and 550 microstrain. However, there is a somewhat improved correlation between the PSPA-measured modulus and $\log _{10}$ (cycles) to failure (Figures 22-24). Figure 30 shows that there is no significant correlation between measured $\log _{10}$ (cycles) to failure and ITS peak stress at 150, 350, and 550 microstrain. 


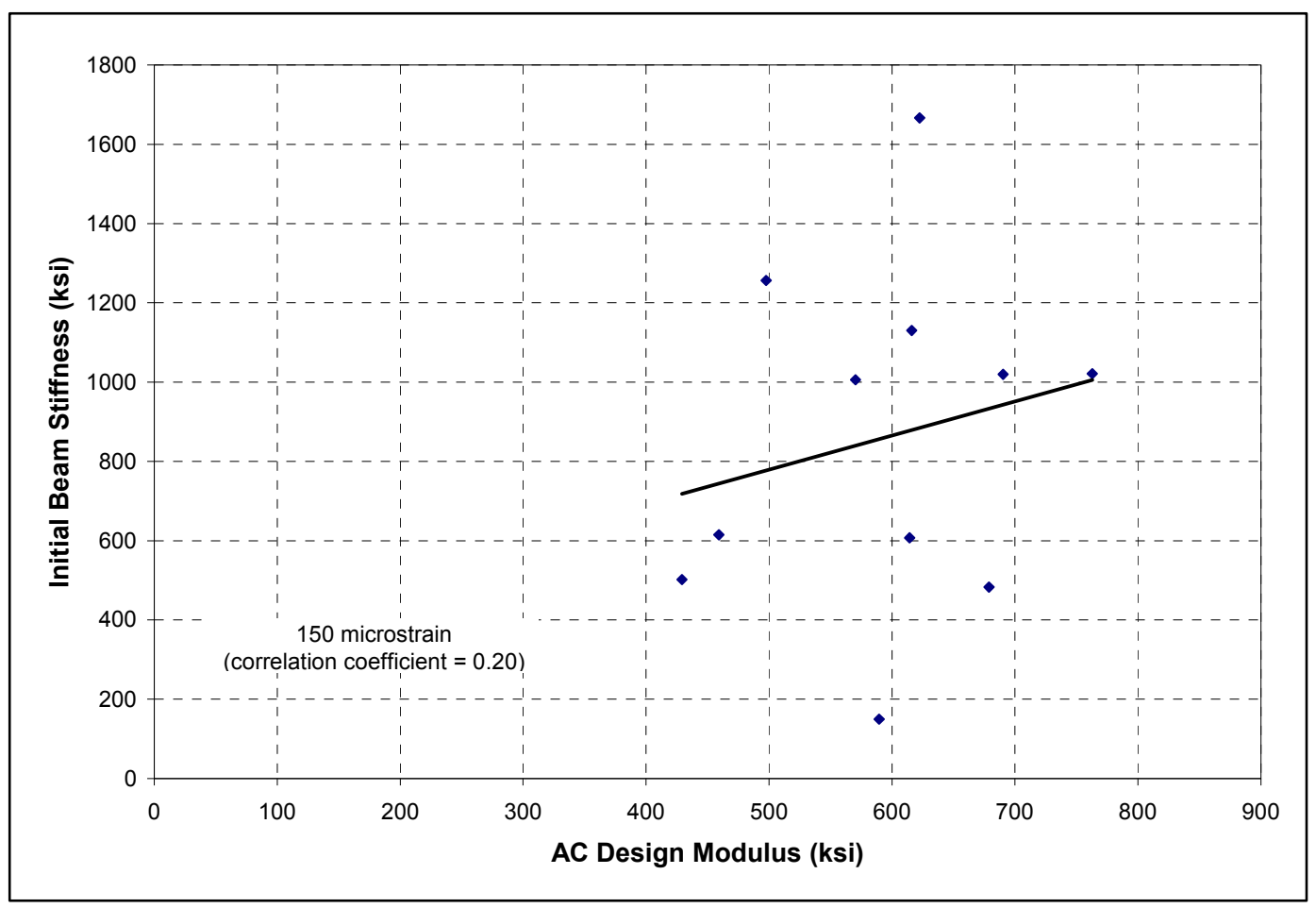

Figure 26. Two methods for measuring stiffness.

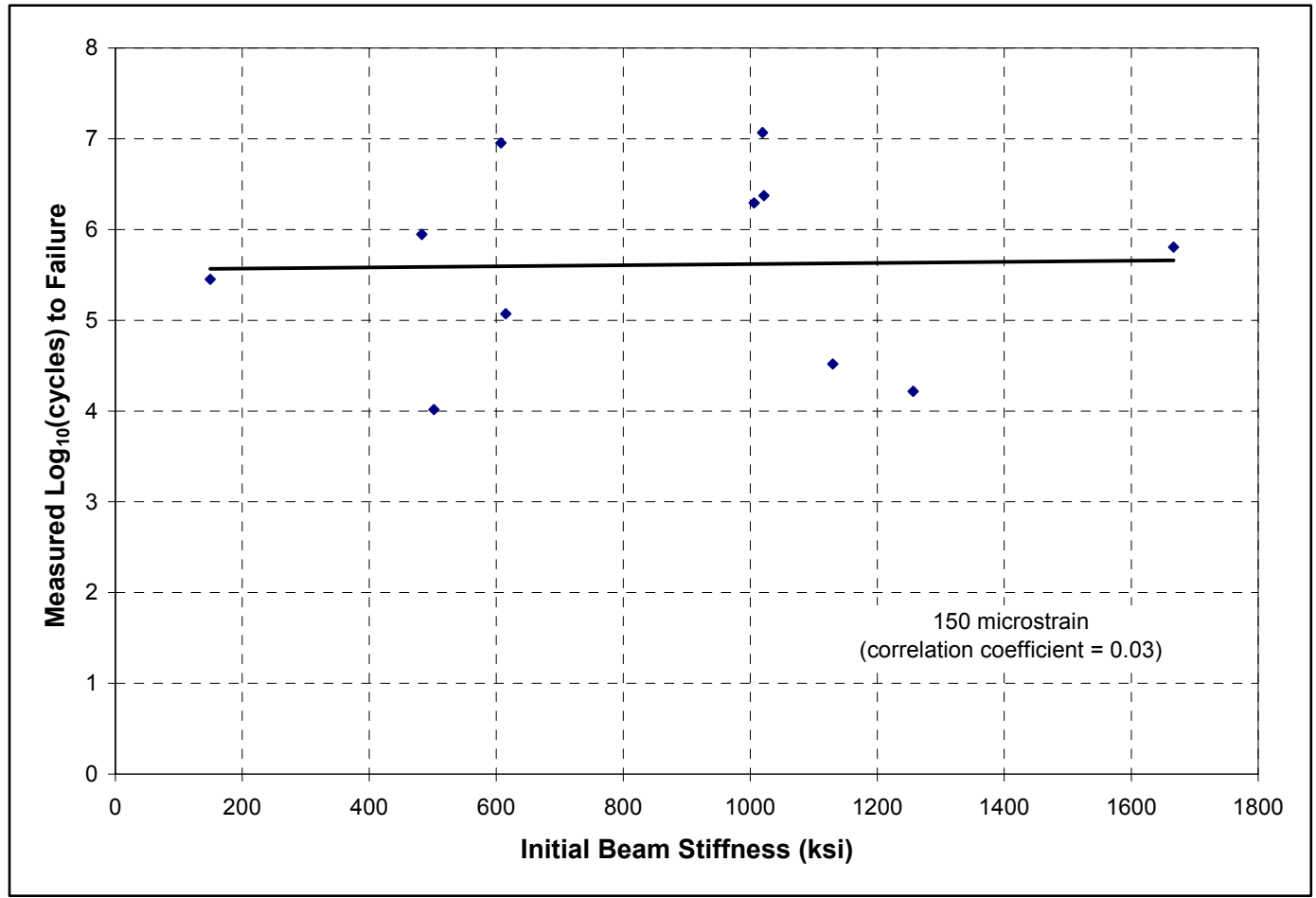

Figure 27. Influence of initial beam stiffness on fatigue performance of beams tested at 150 microstrain. 


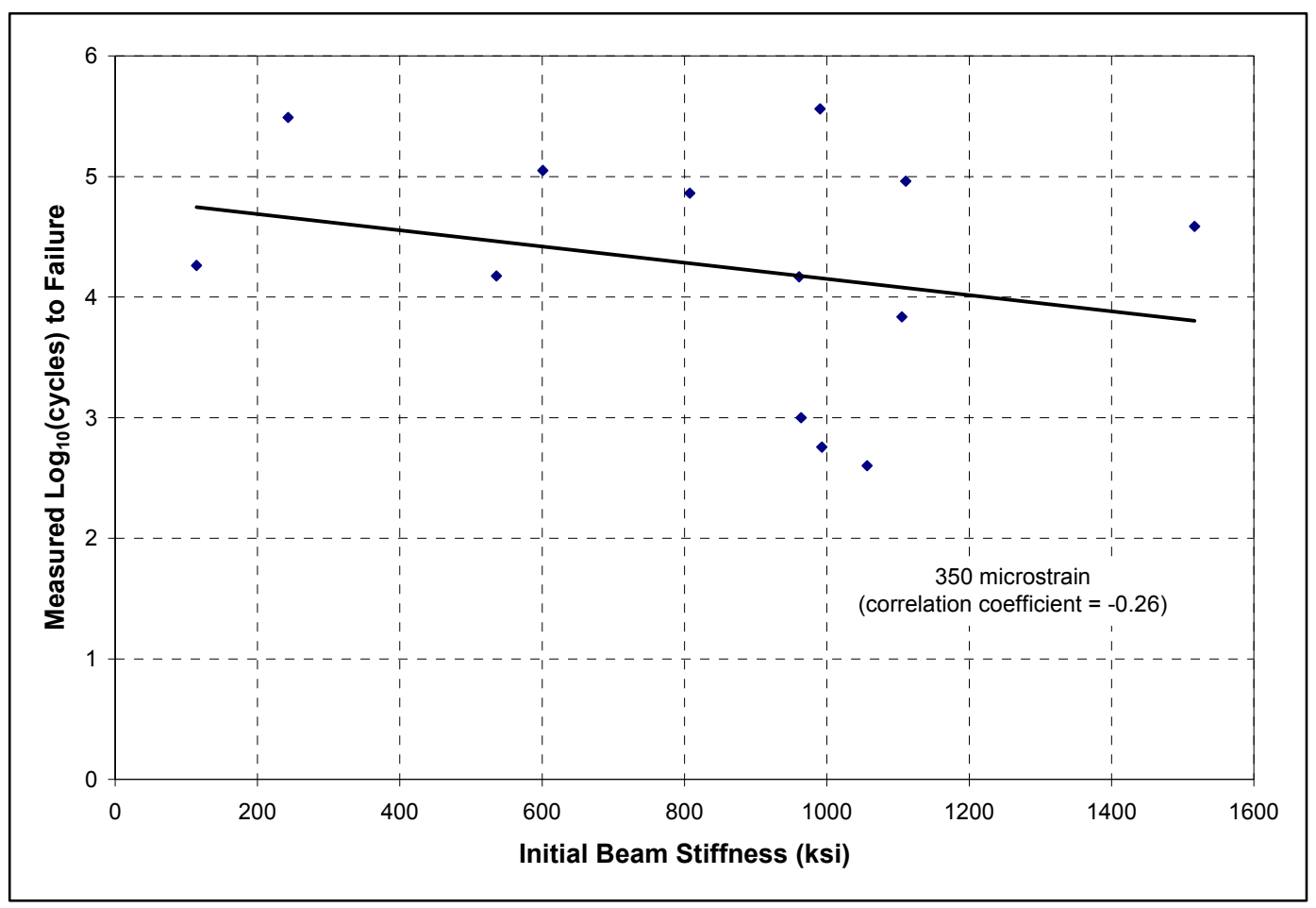

Figure 28. Influence of initial beam stiffness on fatigue performance of beams tested at $\mathbf{3 5 0}$ microstrain.

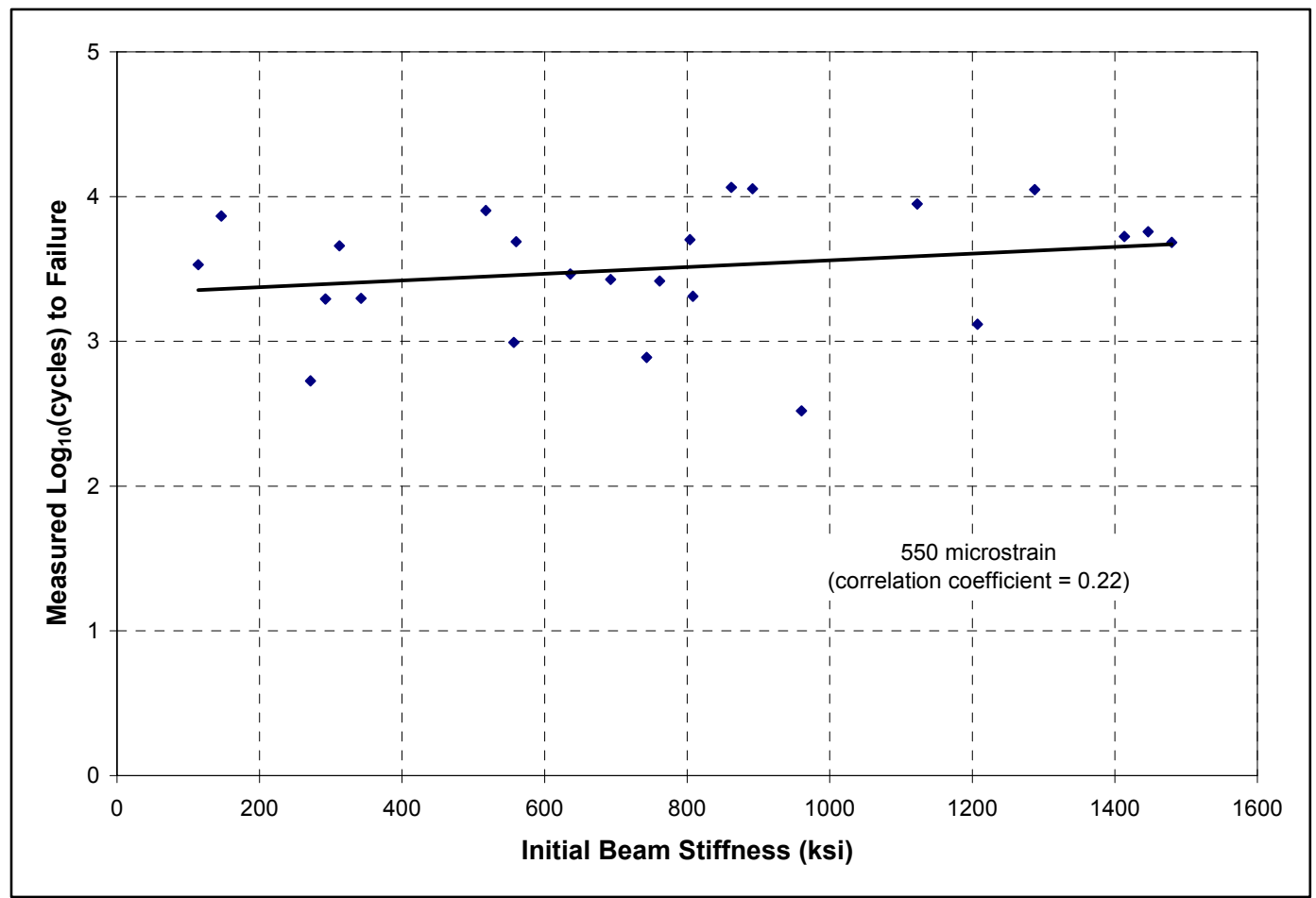

Figure 29. Influence of initial beam stiffness on fatigue performance of beams tested at 550 microstrain. 


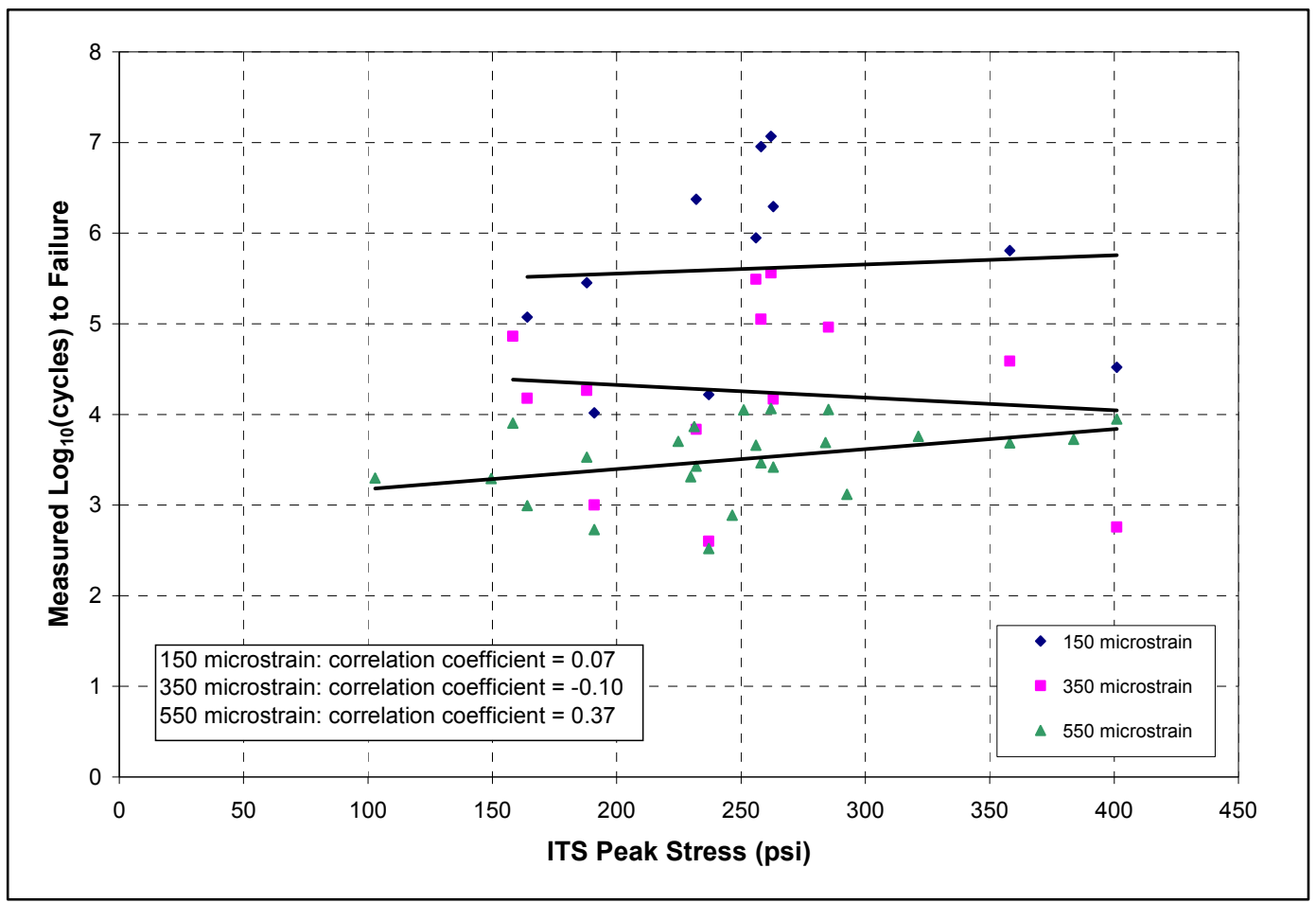

Figure 30. Influence of ITS peak stress on fatigue performance of beams tested at 150, 350, and 550 microstrain.

\section{Independent variables considered for the new fatigue criterion}

The AC properties to be tested for use as independent variables in the new fatigue criterion were selected based on data presented in the Phase I report (Bell and Freeman 2007). In addition, AC age and PCI were included because they represent information that is easy to collect. The properties to be tested can be conveniently categorized as follows:

1. Field parameters: age (years), PCI, and AC design modulus (ksi) measured with the PSPA.

2. ITS test parameters: peak stress (psi), deformation at peak load (in.), and energy to peak load (in.-lb).

3. Asphalt binder parameters obtained using the DSR: $\left(G^{*}\right) /(\sin \delta)$ and $\left(G^{*}\right)(\sin \delta)$.

These data are the independent variables that will be tested for effectiveness in predicting the dependent variable $\log _{10}$ (cycles) to failure for beam-fatigue tests. These data are summarized in Table 12. While several AC-mixture properties were studied in Phase I, they were found as nonbeneficial in the prediction of fatigue behavior and were therefore not 
Table 12. Independent variables to be tested for predicting $\log _{10}$ (cycles) to fatigue failure.

\begin{tabular}{|c|c|c|c|c|c|c|c|c|}
\hline \multirow[b]{2}{*}{ Sample } & \multicolumn{3}{|c|}{ Field Parameters } & \multicolumn{3}{|c|}{ Indirect Tensile Strength Parameters } & \multicolumn{2}{|c|}{ Binder Parameters } \\
\hline & $\begin{array}{l}\text { Pavement Surface } \\
\text { Age, yr }\end{array}$ & $\mathrm{PCl}$ & $\begin{array}{l}\text { AC Design (PSPA) } \\
\text { Modulus, ksi }\end{array}$ & $\begin{array}{l}\text { Peak Stress } \\
\text { psi }\end{array}$ & $\begin{array}{l}\text { Deformation at } \\
\text { Peak Load, in. }\end{array}$ & $\begin{array}{l}\text { Energy to Peak } \\
\text { Load, in.-lb }\end{array}$ & $\begin{array}{l}\left(G^{*}\right) /(\sin \delta) \\
\text { psi }\end{array}$ & $\begin{array}{l}\left(G^{*}\right)(\sin \delta) \\
\text { psi }\end{array}$ \\
\hline${\mathrm{LM}-1^{\mathrm{a}}}$ & 0 & no data & 452 & 80 & 0.173 & 101 & 0.2031 & 0.2031 \\
\hline VA-3 & 41 & no data & 609 & 246 & 0.068 & 124 & 8.9343 & 0.6672 \\
\hline $\mathrm{H}-1$ & 25 & 67 & 595 & 284 & 0.073 & 144 & 1.1458 & 1.1313 \\
\hline $\mathrm{H}-2$ & 19 & 72 & 790 & 251 & 0.068 & 130 & 0.3191 & 0.3046 \\
\hline $\mathrm{H}-3$ & 35 & 64 & 692 & 293 & 0.062 & 138 & 6.7298 & 5.7870 \\
\hline RG-1 & 19 & 58 & 580 & 230 & 0.060 & 105 & 12.7923 & 11.5740 \\
\hline RG-2 & 55 & 53 & 861 & 321 & 0.058 & 139 & 4.5687 & 4.4237 \\
\hline L-1 & 27 & 19 & 268 & 103 & 0.054 & 44 & 9.9496 & 7.1939 \\
\hline $\mathrm{L}-2$ & 27 & no data & 616 & 225 & 0.101 & 175 & 12.2267 & 8.4412 \\
\hline$C-1$ & 12 & 78 & 973 & 401 & 0.095 & 294 & 5.7290 & 5.0908 \\
\hline C-2 & 50 & 79 & 778 & 384 & 0.103 & 303 & 0.4061 & 0.4061 \\
\hline B-1 & 5 & 81 & 419 & 285 & 0.092 & 192 & 0.4931 & 0.4931 \\
\hline B-2 & 42 & 17 & 523 & 158 & 0.064 & 75 & 0.2176 & 0.2031 \\
\hline B-3 & 42 & 4 & 500 & 150 & 0.059 & 68 & 7.6145 & 6.8893 \\
\hline KA-1 & 30 & no data & 584 & 231 & 0.103 & 176 & 82.2944 & 48.5731 \\
\hline LM-2a & 0 & no data & 355 & 118 & 0.167 & 129 & 0.1885 & 0.1885 \\
\hline P-1 & 22 & 8 & 498 & 237 & 0.059 & 90 & 4.5832 & 5.8305 \\
\hline P-2 & 7 & 82 & 622 & 358 & 0.085 & 202 & 0.8122 & 0.8267 \\
\hline $\mathrm{R}-1$ & 21 & 43 & 690 & 262 & 0.082 & 135 & 1.5664 & 1.6389 \\
\hline $\mathrm{R}-2$ & 41 & 47 & 589 & 188 & 0.065 & 76 & 9.7175 & 14.5908 \\
\hline S-1 & 14 & 57 & 679 & 256 & 0.076 & 123 & 3.4664 & 3.9595 \\
\hline $\mathrm{S}-2$ & 14 & 53 & 570 & 263 & 0.097 & 163 & 1.7550 & 1.9870 \\
\hline S-3 & 14 & 48 & 614 & 258 & 0.113 & 183 & 2.4801 & 2.7992 \\
\hline F-1 & 27 & 43 & 763 & 232 & 0.067 & 100 & 0.7832 & 0.8412 \\
\hline $\mathrm{F}-2$ & 27 & 59 & 459 & 164 & 0.086 & 91 & 2.1030 & 2.3496 \\
\hline F-3 & 7 & 66 & 429 & 191 & 0.081 & 94 & 5.3809 & 6.9763 \\
\hline
\end{tabular}


included in the Phase II analysis. These mixture properties included maximum specific gravity, percent binder by extraction, and percent coarse aggregates. Similarly, two conventional binder properties (kinematic viscosity and penetration) were found as nonbeneficial in Phase I, so they were not included in the subsequent study.

\section{Testing independent variables for predictive significance}

The significance with which independent variables were able to predict $\log _{10}$ (cycles) to failure were analyzed by multivariate linear regression tests. First, each of the three broad categories of data was inspected: field data, ITS data, and binder data. In each case, strain level during fatigue testing was also considered a likely significant independent variable. Any independent variables found to be significant in these preliminary tests would be combined into a final multivariate linear regression test.

The following multivariate linear regression tests were performed in a forward stepwise manner. That is, independent variables were added individually, starting with the variable that contributed most significantly to the ability of the regression equation to predict the dependent variable. Any of the independent variables could be excluded from the regression if its contribution to predicting the dependent variable was nonsignificant. The significance of an independent variable's contribution was judged by its $\mathrm{P}$-value, which is the probability of being incorrect if the independent variable is identified as making a significant contribution to the regression. Generally, independent variables with P-values less than 0.05 (5\%) are considered to be worthy of being including in the regression model.

In the following tables that summarize the results of multivariate regressions, an asterisk ${ }^{*}$ ) follows the P-values for those independent variables that contributed significantly to the linear regression. The resulting predictive equation is then shown as a footnote in the table, along with RMSE, $\mathrm{R}^{2}$, and adjusted $\mathrm{R}^{2}$. The RMSE is the root mean squared error (often called the standard error of estimate), which represents the average absolute deviation between actual data and predictions based on the regression (Younger 1979). The $\mathrm{R}^{2}$ is the coefficient of determination, which provides a measure of the amount of response variability explained by the model. Although the $\mathrm{R}^{2}$ provides a measure of "goodness of fit," comparisons of $\mathrm{R}^{2}$ between different regression models that contain different quantities of either independent variables or data points are inaccurate because $\mathrm{R}^{2}$ is affected by the steepness of the regression equation slope, as well as the 
Table 14. Multiple regression for strain and ITS data.

\begin{tabular}{|c|c|c|}
\hline Independent Variable & $\begin{array}{l}\text { Coefficient for Linear } \\
\text { Regression }\end{array}$ & P-value \\
\hline Microstrain & -0.005205 & $<0.0010 *$ \\
\hline ITS Peak Stress (psi) & 0.003881 & $0.0315 *$ \\
\hline Deformation at Peak Load (in.) & 0.005965 & 0.4064 \\
\hline Energy to Peak Load (in.-lb) & 0.002220 & 0.5579 \\
\hline \multicolumn{3}{|c|}{$\begin{array}{l}\text { a } P \text {-value represents the probability of being incorrect if the null hypothesis of equality is } \\
\text { rejected. An asterisk }(*) \text { indicates that the independent variable contributes significantly to } \\
\text { the regression. }\end{array}$} \\
\hline \multicolumn{3}{|l|}{ Resulting Linear Equation: } \\
\hline $\begin{array}{l}\text { Regression Statistics: } \\
\qquad \text { RMSE }=0.7446, \mathrm{R}^{2}=0.5\end{array}$ & adjusted $R^{2}=0.56, P-$ & gression < 0.001 \\
\hline
\end{tabular}

When binder data were used as independent variables, along with strain, only strain level added significantly to the linear regression. Neither $\left(G^{*}\right) /(\sin \delta)$ nor $\left(G^{*}\right)(\sin \delta)$ contributed significantly to the linear regression (Table 15).

Table 15. Multiple regression for strain and DSR binder data.

\begin{tabular}{|c|c|c|}
\hline Independent Variable & $\begin{array}{l}\text { Coefficient for Linear } \\
\text { Regression }\end{array}$ & P-value ${ }^{a}$ \\
\hline Microstrain & -0.005098 & $<0.0010 *$ \\
\hline$\left(G^{*}\right) /(\sin \delta)$ & -0.566273 & 0.6893 \\
\hline$\left(G^{*}\right)(\sin \delta)$ & -1.94827 & 0.3812 \\
\hline \multicolumn{3}{|c|}{$\begin{array}{l}\text { a P-value represents the probability of being incorrect if the null hypothesis of equality is } \\
\text { rejected. An asterisk }\left({ }^{*}\right) \text { indicates that the independent variable contributes significantly to } \\
\text { the regression. } \\
\text { Resulting Linear Equation: } \\
\qquad \log _{10} \text { (cycles) }=6.2504-0.005098 \times \text { (Microstrain) }\end{array}$} \\
\hline \multicolumn{3}{|c|}{$\begin{array}{l}\text { Regression Statistics: } \\
\qquad \mathrm{RMSE}=0.7757, \mathrm{R}^{2}=0.54, \text { adjusted } \mathrm{R}^{2}=0.52, \mathrm{P} \text {-value for regression }<0.001\end{array}$} \\
\hline
\end{tabular}

Finally, all significant independent variables were combined to test by multiple linear regressions. These variables included strain, AC design PSPA modulus, and ITS peak stress. Only strain and AC design PSPA modulus were found to be significant in this analysis. ITS peak stress did not contribute significantly to predicting $\log _{10}$ (cycles) to failure (Table 16). 


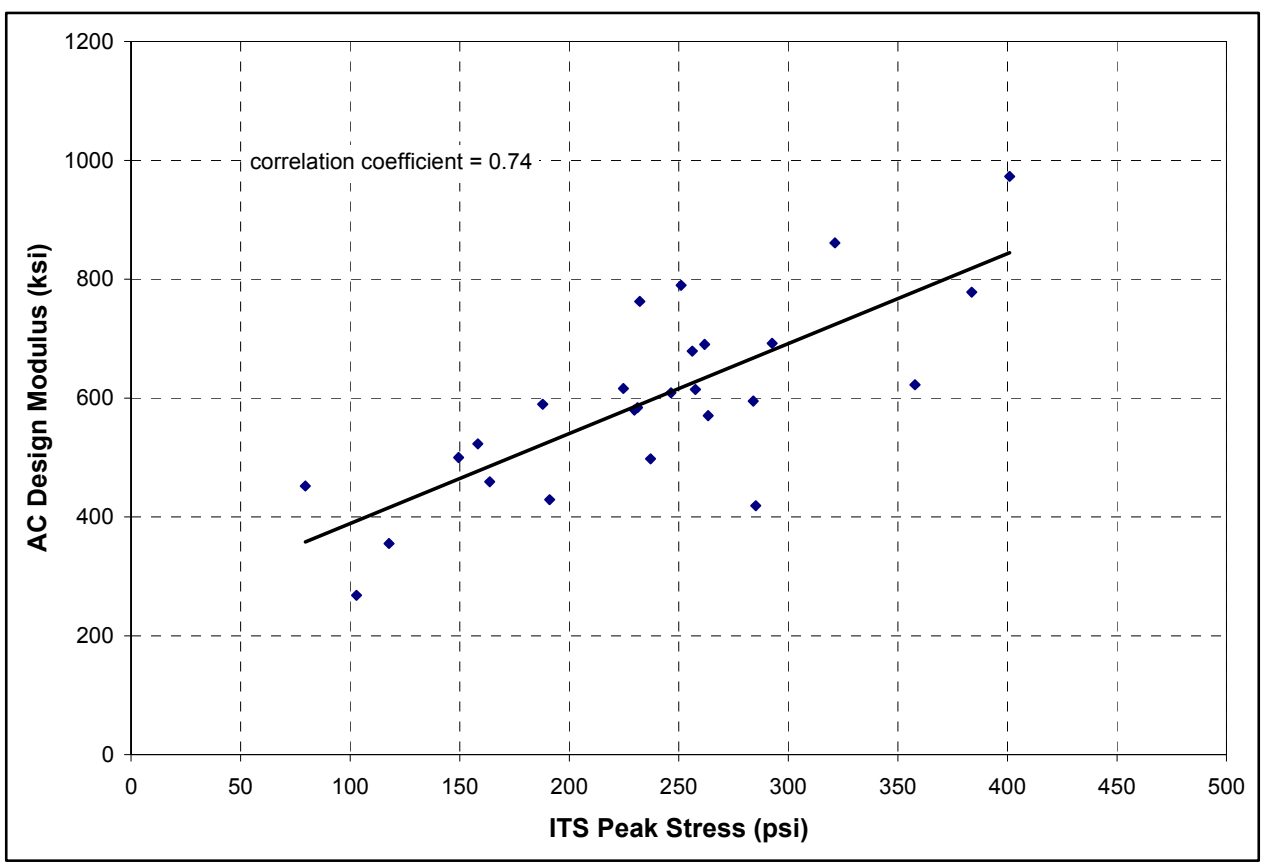

Figure 31. Correlation between ITS peak stress and AC design modulus.

\section{Defining the new criteria in equation form}

In this section, a new criterion equation will be provided for each of the following two situations.

1. AC design modulus (at $15 \mathrm{~Hz}$ and $77^{\circ} \mathrm{F}$ ) can be estimated with a PSPA.

2. A 4-in.-diam core can be obtained for measuring ITS peak stress at $77^{\circ} \mathrm{F}$.

As shown previously, obtaining an estimate for AC design modulus is preferable, so its associated criterion equation will be examined first. Although linear regressions (multivariate) were used to find significant predictive independent variables, both linear and nonlinear equations were considered for this new criterion. While the linear equation was obtained from the linear regression, multiple nonlinear equations were produced with the curvefitting software, Tablecurve $3 \mathrm{D}^{\circledR}$ by Systat Software, Inc. Only the most promising nonlinear equation is presented here. Other nonlinear equations were rejected either because they were inefficiently complex or they offered erroneous trends. The erroneous trends resulted when complex equations tried to model intricate relationships between variables, even though the dataset was small and incomplete. For example, some nonlinear equations gave a minimum fatigue life for the medium strain levels, thus increasing for both lower and higher strain levels. When an equation disagreed with engineering sense, it was immediately rejected. 
The linear regression is reproduced below. Variable units and abbreviations are altered to be consistent with the original DoD criterion.

$$
\log _{10}\left(\varepsilon_{r a}\right)=4.89-\frac{S_{A} \times 10^{6}}{191}+\frac{E}{422,000 \mathrm{psi}}
$$

where:

$$
\begin{aligned}
\varepsilon_{r a} & =\text { allowable strain repetitions for aged, field AC } \\
S_{A} & =\text { tensile strain of AC, in./in. } \\
E & =\text { AC design modulus, psi. }
\end{aligned}
$$

Equation 7 presents the most promising nonlinear regression. The linear and nonlinear equations will be compared quantitatively to produce the final recommended criterion for predicting cycles to fatigue failure for aged AC.

$$
\log _{10}\left(\varepsilon_{r a}\right)=7.94-\left[\frac{L N\left(S_{A} \times 10^{6}\right)}{2.61}\right]^{2}+\frac{E}{438,000 \mathrm{psi}}
$$

These two equations were first compared using scatter plots showing predicted $\log _{10}$ (cycles) to failure versus measured $\log _{10}$ (cycles) to failure. The plots appear to be very similar, and the correlation coefficients are approximately equal (Figures 32 and 33). Both plots show substantially improved predictions as compared with Figure 20, which is a similar presentation for the original DoD criterion when applied to aged AC (correlation coefficient $=0.66$ ).

The second comparison for the two equations involved bar chart presentations of Log Ratios (Figures 34 and 35). The charts are a convenient way to view the percentage of fatigue cycle predictions that are different from measured cycles to failure by one or two log cycles. While the linear equation predictions tend to err more on the unconservative side (negative Log Ratios), the nonlinear predictions are more evenly distributed between unconservative and conservative. The nonlinear predictions are shown to be more accurate. Neither of these bar charts shows any Log Ratios that exceed either 2 or $\mathbf{- 2}$. Therefore, no predictions are more than two log cycles in error. In contrast, Figure 21 shows that, when the original DoD criterion was applied to aged AC, approximately $34 \%$ of the predictions were unconservative by factors exceeding two log cycles. 


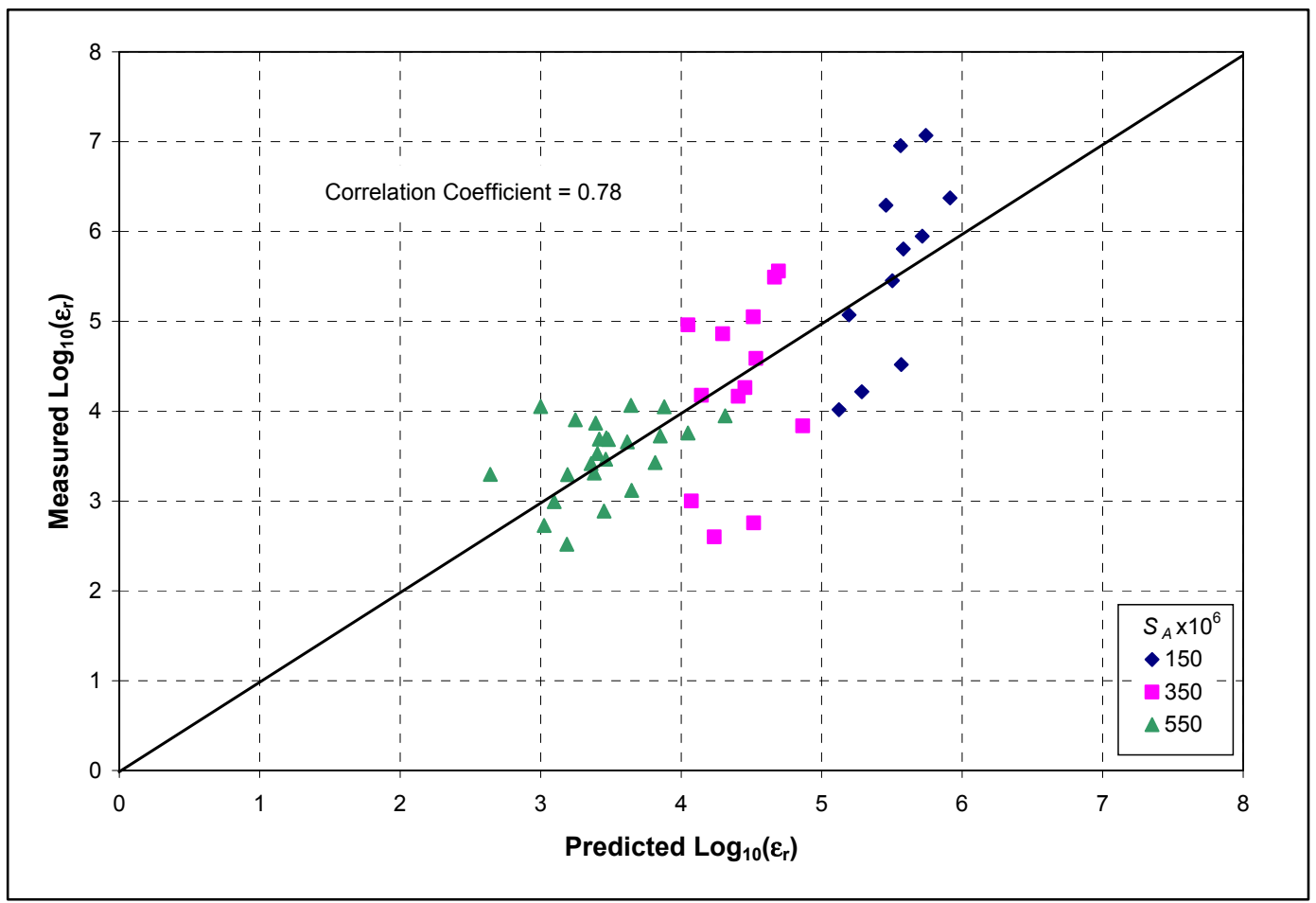

Figure 32. Predictions versus measured $\log _{10}\left(\varepsilon_{r}\right)$ for the linear predictive equation based on strain and $A C$ design modulus.

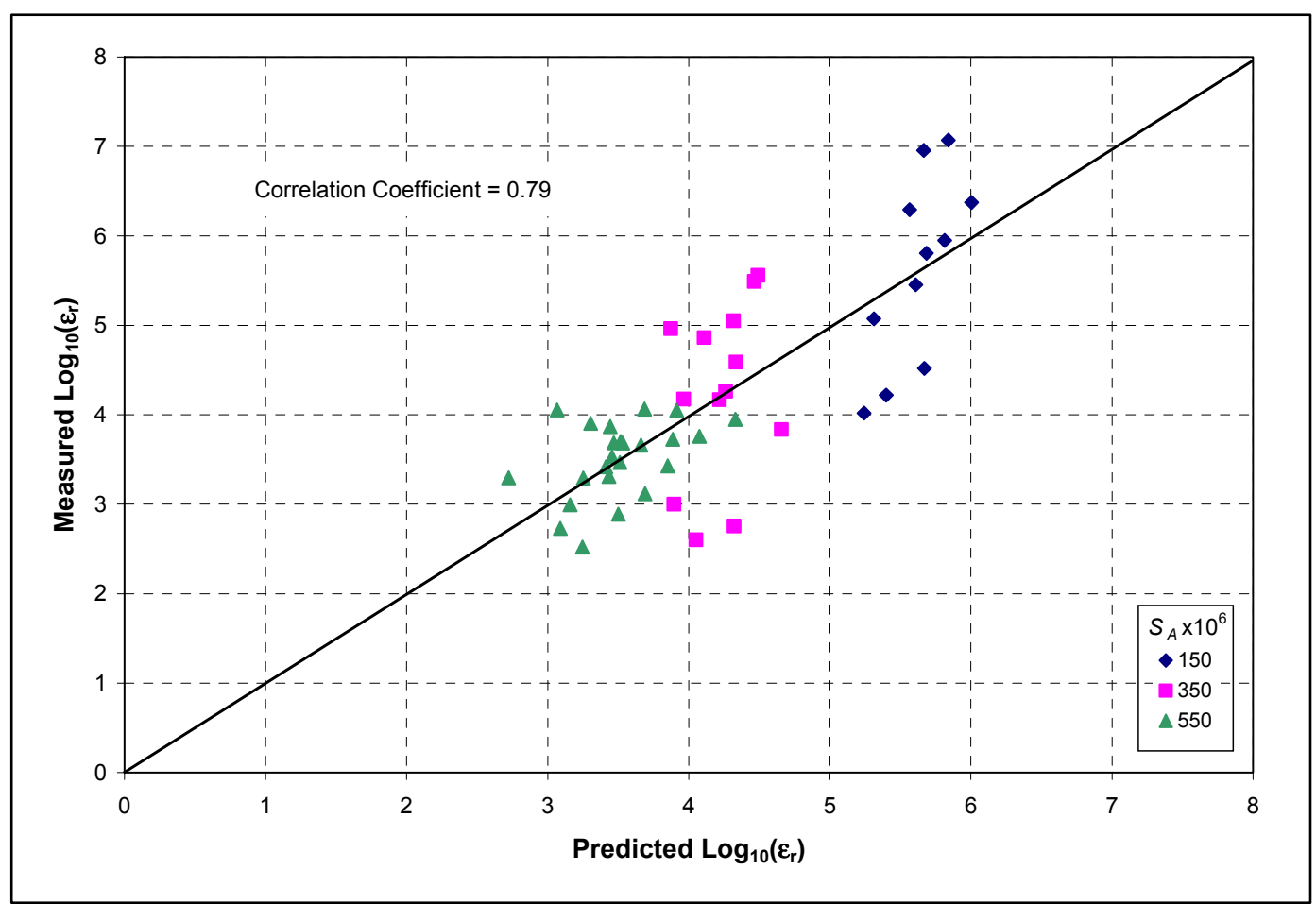

Figure 33. Predictions versus measured $\log _{10}\left(\varepsilon_{r}\right)$ for the nonlinear predictive equation based on strain and AC design modulus. 


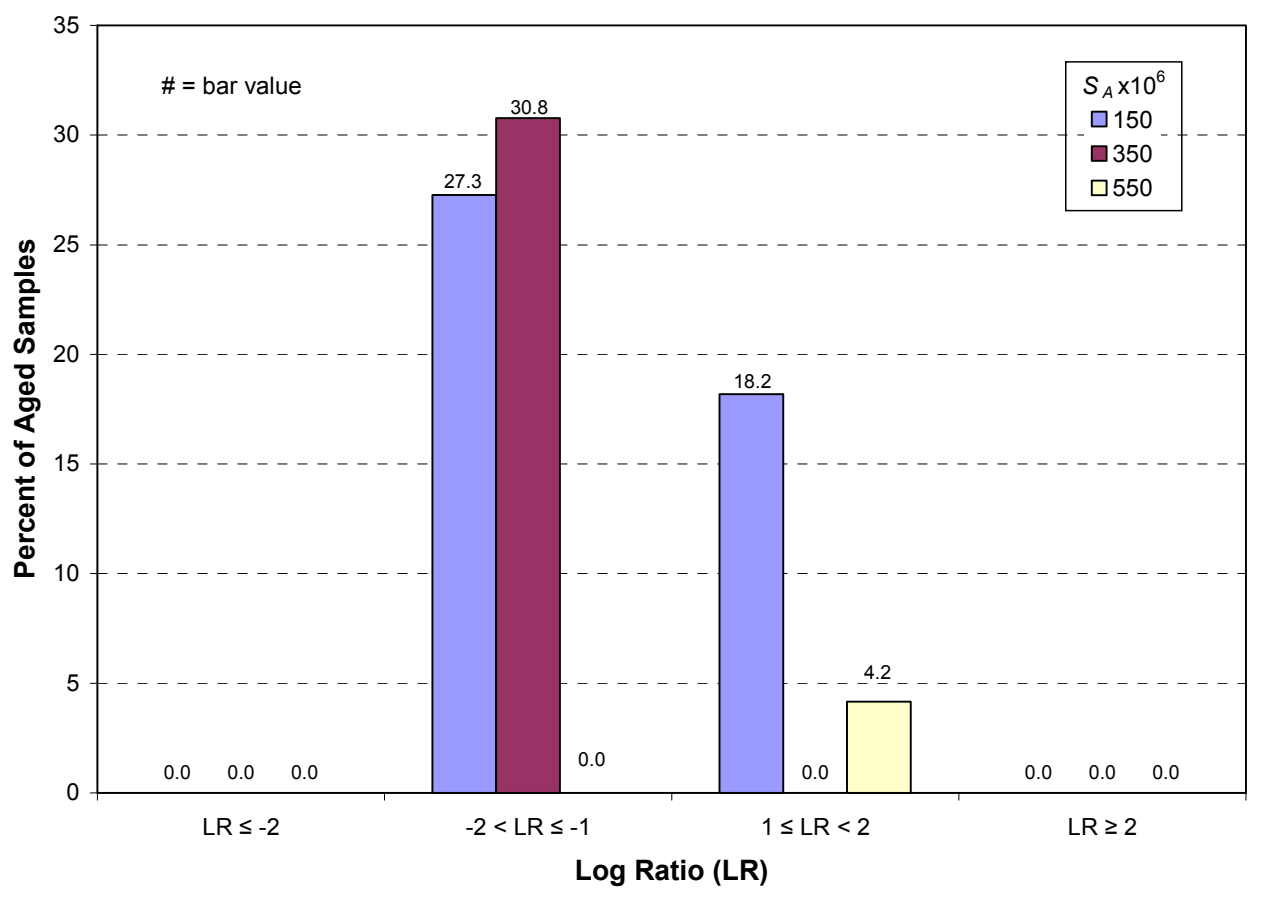

Figure 34. Extreme Log Ratios for the linear predictive equation based on strain and $A C$ design modulus.

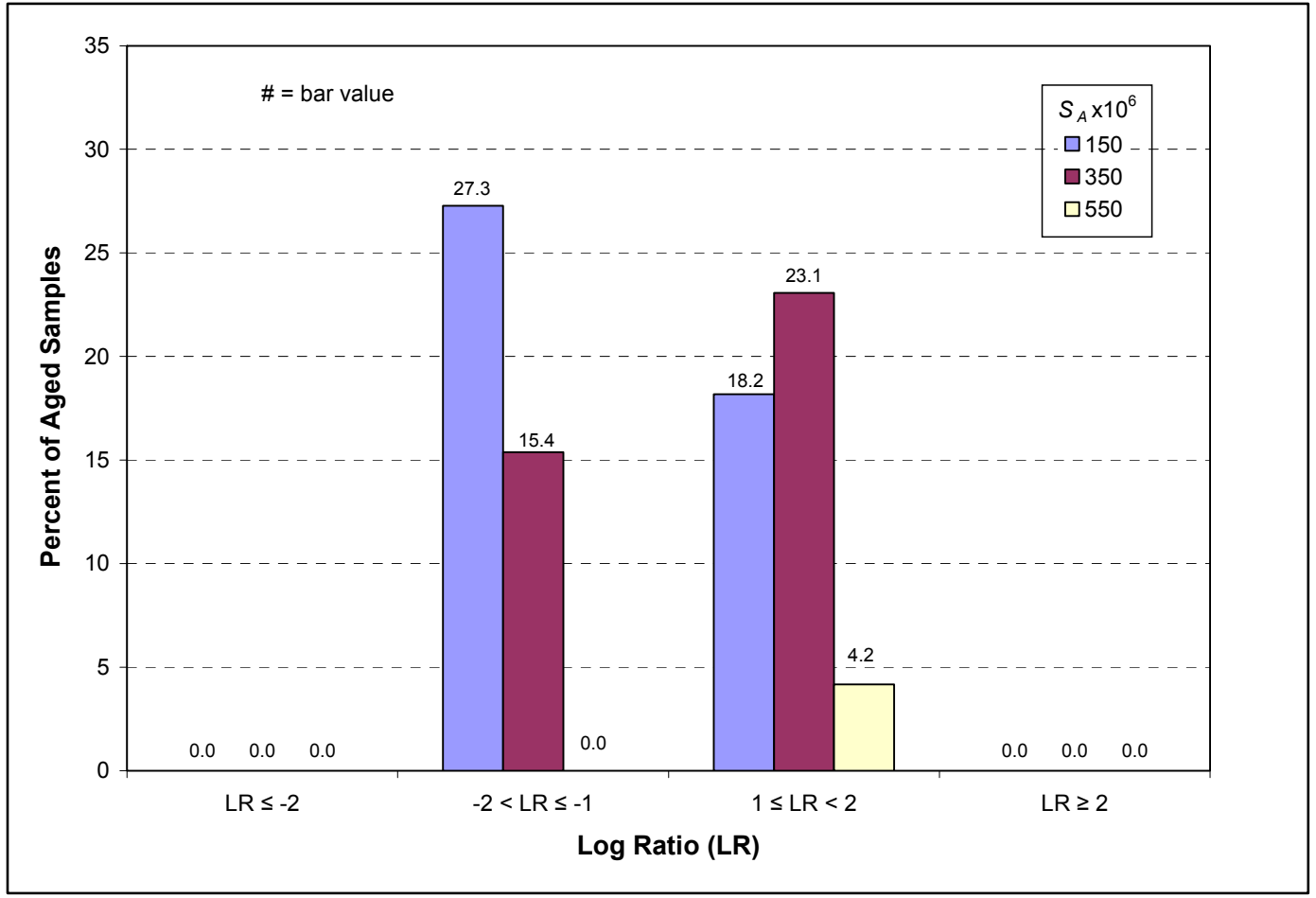

Figure 35. Extreme Log Ratios for the nonlinear predictive equation based on strain and AC design modulus. 
The final comparison for the linear and nonlinear predictive equations will involve the display of the equations in the form of families of lines and smooth curves. The plots maintain the limits of moduli found during this study. The limits of microstrain were extended slightly beyond the range used in this study; the plotted limits are 100 to 600 microstrain. These plots, which are shown as Figures 36 and 37, could be used as pavement evaluation tools in a manner similar to the use of Figure 15 for the current DoD fatigue criterion. The plots are similar, except the nonlinear plot shows that the incremental increase in cycles to failure increases as strain level decreases. Based on the results of the fatigue testing, this representation is judged accurate and is therefore considered an advantage for the nonlinear equation.

The nonlinear equation (Equation 7) is judged to be the most effective equation for predicting fatigue failure for aged $\mathrm{AC}$, based on $\mathrm{AC}$ design modulus and strain data, for two reasons.

1. The nonlinear equation offers an improved distribution of conservative and unconservative errors when predicted cycles to failure are compared to measured cycles to failure via the calculated Log Ratios.

2. The nonlinear equation accounts for the larger differences in cycles to failure for incremental changes in microstrain at small strain levels, as compared to relatively high strain levels.

Given these findings, a similar nonlinear equation (Equation 8) was identified for the case of predicting fatigue life using ITS peak stress data along with strain data.

$$
\log _{10}\left(\varepsilon_{r a}\right)=8.36-\left[\frac{L N\left(S_{A} \times 10^{6}\right)}{2.62}\right]^{2}+\frac{\text { ITS Peak Stress, psi }}{264 \mathrm{psi}}
$$

To verify the accuracy and precision of this predictive equation, the scatter plot showing predicted $\log _{10}$ (cycles) to failure versus measured $\log _{10}$ (cycles) to failure is displayed as Figure 38. Also, the bar chart showing the percentage of extreme Log Ratios is included as Figure 39. The predictive equation using strain and ITS peak stress is shown by these figures to provide accuracy and precision commensurate with the predictive equation using strain and AC design modulus. 


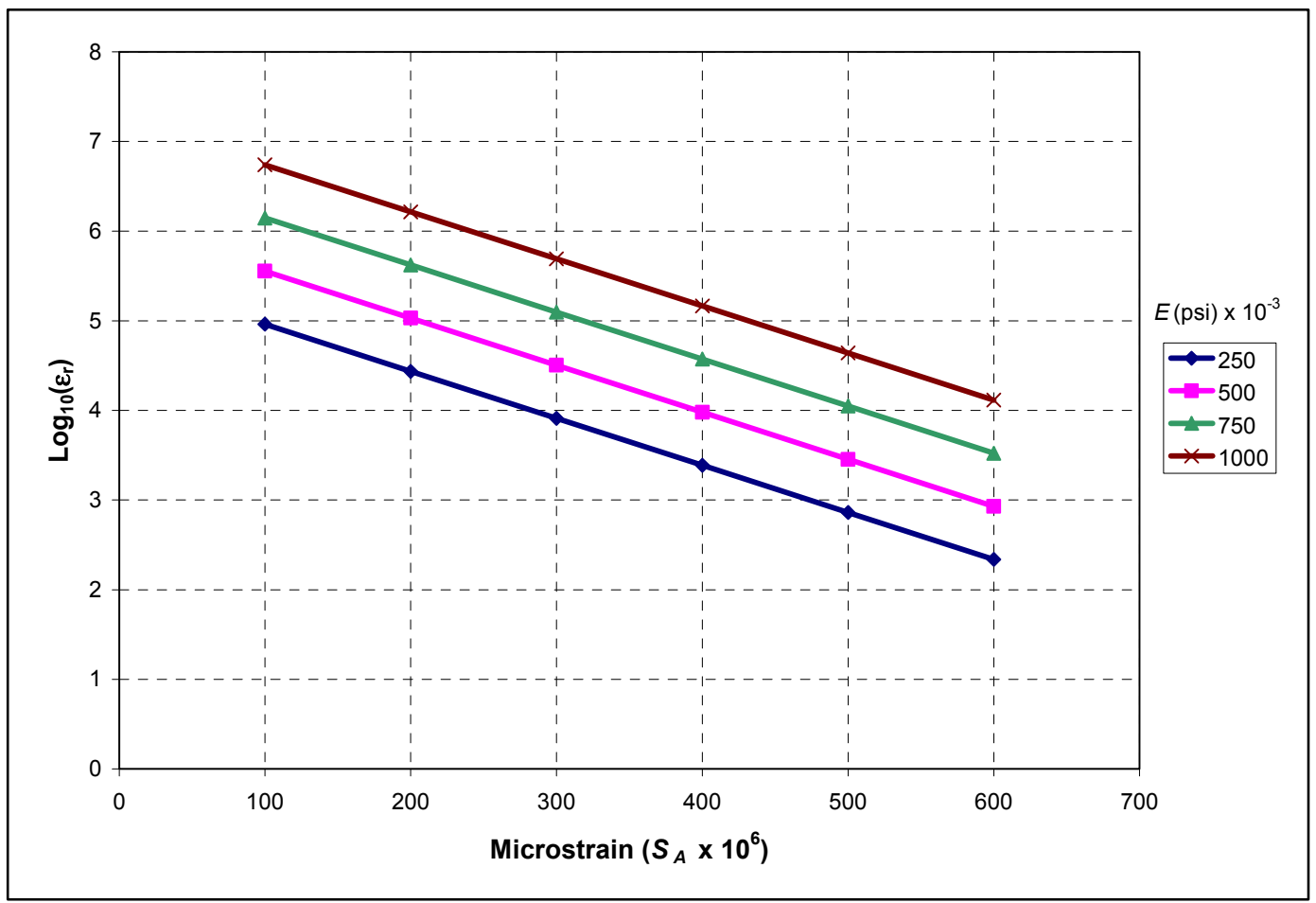

Figure 36. Linear predictive equation for fatigue of aged $A C$ based on strain and $A C$ design modulus.

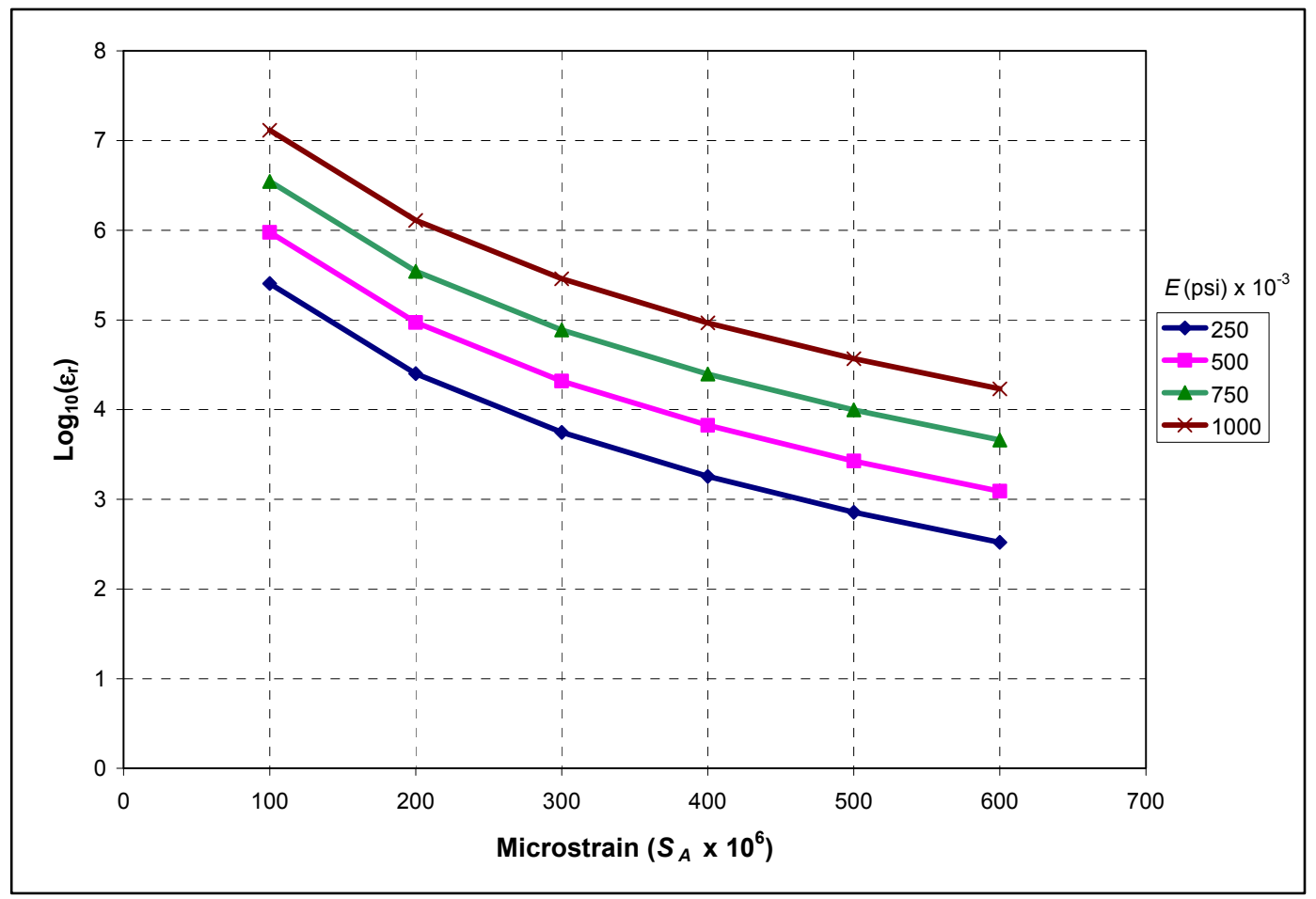

Figure 37. Nonlinear predictive equation for fatigue of aged AC based on strain and $A C$ design modulus. 


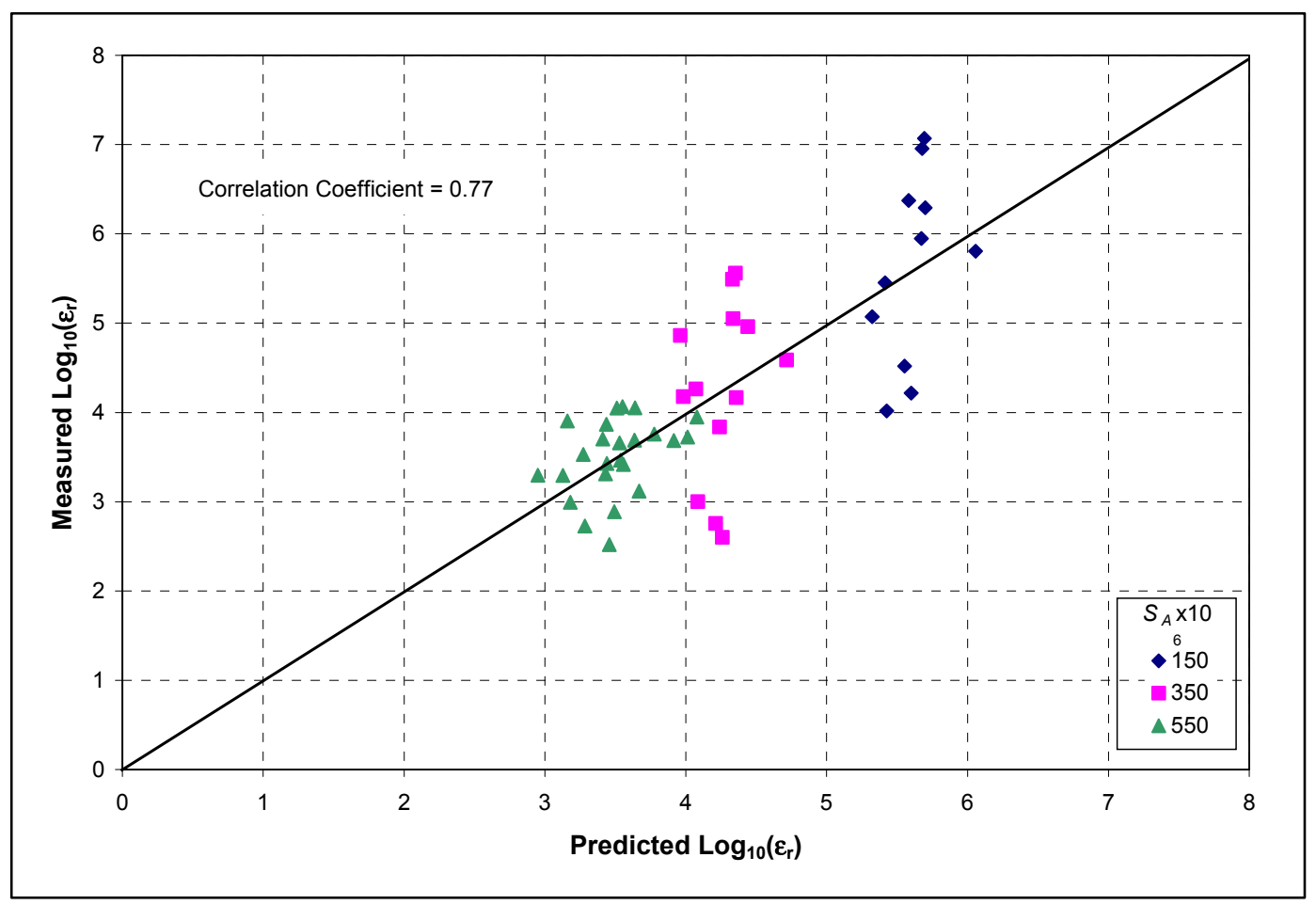

Figure 38. Predicted versus measured $\log _{10}\left(\varepsilon_{r}\right)$ for the nonlinear predictive equation based on strain and ITS peak stress.

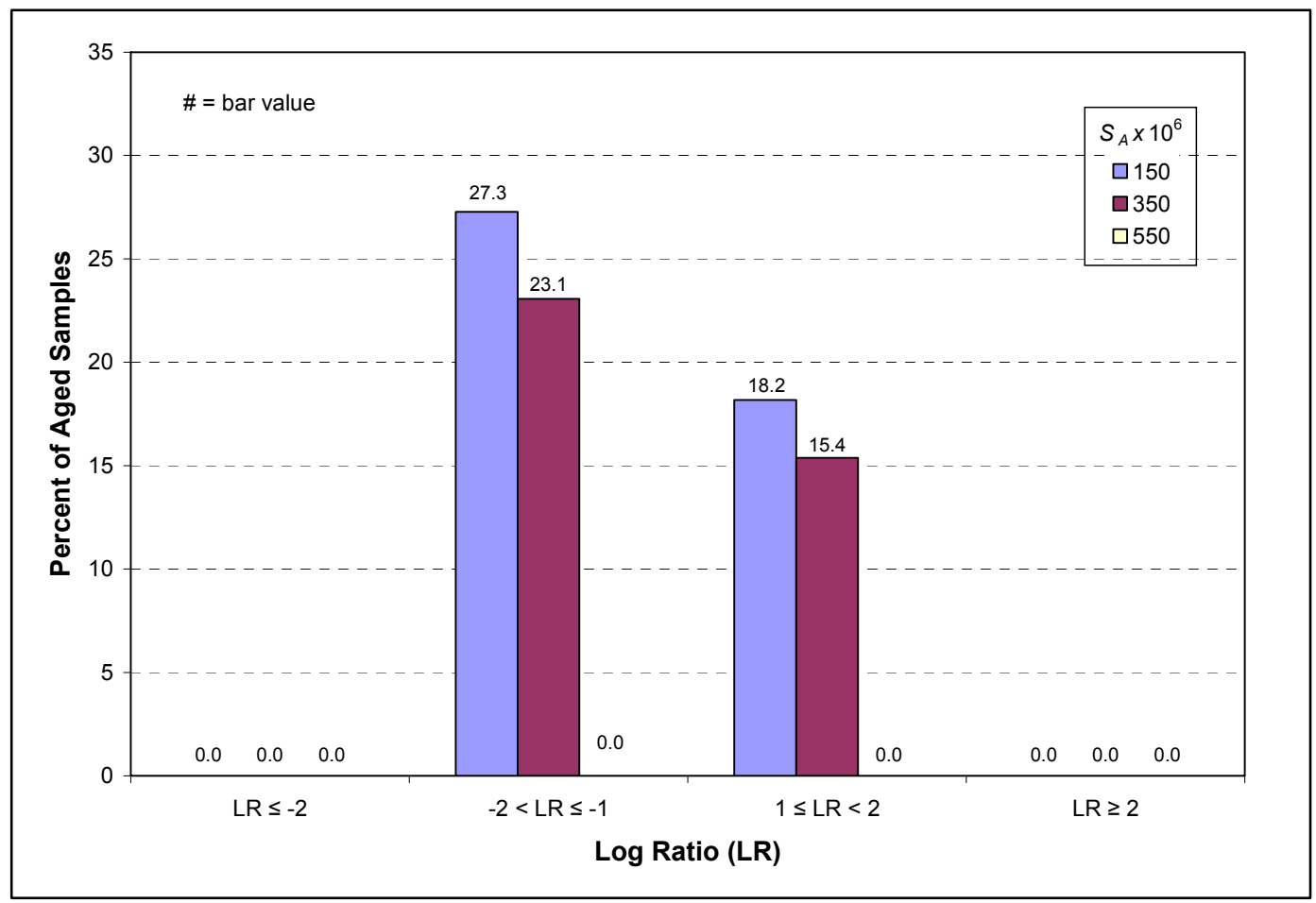

Figure 39. Extreme Log Ratios for the nonlinear predictive equation based on strain and ITS peak stress. 
Finally, the nonlinear predictive equation based on strain and ITS peak stress is displayed in the form of a family of smooth curves (Figure 40). This plot maintains the limits of ITS peak stress found during this study. The limits of microstrain were extended slightly beyond the range used in this study; the plotted limits are 100 to 600 microstrain. These curves are very similar in form and magnitude to those on the nonlinear plot showing predicted $\log _{10}$ (cycles) to failure based on strain and AC design modulus (Figure 37).

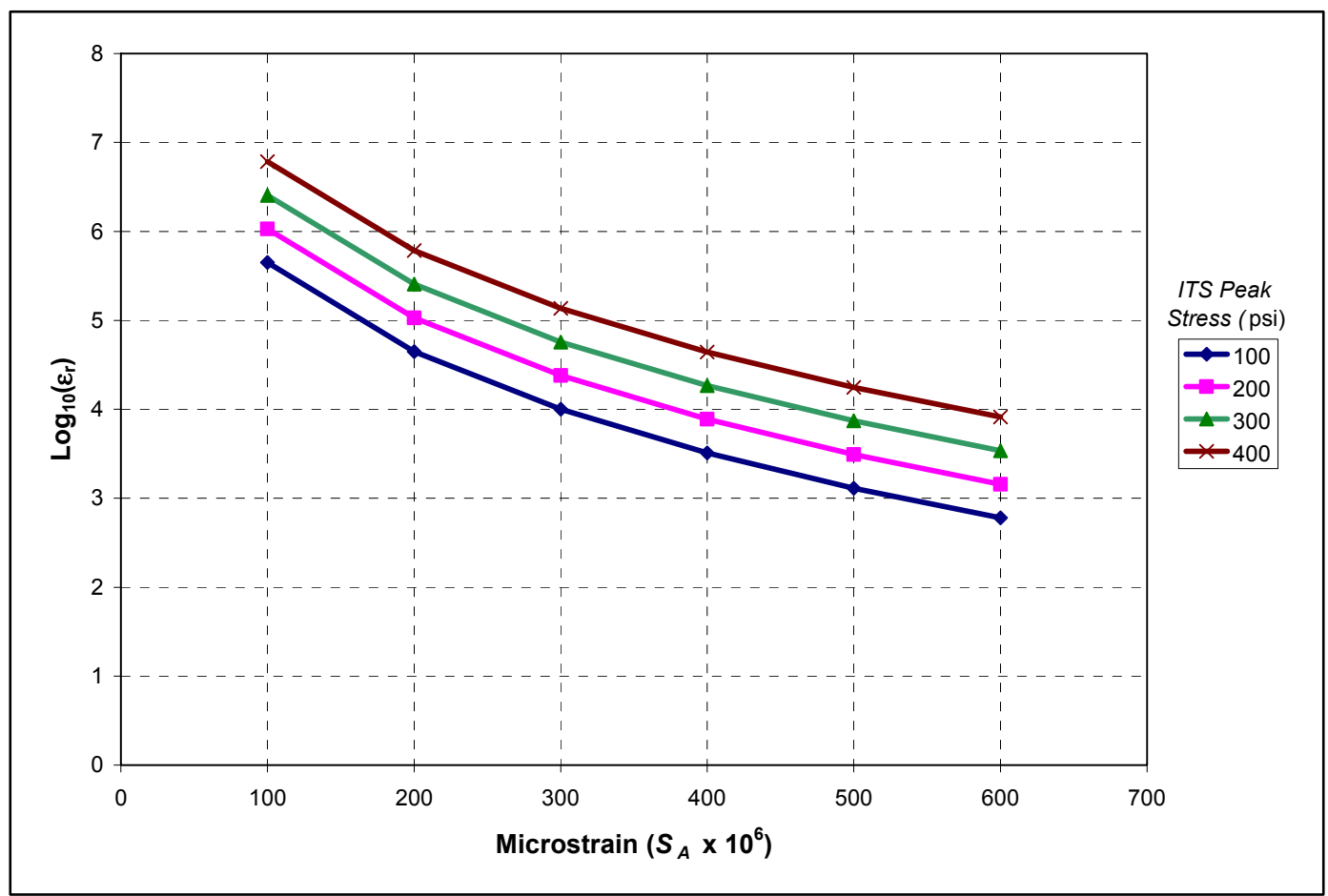

Figure 40. Nonlinear predictive equation for fatigue of aged AC based on strain and ITS peak stress.

\section{Extending the aged asphalt fatigue criteria to temperatures other than $\mathbf{7 7}^{\circ} \mathrm{F}$}

The fatigue criteria developed thus far in this study address the performance of aged, field $\mathrm{AC}$ at $77^{\circ} \mathrm{F}$. This limitation in applicable temperatures is a consequence of keeping the field sampling and laboratory testing to a reasonable volume of work. All laboratory beam fatigue testing was performed at room temperature. Also, the fatigue input parameters of $\mathrm{AC}$ design modulus (as measured by the PSPA) and ITS peak stress (as measured from core testing) are both limited to representing asphalt mechanical properties at $77^{\circ} \mathrm{F}$. 
To extend these criteria to other pavement temperatures, a method was developed in which the fatigue criteria for aged, field AC could take advantage of the original DoD criterion (Equation 2). The original DoD criterion was developed with unaged AC tested at multiple temperatures. The necessary steps in a fatigue analysis that utilize both the original DoD criterion and the new criteria for aged $\mathrm{AC}$ will be presented with the help of two examples of pavement evaluations.

- Step 1 - Measure the stiffness of in situ AC. Estimate AC design modulus $\left(15 \mathrm{~Hz}, 77^{\circ} \mathrm{F}\right)$, preferably with a PSPA, or estimate ITS peak stress $\left(\right.$ at $77^{\circ} \mathrm{F}$ ) for the $\mathrm{AC}$ surface layer. These parameters provide an indication of material integrity and oxidizing effects. In this example, assume that Pavement A was tested with the PSPA and found to have an $\mathrm{AC}$ design modulus of $1,000,000$ psi. Assume that a core was removed from Pavement $B$ and tested by indirect tension to find an ITS peak stress of 200 psi. Based on these test results, the AC in Pavement $\mathrm{A}$ appears to be intact, and the $\mathrm{AC}$ in Pavement $\mathrm{B}$ appears to have deteriorated.

- Step 2 - Predict maximum tensile strain at the bottom of the AC layer. Predict tensile strain at the bottom of the $\mathrm{AC}$ at $77^{\circ} \mathrm{F}$ for the design aircraft and design loading frequency. Currently, strain predictions would be accomplished with layered (linear) elastic analysis tools, such as the WinJULEA program within the pavement evaluation software of PCASE (Pavement-Transportation Computer Assisted Structural Engineering, http://www.pcase.com). The modulus of AC, which would be required for a layered elastic analysis, would be estimated either from mean pavement temperature and loading-frequency data (Figure $4-6$ of UFC $3-260-03$ ) or by the PSPA ( $15 \mathrm{~Hz}$ and $77^{\circ} \mathrm{F}$ ). While the PSPA-estimated AC design modulus $\left(15 \mathrm{~Hz}\right.$ and $\left.77^{\circ} \mathrm{F}\right)$ is appropriate for runway evaluations, a taxiway evaluation would require conversion of the $15-\mathrm{Hz}$ modulus to a modulus at $2 \mathrm{~Hz}$ (Figure 4-6 of UFC 3-260-03). The modulus values for the other pavement layers would likely be obtained from the analysis of data from falling weight deflectometer tests. Assume that Pavement A is a runway with a PSPAestimated modulus of $1,000,000 \mathrm{psi}\left(15 \mathrm{~Hz}\right.$ and $\left.77^{\circ} \mathrm{F}\right)$ and an estimated AC tensile stain of $200 \times 10^{-6} \mathrm{in}$./in. Assume that Pavement $\mathrm{B}$ is a taxiway with a temperature-estimated modulus of $320,000 \mathrm{psi}(2 \mathrm{~Hz}$ and $77^{\circ} \mathrm{F}$ ) and an estimated AC tensile stain of $400 \times 10^{-6} \mathrm{in}$./in.

- Step 3 - Calculate allowable fatigue repetitions for aged, field asphalt. Use the fatigue criteria developed in this study for aged, 
field AC to obtain predictions of $\log _{10}$ (cycles) to failure at $77^{\circ} \mathrm{F}$. For Pavement A, the estimated tensile strain and the AC design modulus are applied to Equation 7.

$$
\log _{10}\left(\varepsilon_{r a}\right)=7.94-\left[\frac{L N\left(0.0002 \times 10^{6}\right)}{2.61}\right]^{2}+\frac{1,000,000}{438,000}=6.10
$$

For Pavement B, the estimated tensile strain and the ITS peak stress are applied to Equation 8.

$$
\log _{10}\left(\varepsilon_{r a}\right)=8.36-\left[\frac{L N\left(0.0004 \times 10^{6}\right)}{2.62}\right]^{2}+\frac{200}{264}=3.89
$$

- Step 4 - Calculate allowable fatigue repetitions using original DoD criterion. These cycles to failure are then compared to the predictions based on the original DoD fatigue criterion (Equation 2). The $\log _{10}$ (cycles) to failure for Pavement A follows:

$$
\log _{10}\left(\varepsilon_{r}\right)=2.68-5.0 * \log (0.0002)-2.665 * \log (1,000,000)=5.18
$$

The $\log _{10}$ (cycles) to failure for Pavement B follows:

$$
\log _{10}\left(\varepsilon_{r}\right)=2.68-5.0 * \log (0.0004)-2.665 * \log (320,000)=5.00
$$

- Step 5 - Calculate correction factor to be applied to the original DoD criterion. A comparison between the prediction for aged, field $\mathrm{AC}$ and original DoD criterion provides a correction factor that reflects $\mathrm{AC}$ integrity and can then be applied to fatigue predictions at any other temperature. The correction factor is called "aged, field asphalt fatigue correction" (AFC).

$$
A F C=\frac{\log _{10}\left(\varepsilon_{r a}\right) a t 77^{\circ} F \text { using aged, field asphalt criteria }}{\log _{10}\left(\varepsilon_{r}\right) a t 77^{\circ} F \text { using the original DoD criterion }}
$$


The AFC for Pavement A follows:

$$
A F C=\frac{6.10}{5.18}=1.18
$$

The AFC for Pavement B follows:

$$
A F C=\frac{3.89}{5.00}=0.78
$$

- Step 6 - Apply the AFC to other fatigue predictions for the same pavement. Now these correction factors can be applied to any other fatigue predictions that are necessary for the pavement evaluations. The AFC is multiplied by allowable fatigue repetitions predicted with the original DoD criterion $\left(\varepsilon_{r}\right)$. The corrected allowable fatigue repetitions will be labeled $\left(\varepsilon_{r c}\right)$.

$$
\begin{aligned}
\log _{10}\left(\varepsilon_{r c}\right) & =\log _{10}\left(\varepsilon_{r}\right) \times A F C \\
\varepsilon_{r c} & =\left(\varepsilon_{r}\right)^{A F C}
\end{aligned}
$$

For example, if the pavement evaluation considers each calendar month as a different design period, each month will have a different estimate for $\mathrm{AC}$ modulus and a different estimate for tensile strain at the bottom of the AC. For Pavement A, assume that the estimated AC modulus during a particularly cold month is 2,000,000 psi, and the corresponding AC tensile strain under design aircraft loading is $175 \times 10^{-6} \mathrm{in} . /$ in.

$$
\begin{gathered}
\log _{10}\left(\varepsilon_{r}\right)=\left[2.68-5.0 * \log _{10}(0.000175)-2.65 * \log _{10}(2,000,000)\right] \\
\varepsilon_{r}=(10)^{4.77}=59,000 \text { repetitions } \\
\varepsilon_{r c}=(59,000)^{1.18}=426,000 \text { repetitions }
\end{gathered}
$$

For Pavement B, assume that the estimated AC modulus during a particularly hot month is $160,000 \mathrm{psi}$, and the corresponding AC tensile strain under design aircraft loading is $450 \times 10^{-6} \mathrm{in}$./in. 


$$
\begin{gathered}
\log _{10}\left(\varepsilon_{r}\right)=\left[2.68-5.0 * \log _{10}(0.000450)-2.65 * \log _{10}(160,000)\right] \\
\varepsilon_{r}=(10)^{5.62}=417,000 \text { repetitions } \\
\varepsilon_{r c}=(417,000)^{0.78}=24,000 \text { repetitions }
\end{gathered}
$$

- Summary. By accounting for the high integrity of the AC in Pavement A, as determined by PSPA measurements, the predicted repetitions to failure for relatively cold conditions increased from $\varepsilon_{r}=59,000$ (original DoD criterion) to $\varepsilon_{r c}=426,000$ (AFC-corrected). By accounting for the poor integrity of the $\mathrm{AC}$ in Pavement B, as determined by ITS measurements, the predicted repetitions to failure for relatively hot conditions decreased from $\varepsilon_{r}=417,000$ (original DoD criterion) to $\varepsilon_{r c}=24,000$ (AFC-corrected). 


\section{Conclusions and Recommendations}

The ERDC was tasked by the AFCESA to develop an evaluation method that accounts for the condition of aged AC surfaces. This report addresses the evaluation of aged AC samples that were extracted from military airfields. The report describes field sampling, laboratory testing, and data analysis. Conclusions from the investigation and recommendations for evaluating aged $\mathrm{AC}$ pavements are provided in the following text. The recommendations also suggest a beneficial follow-up study.

\section{Conclusions}

The following conclusions resulted from the evaluation of aged AC pavements:

1. The current DoD criterion for $\mathrm{AC}$ fatigue life, which was developed using laboratory-produced beam samples, predicts fatigue life as a function of $\mathrm{AC}$ modulus and tensile strain (or tensile stress). The current DoD criterion has difficulty predicting fatigue failure for aged AC samples obtained from the field. Results from this study indicate that the error in this prediction can be highly unconservative. Predicted repetitions to failure were, in some cases, more than $2 \log$ cycles (factor of 100) higher than measured repetitions to failure.

2. One significant cause of error in predicting the fatigue life of aged, field AC samples using the original DoD criterion was attributed in this report to a discrepancy between mixture properties of samples artificially aged in the laboratory and those actually aged over a significant period of time in the field. In the original DoD criterion, different modulus values were obtained by changing the beam fatigue testing temperature. Therefore, changes in mixture properties were the result of changing the stiffness of the mixture. In contrast, different $\mathrm{AC}$ modulus values measured in the field provided information related to the stiffening of the $\mathrm{AC}$, but this change in $\mathrm{AC}$ modulus also occurs as the result of durability issues such as repeated loads and water damage. Also, the stiffness measured in the field was determined with the PSPA, and in the laboratory, the stiffness was determined from stiffness measurements made during the beam fatigue tests.

3. The original DoD fatigue criterion showed a decrease in fatigue life as the stiffness increased, since this was based on constant strain testing. The inverse relationship between cycles to failure and strain compares 
favorably to that of other researchers. However, when the new model was developed during this study, it showed a direct relationship between cycles to failure and mixture stiffness. There are likely two reasons for this general difference between the two models. The differences are likely caused by significant scatter in a relatively small database for the study in which the PSPA was used, and it is possible that the PSPA-measured stiffness may provide information about the integrity of the aged mixture. In the field, the asphalt mixture is exposed to repeated loads and some durability issues which may actually have adverse effects on the stiffness and the cycles to failure at the same time. In other words, the modulus may be reduced and the cycles to failure may be reduced at the same time. So, it is possible in this case that a reduction in stiffness in the field also results in a reduction of fatigue life.

4. A method for correcting the current DoD fatigue criterion in order to better predict fatigue performance of aged, field $\mathrm{AC}$ was developed and can be applied to various strain levels and $\mathrm{AC}$ moduli. This model has a similar form to the current fatigue model but does provide a much improved answer for in-place aged AC pavements.

5. Multivariate regression analyses were performed to find the independent variables that contributed significantly to predicting fatigue performance of aged, field AC. Similar to the original DoD fatigue criterion, strain level was the most informative independent variable for predicting the fatigue performance of aged, field AC. The second most informative independent variable was AC design modulus, as measured by the PSPA.

6. The only other material parameter that, when used with strain level, offered a significant contribution to predicting fatigue performance of aged, field AC was peak stress from the ITS test. When ITS peak stress was combined with both strain and AC design modulus, however, the ITS peak stress dropped out of the stepwise multivariate regression. The reason that ITS peak stress dropped out can be attributed to its positive correlation with $\mathrm{AC}$ design modulus. In other words, the ITS results and the AC design moduli served similar purposes in explaining variability between the fatigue performance of different $\mathrm{AC}$ samples. These independent variables did not complement each other.

7. Based on paragraph 6, ITS peak stress, as measured from core samples, can be used as a substitute for field measurements of modulus for indicating the quality (or integrity) of aged, field $\mathrm{AC}$ and to predict remaining fatigue life.

8. Material parameters that did not contribute significantly to predicting the fatigue performance of aged, field $\mathrm{AC}$ included $\mathrm{AC}$ age (this is related to the 
mixture stiffness), PCI, several AC-mixture properties (many are related to the stiffness), and several AC binder properties (related to the stiffness).

9. All laboratory testing in this study was conducted at room temperature, so the fatigue criteria for aged, field $\mathrm{AC}$ developed herein are intended for predicting fatigue performance at $77^{\circ} \mathrm{F}$. A method is proposed, however, by which the failure prediction for aged, field $\mathrm{AC}$ is compared to a similar prediction by the original DoD fatigue criterion (using the same strain and modulus values). The ratio of these two predictions, each in terms of $\log _{10}$ (cycles), forms a correction factor that can then be applied to further predictions of fatigue performance for the aged, field $\mathrm{AC}$ as they are accomplished with the current $\mathrm{DoD}$ fatigue criterion. With this system, the aged, field fatigue criteria can influence predictions for fatigue performance at a wide range of temperatures and strain levels. The aged, field fatigue criteria can therefore be used in pavement evaluations for which the pavement life is divided into performance periods, each with a different mean pavement temperature.

10. There was very little correlation between the stiffness of the asphalt mixture by the PSPA test and by the beam stiffness test in the laboratory. Obtaining different results between two methods for measuring stiffness indicates part of the problem when assigning stiffness values to $\mathrm{AC}$ mixtures. As stated earlier, it is believed that the PSPA likely is a measure of stiffness as well as other characteristics of the mixture that may be related to fatigue performance.

\section{Recommendations}

The following recommendations are based upon the results of the field and laboratory testing of aged, field AC pavements.

1. Pavement evaluations should include one of the following two measures of AC quality (or integrity).

a. AC design modulus ( $15 \mathrm{~Hz}$ and $77^{\circ} \mathrm{F}$ ), as obtained by the PSPA.

b. ITS for a 4-in.-diam core, specifically the peak stress from this test.

2. If the PSPA is included in a pavement evaluation to indicate AC integrity in terms of elastic modulus, use the following equation to predict the fatigue life of aged, field $\mathrm{AC}$ at $77^{\circ} \mathrm{F}$. The estimated tensile strain at the bottom of the AC layer should be found by layered elastic analysis using the $\mathrm{AC}$ modulus, $E$. 


$$
\log _{10}\left(\varepsilon_{r a}\right)=7.94-\left[\frac{L N\left(S_{A} \times 10^{6}\right)}{2.61}\right]^{2}+\frac{E}{438,000 \mathrm{psi}}
$$

where:

$\varepsilon_{r a}=$ allowable strain repetitions for aged, field $\mathrm{AC}$

$S_{A}=$ tensile strain of AC, in./in.

$E=$ AC design modulus, psi.

3. If an ITS test is used in a pavement evaluation to indicate AC integrity in terms of peak stress, use the following equation to predict the fatigue life of aged, field $\mathrm{AC}$ at $77^{\circ} \mathrm{F}$. An estimate for $\mathrm{AC}$ modulus is needed to calculate the AC tensile strain by layered elastic analysis. Methods of estimating AC modulus are presented in the Unified Facilities Criteria "Airfield Pavement Evaluation" manual (UFC 3-260-03).

$$
\log _{10}\left(\varepsilon_{r a}\right)=8.36-\left[\frac{L N\left(S_{A} \times 10^{6}\right)}{2.62}\right]^{2}+\frac{\text { ITS Peak Stress, psi }}{264 \mathrm{psi}}
$$

4. To predict repetitions to failure for aged, field $\mathrm{AC}$ at any temperature other than $77^{\circ} \mathrm{F}$, an "aged, field $\mathrm{AC}$ fatigue correction factor" (AFC) must be calculated and applied as follows. Each $\log _{10}\left(\varepsilon_{r}\right)$ is calculated with the same assumption for strain.

$$
A F C=\frac{\log _{10}\left(\varepsilon_{r a}\right) a t 77^{\circ} F \text { using aged, field asphalt criteria }}{\log _{10}\left(\varepsilon_{r}\right) a t 77^{\circ} F \text { using the original DoD criterion }}
$$

5. Once the AFC is known, it is applied to the original DoD criterion for calculated repetitions to failure at any temperature. $\log _{10}\left(\varepsilon_{r}\right)$ is determined at the desired pavement temperature using the original DoD fatigue criterion equation (Equation 2).

$$
\begin{gathered}
\log _{10}\left(\varepsilon_{r c}\right)=\log _{10}\left(\varepsilon_{r}\right) \times A F C \\
\varepsilon_{r c}=\left(\varepsilon_{r}\right)^{A F C}
\end{gathered}
$$




\section{Research recommendations}

1. Considering the variability that is inherent in measuring stiffness and fatigue life of asphalt mixtures, more laboratory-produced AC beams are needed for validation and/or refinement of the original DoD fatigue criterion, for the purpose of pavement design. Additional data for aged, field AC samples will allow for continued development of the proposed fatigue criterion for pavement evaluations.

2. This study has provided an improved method for determining the remaining fatigue life of $\mathrm{AC}$ pavements. This recommended procedure will provide improved pavement performance prediction when compared to the current DoD fatigue criterion.

Previous research based on laboratory experiments has shown that increased AC stiffness decreases the fatigue life at a given strain level. The laboratory studies based the conclusions on changes in AC test specimen stiffness resulting from changing test temperatures or from modifications to material properties, e.g., binder type. However, this study using fieldcollected stiffness measurements indicated that increased stiffness improves the fatigue life at a given strain level. The field measurements showed that stiffness decreased as a result of increasing pavement fatigue. Thus, the remaining pavement life decreased.

The authors were unable to locate literature of past research efforts in which fatigue or weathered field samples were used to measure fatigue life. Low stiffness can provide good fatigue resistance for an $\mathrm{AC}$ pavement if the AC mixture integrity is sound. However, if the low stiffness is due to loss of mixture integrity (i.e., weathering damage), the $\mathrm{AC}$ pavement will exhibit poor fatigue resistance. This conclusion delineates the requirement for developing a procedure that can be used to determine the cause of stiffness change (oxidation or loss of integrity) and the effect of this change on fatigue life.

Two research topics need to be addressed to improve the prediction ability. First, based on the findings of this study, there is a need to be able to determine whether changes in mixture stiffness are due to oxidation or loss of integrity. For old pavements, the measured stiffness will almost always be a combination of both of these factors. The portion of stiffness change caused by oxidation can be estimated by taking cores from old asphalt mixtures, determining the indirect tensile strength of the cores 
(to provide an estimate of the tensile strength and stiffness due to oxidation and loss of integrity), and then recompacting the cores to the same density and determining the indirect tensile strength (to estimate the tensile strength and stiffness due to oxidation). These determined values for stiffness can be used in the following general equation, after solving for the regression constants, to determine the remaining fatigue life. This is simply an extension of the general model that was used for the initial fatigue equation and the modified equation based on the findings of this research.

$$
\log (\varepsilon)=\mathrm{C}_{1}+\mathrm{C}_{2} * \log \left(\mathrm{S}_{\mathrm{A}}\right)+\mathrm{C}_{3} * \log \left(\mathrm{E}_{\mathrm{r}}\right) \mathrm{C}_{4} * \log \left(\mathrm{E}_{\mathrm{r}}-\mathrm{E}_{\mathrm{c}}\right)
$$

where:

$$
\begin{aligned}
\log (\varepsilon)= & \log \text { of the strain cycles to failure } \\
\mathrm{C}_{1}, \mathrm{C}_{2}, \mathrm{C}_{3}, \text { and } \mathrm{C}_{4}= & \text { regression constants } \\
\mathrm{S}_{\mathrm{A}}= & \text { tensile strain of } \mathrm{AC} \text {, in./in. } \\
\mathrm{E}_{\mathrm{r}}= & \text { stiffness modulus determined from tensile strength } \\
& \text { of recompacted samples (modulus for oxidized } \\
& \text { mixture not including loss of integrity), psi } \\
\mathrm{E}_{\mathrm{c}}= & \text { stiffness modulus determined from tensile strength } \\
& \text { cores removed from pavement (modulus of mixture } \\
& \text { as a result of oxidation as well as loss of } \\
& \text { integrity), psi. }
\end{aligned}
$$

3. There is always a shift between lab results and observed field performance. Therefore, a calibration factor needs to be determined and applied to the lab results to better predict the performance of existing pavements. This calibration factor can be a fairly large number; factors between 10 and 20 are typically recognized. Without this calibration, fatigue life will be very difficult to predict with optimum accuracy. This research item can be conducted based on observed performance of pavements that eventually fail in fatigue, either through accelerated loading or through normal traffic. Prediction of pavement life will need to be made on existing pavements prior to failure. Then, failure will need to be observed at some point, for comparison with the predicted results. The predicted load cycles at failure can then be compared to the actual load cycles at failure, and the results can be calibrated to produce a calibrated prediction model. 


\section{References}

American Society for Testing and Materials. 2007. Standard test method for indirect tensile (IDT) strength of bituminous mixtures. Designation: D 6931-07, West Conshohocken, PA.

Barker, W. R., and W. N. Brabston. 1975. Development of a structural design procedure for flexible airport pavements. Report FAA-RD-74-199. Washington, DC: Federal Aviation Administration, U.S. Department of Transportation.

Bell, H. P., and R. B. Freeman. 2007. Evaluation criteria for aged asphalt concrete surfaces. ERDC/GSL TR-07-18. Vicksburg, MS: U.S. Army Engineer Research and Development Center.

Headquarters, Departments of the Army, the Navy, and the Air Force. 2001a. Airfield pavement evaluation. Unified Facilities Criteria 3-260-03. Washington, DC.

2001b. Pavement design for airfields. Unified Facilities Criteria 3-260-02. Washington, DC.

Heukelom, W., and A. J. G. Klomp. 1963. Dynamic testing as a means of controlling pavements during and after construction. In Proceedings, International Conference on the Structural Design of Asphalt Pavements, August 1962. Ann Arbor, MI: The University of Michigan.

Huang, Y. H. 1993. Pavement analysis and design. Prentice Hall.

Kingham, R. I., and B. F. Kallas. 1972. Laboratory fatigue and its relationship to pavement performance. In Proceedings, Third International Conference on the Structural Design of Asphalt Pavements, September 1972, London, England. Ann Arbor, MI: The University of Michigan.

Nazarian, S., V. Tandon, and D. Yuan. 2005. Mechanistic quality management of asphalt concrete layers with seismic methods. Journal of ASTM International 2(8). West Conshohocken, PA: American Society for Testing and Materials.

Nijboer, L. W. 1959. La Technique Routière, 4.

Roberts, F. L., S. K. Prithvi, R. E. Brown, D.-Y. Lee, and T. W. Kennedy. 1996. Hot mix asphalt materials, mixture design, and construction. $2 \mathrm{~d}$ ed. Lanham, MD: National Asphalt Pavement Association Research and Education Foundation.

Sanders, D. H., R. J. Eng, and A. F. Murph. 1985. Statistics: A fresh approach. New York: McGraw-Hill.

Seber, G. A. F. 1977. Linear regression analysis. New York: John Wiley and Sons.

Yoder, E. J., and M. W. Witczak. 1975. Principles of pavement design. New York: John Wiley and Sons.

Younger, M. S. 1979. Handbook for linear regression. Pacific Grove, CA: Duxbury Press. 


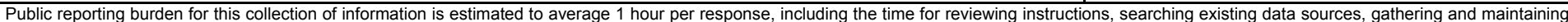

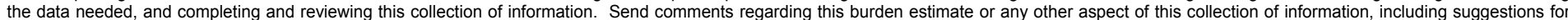

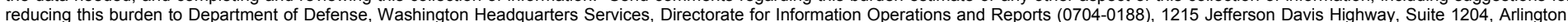

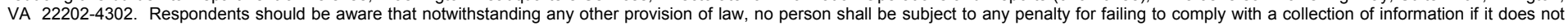
display a currently valid OMB control number. PLEASE DO NOT RETURN YOUR FORM TO THE ABOVE ADDRESS.

\begin{tabular}{l|l}
$\begin{array}{l}\text { 1. REPORT DATE (DD-MM- } Y Y Y Y) \\
\text { May } 2008\end{array}$ & $\begin{array}{c}\text { 2. REPORT TYPE } \\
\text { Final report }\end{array}$ \\
\hline
\end{tabular}

\section{TITLE AND SUBTITLE}

Evaluation Criteria for Aged Asphalt Concrete Surfaces; Phase II

3. DATES COVERED (From - To)

5a. CONTRACT NUMBER

5b. GRANT NUMBER

5c. PROGRAM ELEMENT NUMBER

\section{AUTHOR(S)}

Haley P. Bell, Reed B. Freeman, and E. Ray Brown 5d. PROJECT NUMBER

5e. TASK NUMBER

5f. WORK UNIT NUMBER

8. PERFORMING ORGANIZATION REPORT NUMBER

ERDC/GSL TR-08-6

U.S. Army Engineer Research and Development Center

Geotechnical and Structures Laboratory

3909 Halls Ferry Road

Vicksburg,MS 39180-6199

9. SPONSORING / MONITORING AGENCY NAME(S) AND ADDRESS(ES)

10. SPONSOR/MONITOR'S ACRONYM(S)

Headquarters, Air Combat Command

129 Andrews Street, Suite 102

Langley AFB, VA 23666

11. SPONSOR/MONITOR'S REPORT NUMBER(S)

\section{DISTRIBUTION / AVAILABILITY STATEMENT}

Approved for public release; distribution is unlimited.

\section{SUPPLEMENTARY NOTES}

\section{ABSTRACT}

An evaluation of aged asphalt concrete (AC) was performed during the period March-August 2007 at Polk Army Airfield (Fort Polk, LA), Redstone Army Airfield (Huntsville, AL), Simmons Army Airfield (Fort Bragg, NC), and Forney Army Airfield (Fort Leonard Wood, MO) to develop a method for predicting the performance of aged AC surfaces in situ. This research project was an extension of an investigation that was conducted in fiscal year 2006. Similar test procedures were followed for both projects. A portable seismic pavement analyzer was used on the in situ AC pavements to determine the pavement modulus. The aged AC samples obtained from the military airfields were brought to the U.S. Army Engineer Research and Development Center for laboratory testing. Dynamic shear rheometer tests were conducted on the asphalt binder samples, indirect tensile strength tests were run on core samples, and beam fatigue tests were performed on beam samples. The results from this study were used to develop adjustments to the current Department of Defense fatigue criterion to improve fatigue life predictions for aged AC surfaces. Also, the results of this investigation were used to develop fatigue criteria to be used when evaluating AC pavements in the field.

\section{SUBJECT TERMS}

Asphalt concrete

Department of Defense

16. SECURITY CLASSIFICATION OF:

\section{a. REPORT}

UNCLASSIFIED

b. ABSTRACT
UNCLASSIFIED

Dynamic shear rheometer

Fatigue criteria

Fatigue testing

c. THIS PAGE

UNCLASSIFIED
Indirect tensile strength

Modulus

PSPA

\begin{tabular}{l|l} 
17. LIMITATION \\
OF ABSTRACT \\
\end{tabular}

\begin{tabular}{c|l}
\begin{tabular}{c|} 
18. NUMBER \\
OF PAGES
\end{tabular} & $\begin{array}{l}\text { 19a. NAME OF RESPONSIBLE } \\
\text { PERSON }\end{array}$ \\
\cline { 2 - 2 } 75 & $\begin{array}{l}\text { 19b. TELEPHONE NUMBER (include } \\
\text { area code) }\end{array}$ \\
&
\end{tabular}

Standard Form 298 (Rev. 8-98)

Prescribed by ANSI Std. 239.18 